UNIVERSIDADE DE SÃO PAULO

FACULDADE DE ECONOMIA, ADMINISTRAÇÃO E CONTABILIDADE DEPARTAMENTO DE CONTABILIDADE E ATUÁRIA

PROGRAMA DE PÓS-GRADUAÇÃo EM CONTROLADORIA E CONTABILIDADE

FLÁVIA FONTE DE SOUZA MACIEL

Escolhas contábeis na Demonstração dos Fluxos de Caixa no contexto do mercado de capitais brasileiro 
Prof. Dr. Marco Antonio Zago

Reitor da Universidade de São Paulo

Prof. Dr. Adalberto Américo Fischmann

Diretor da Faculdade de Economia, Administração e Contabilidade

Prof. Dr. Gerlando Augusto Sampaio Franco de Lima

Chefe do Departamento de Contabilidade e Atuária

Prof. Dr. Andson Braga de Aguiar Coordenador do Programa de Pós-Graduação em Controladoria e Contabilidade 
FLÁVIA FONTE DE SOUZA MACIEL

\title{
Escolhas contábeis na Demonstração dos Fluxos de Caixa no contexto do mercado de capitais brasileiro
}

\author{
Dissertação apresentada ao Programa de Pós-Graduação em \\ Controladoria e Contabilidade da Universidade de São \\ Paulo, como parte dos requisitos para obtenção do título de \\ Mestra em Ciências.
}

Orientador: Prof. Dr. Bruno Meirelles Salotti

Coorientador: Prof. Dr. Joshua O. Imoniana

São Paulo

2015 
FICHA CATALOGRÁFICA

Elaborada pela Seção de Processamento Técnico do SBD/FEA/USP

Maciel, Flávia Fonte de Souza

Escolhas contábeis na demonstração dos fluxos de caixa no contexto do mercado de capitais brasileiro / Flávia Fonte de Souza Maciel. -São Paulo, 2015.

$93 \mathrm{p}$.

Dissertação (Mestrado) - Universidade de São Paulo, 2015.

Orientador: Bruno Meirelles Salotti.

Coorientador: Joshua O. Imoniana.

1. Fluxo de caixa 2. Escolhas contábeis 3. Demonstração financeira 4. Mercado de capitais I. Universidade de São Paulo. Faculdade de Economia, Administração e Contabilidade. II. Título.

CDD -658.15244 
Ao meu esposo, Francisco Júnior, ao meu filho, Vinícius, aos meus pais, Pereira e Fátima, e aos meus irmãos, Tadeu e Davi. 


\section{AGRADECIMENTOS}

Ao nosso Deus maravilhoso, que nos concede inúmeras bênçãos e que me presenteou com uma fase de vida tão marcante, repleta de mudanças, conquistas e sonhos realizados.

Ao meu esposo, Francisco Júnior, que me apoiou durante essa caminhada e me encorajou nos momentos de dificuldades. Por todo o amor e carinho demonstrados a cada dia. Obrigada, Senhor Deus, por esse companheiro tão especial e amado!

Aos meus pais, Pereira e Fátima, que lutaram para me proporcionar educação, conhecimento e valores, sem os quais eu não teria conseguido alcançar mais essa vitória. Agora começo a entender quanto amor e sacrifício estão envolvidos na criação de um filho. Obrigada, Senhor Deus, pelos pais incríveis e batalhadores!

Ao meu filho, Vinícius, que me acompanhou nessa jornada, desde a gestação até as primeiras semanas de vida. Além de companheiro, foi um colaborador ao se comportar bem durante as horas de pesquisa e no dia da defesa. Sua vinda foi um encorajamento extra para a conclusão desse trabalho. Obrigada, Senhor Deus, pelo filho lindo e saudável!

Aos meus sogros, Francisco Filho e Dalva, cujas orações incessantes foram ouvidas e assim obtive a força necessária para concluir o mestrado e alcançar tantas outras realizações. Obrigada, Senhor Deus, pelos pais amáveis e abençoadores!

Aos amigos e amigas, ingressantes 2014.1 do mestrado e doutorado do PPGCC da FEA-USP, que contribuíram de uma forma única para o meu crescimento pessoal e intelectual, além dos tempos de alegria e diversão. De uma maneira particular, agradeço toda a ajuda das amigas Ludmila Melo e Samantha Telles, as quais me apoiaram em vários momentos. Obrigada, Senhor Deus, pelos amigos queridos e leais!

Ao meu orientador, Prof. Dr. Bruno Salotti, e meu coorientador, Prof. Dr. Joshua Imoniana, por todo o incentivo e direção durante essa nova experiência. Aos membros da comissão julgadora, Prof. ${ }^{a}$ Dr. ${ }^{a}$ Sirlei Lemes, Prof. Dr. Paulo Lustosa e Prof. Dr. Fernando Murcia, pelas contribuições preciosas ao avaliarem o projeto de pesquisa e a dissertação. Um agradecimento adicional ao Prof. Dr. Fernando Murcia, pelas palavras de motivação e pelo reconhecimento do trabalho efetuado. Aos demais professores do PPGCC, que me apresentaram novas formas de pensar, em especial, o Prof. Dr. Gerlando Lima, pela revisão do projeto de pesquisa e apoio prestado. Obrigada, Senhor Deus, pelos mestres exemplares!

$\mathrm{E}$ a todos que de alguma forma me ajudaram, seja baixando os relatórios anuais do site da CVM (meu irmão Davi e meu esposo) ou qualquer outra ajuda relacionada à pesquisa, seja através das orações ou do convívio feliz e harmonioso. Deus seja louvado por tudo! 
"Confia no Senhor de todo o coração e não se apoie em seu próprio conhecimento”.

Provérbios 3:5 


\section{RESUMO}

Maciel, F. F. S. (2015). Escolhas contábeis na Demonstração dos Fluxos de Caixa no contexto do mercado de capitais brasileiro. Dissertação de Mestrado, Faculdade de Economia, Administração e Contabilidade, Universidade de São Paulo, São Paulo.

As normas contábeis brasileiras estabelecem algumas opções de classificação na Demonstração dos Fluxos de Caixa (DFC), especificamente os fluxos de caixa relacionados aos juros, dividendos e juros sobre capital próprio (JCP) pagos e recebidos. Tais fluxos de caixa podem ser classificados na DFC em três diferentes atividades: operacional (FCO), de investimento (FCI) ou de financiamento (FCF). Por um lado, essa flexibilidade de classificação permite que uma informação mais fidedigna seja divulgada, uma vez que a apresentação da DFC poderá ser adaptada às circunstâncias específicas de cada empresa. Por outro lado, abre espaço para comportamentos oportunistas, ao permitir a escolha da opção que gera a informação mais conveniente. Este trabalho busca identificar incentivos, relacionados às características das empresas não financeiras do mercado de capitais brasileiro, que influenciaram as escolhas de classificação dos juros, dividendos e JCP na DFC, no período de 2008 a 2014. As hipóteses resultantes desse objetivo referem-se a: classificação dos fluxos de caixa de acordo com o encorajamento do CPC 03; identificação de uma possível padronização das classificações na DFC entre empresas com aspectos semelhantes (mesmo setor ou firma de auditoria); relação entre mudanças de classificação dos juros pagos com a troca de auditor; e, o efeito da escolha de classificação dos juros, dividendos e JCP na DFC sobre o FCO, de acordo com características financeiras e de desempenho das empresas. Para fins de mensuração do efeito sobre o FCO, tomou-se por referência o parágrafo 34A do CPC 03, que encoraja a classificação dos juros recebidos ou pagos, dos dividendos recebidos e JCP recebidos como FCO; assim como os dividendos pagos e JCP pagos como FCF. Para análise do referido efeito, foram utilizados dados em painel e duas regressões com as seguintes variáveis dependentes: 1) a diferença em reais entre o FCO divulgado e o valor que seria o FCO ao seguir as opções encorajadas pelo CPC 03; e, 2) a escolha de classificação dos juros pagos (variável dummy). Considerou-se os juros pagos, pois, entre as alternativas, trata-se daquela que aumenta o FCO caso não seja seguida a classificação recomendada pelo CPC. Com uma amostra de 352 empresas, 2.290 relatórios analisados e 3.764 dados levantados, os resultados apontaram que: i) a maior parte das empresas brasileiras segue as classificações encorajadas pelo CPC 03, exceto quanto ao item dividendos/JCP recebidos; ii) alguns setores seguiram uma classificação predominante em todos ou parte dos itens que possuem flexibilidade de apresentação na DFC; iii) há classificações predominantes para empresas que possuem determinadas firmas de auditoria; iv) as mudanças de classificação dos juros pagos ocorreram independentemente da troca de auditor; e, v) há evidências de que o endividamento influencia na divulgação de um FCO em montante diferente do que seria se a recomendação de classificação do CPC fosse seguida. Os resultados alcançados trazem evidências sobre a relação entre características das empresas brasileiras e o FCO divulgado decorrente da escolha de classificação na DFC.

Palavras-chave: fluxo de caixa, escolhas contábeis, demonstração financeira, mercado de capitais. 


\begin{abstract}
Maciel, F. F. S. (2015). Accounting choices in the Statement of Cash Flows in the context of the Brazilian capital market. Master Thesis, Faculdade de Economia, Administração e Contabilidade, Universidade de São Paulo, São Paulo.
\end{abstract}

Brazilian accounting standards establish some classification options in the Statement of Cash Flows (SCF), specifically the cash flows related to interest, dividends and interest on capital paid and received. Such cash flows can be classified in the SCF in three different activities: operating (FCO), investment (FCI) or financing (FCF). This flexibility of classification, on one hand, allows the disclosure of a more accurate information, since the presentation of SCF can be adapted to the specific circumstances of each company. On the other hand, it makes room for opportunistic behavior by allowing choice of which option to generate the most suitable information. This study aims to identify incentives related to the characteristics of non-financial companies in the Brazilian capital markets, which influenced the choices of classification of interest, dividends and interest on capital in the SCF, from 2008 to 2014. The resultant hypotheses from the objective refer to: cash flows classification according to the encouragement of the CPC 03; identification of a possible standardization of classifications in SCF among companies with similar features (same sector or audit firm); relationship between classification shift of the interest paid with the change of auditor; and, the effect on the FCO of the classification choice of interest, dividends and interest on capital in the SCF, according to financial characteristics and performance of companies. For the measurement purposes of the effect on the FCO, paragraph 34A of CPC 03 is taken as a reference, which encourages the classification of interest received or paid, dividends received and interest on capital received as FCO; as well as dividends paid and interest on capital paid as FCF. For analysis of that effect, panel data and two regressions with the following dependent variables have been adopted: 1) the difference in reais between the disclosed FCO and the amount that the FCO would be if the options encouraged by the CPC 03 had been followed; and, 2) the classification choice of interest paid (dummy). The interest paid was considered because, among alternatives, it is that which increases the FCO if the classification recommended by the CPC is not followed. With a sample of 352 companies, 2.290 reports analyzed and 3.764 data collected, the results show that: i) the most Brazilian companies follow the classifications encouraged by CPC 03, except those related to dividends/interest on capital received; ii) some sectors followed a predominant classification in all items or part of them that allow flexibility of presentation in SCF; iii) there are prevalent classifications for companies with certain audit firms; iv) classification shift of the interest paid occurred regardless of the change of auditor; and, v) there is evidence that the debt influences the disclosure of an FCO in a different amount than if the CPC classification recommendation had been followed. The achieved results provide evidence on the relationship between characteristics of Brazilian companies and the FCO released due to the choice of classification in the SCF.

Keywords: cash flow, accounting choices, financial statements, capital markets. 


\section{LISTA DE TABELAS}

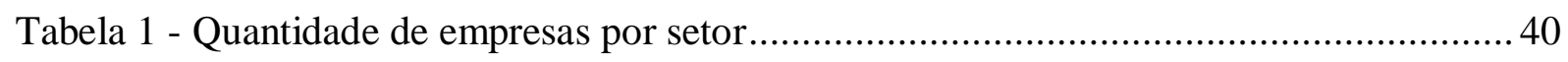

Tabela 2 - Conciliação da quantidade de DFs anuais (por ano) ......................................... 41

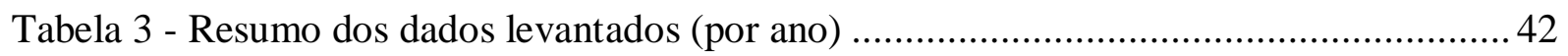

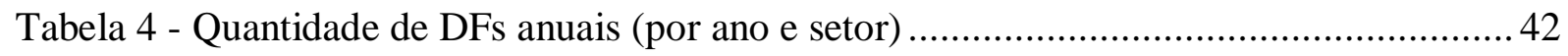

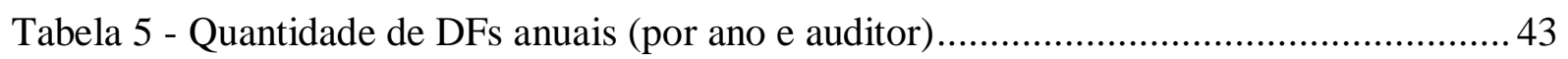

Tabela 6 - Classificação encorajada pelo CPC 03, parágrafo 34A ........................................ 43

Tabela 7 - Modelos e variáveis referentes ao $4^{\circ}$ grupo de hipóteses ..................................... 44

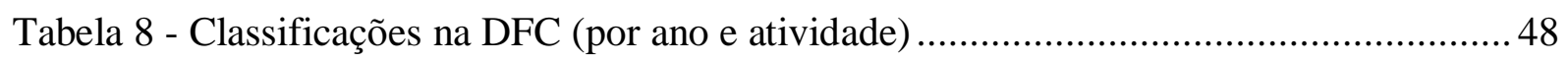

Tabela 9 - Comparativo dos resultados com pesquisas afins ............................................50

Tabela 10 - Classificações na DFC conforme encorajamento do CPC 03 (por setor)..............53

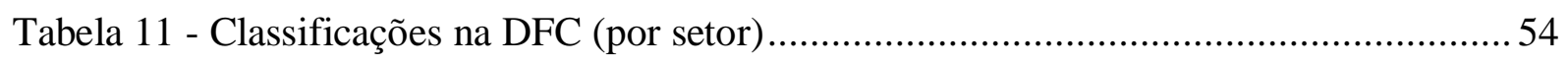

Tabela 12 - Resumo das classificações predominantes (por setor) ......................................55

Tabela 13 - Classificações na DFC conforme encorajamento do CPC 03 (por auditor) ......... 56

Tabela 14 - Classificações na DFC (por auditor) ...........................................................57

Tabela 15 - Resumo das classificações predominantes (por auditor) ....................................58

Tabela 16 - Reclassificações de juros pagos (por auditor e atividades na DFC)....................59

Tabela 17 - Resumo das reclassificações de juros pagos (por auditor e situação da auditoria)60

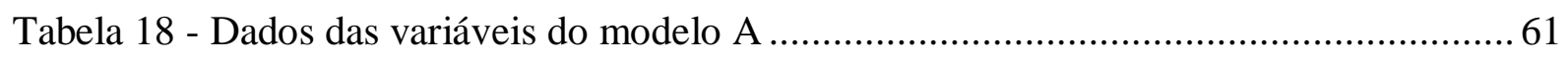

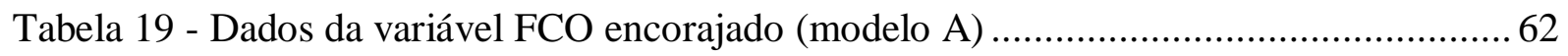

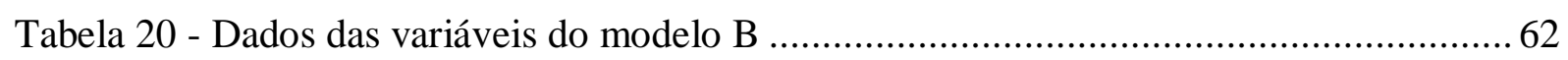

Tabela 21 - Dados das variáveis Juros pagos e FCO encorajado (modelo B)........................ 63

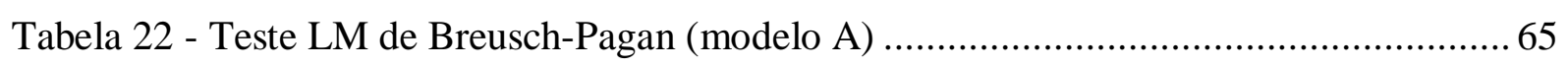

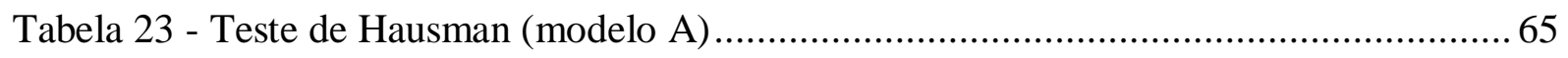

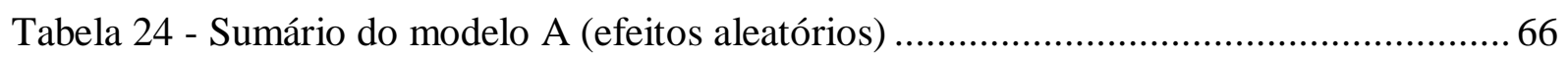

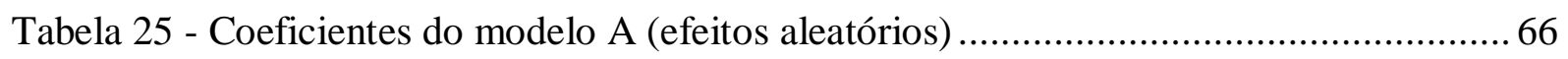

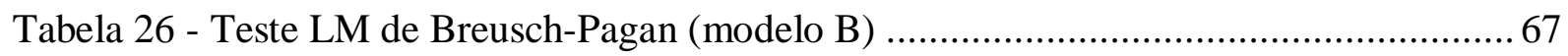

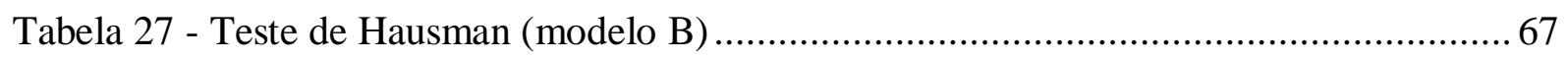

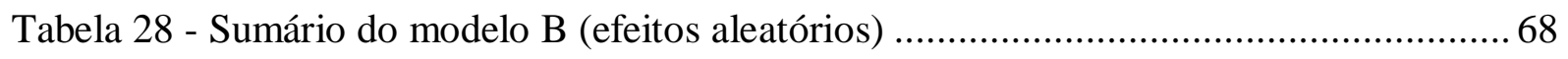

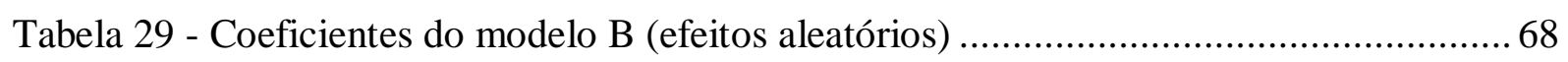




\section{LISTA DE ABREVIATURAS E SIGLAS}

BM\&FBOVESPA - Bolsa de Valores, Mercadorias e Futuros

CFC - Conselho Federal de Contabilidade

CNPJ - Cadastro Nacional da Pessoa Jurídica

CPC - Comitê de Pronunciamentos Contábeis

CVM - Comissão de Valores Mobiliários

Deloitte - Deloitte Touche Tohmatsu Limited

DFC - Demonstração dos Fluxos de Caixa

DFs Anuais - Demonstrações Financeiras Anuais Completas

DOAR - Demonstração de Origens e Aplicações de Recursos

DRE - Demonstração do Resultado do Exercício

EY - Ernst \& Young Global Limited

FASB - Financial Accounting Standards Board

FCF - Fluxo de Caixa de Financiamento

FCI - Fluxo de Caixa de Investimento

FCO - Fluxo de Caixa Operacional

FCO encorajado - Fluxo de Caixa Operacional de acordo com o encorajamento do CPC 03

GFCO - Gerenciamento do Fluxo de Caixa Operacional

HME - Hipótese de Mercados Eficientes

IAS - International Accounting Standards

IASB - International Accounting Standards Board

IBOVESPA - Índice BOVESPA

IFRS - International Financial Reporting Standards

JCP - Juros sobre Capital Próprio

KPMG - KPMG International Cooperative

N/I - Não Informado

Novo Mercado - Novo Mercado da BM\&FBOVESPA

OCDFC - Opções de Classificação na Demonstração dos Fluxos de Caixa

PEPS - Primeiro a Entrar, Primeiro a Sair

Price - PricewaterhouseCoopers International Limited

SFAS - Statement of Financial Accounting Standards

UEPS - Último a Entrar, Primeiro a Sair

USGAAP - United States Generally Accepted Accounting Principles 


\section{SUMÁRIO}

1 INTRODUÇÃ O......................................................................................................13

1.1 Contextualização ....................................................................................................13

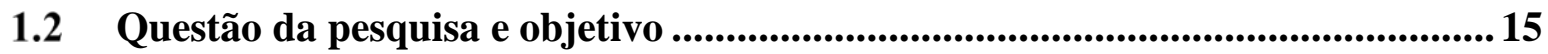

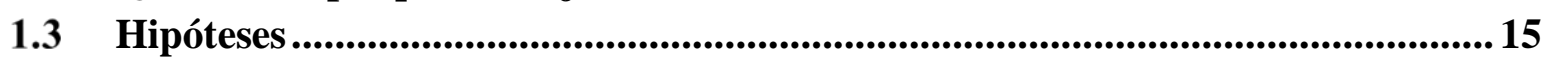

1.4 Justificativas e Contribuições ...........................................................................19

1.5 Delimitações da pesquisa ........................................................................................21

1.6 Estrutura do Trabalho ................................................................................................22

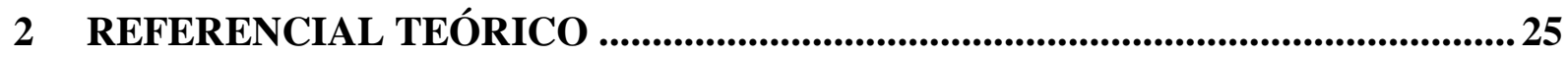

2.1 A Demonstração dos Fluxos de Caixa................................................................25

2.1.1 Histórico de divulgação no Brasil................................................................26

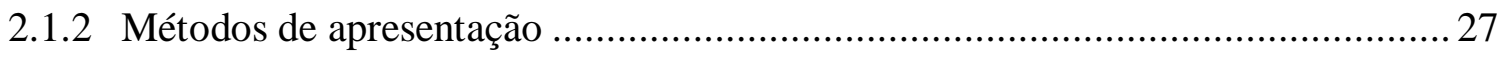

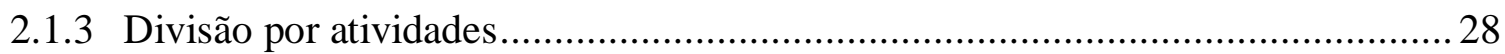

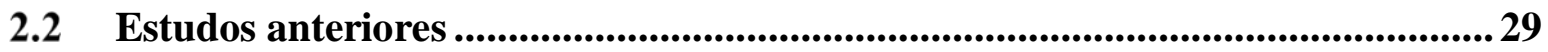

2.3 Escolhas contábeis ......................................................................................................32

2.4 Teoria de gerenciamento de resultados ....................................................................34

2.5 Teoria de investimento e Estrutura conceitual...........................................................36

3 METODOLOGIA .......................................................................................................38

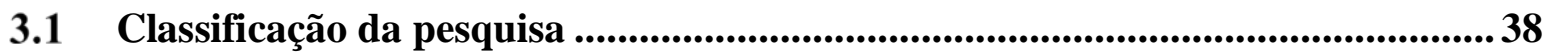

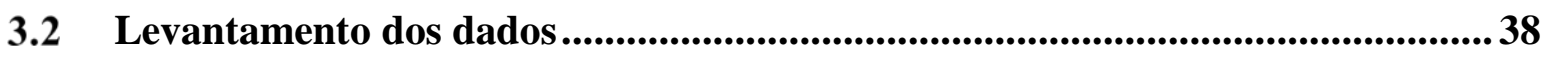

3.3 Amostra e critérios de seleção ................................................................................40

3.4 Procedimentos e análise dos dados ........................................................................43

3.5 Dados em painel........................................................................................................45

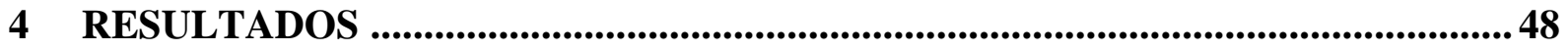

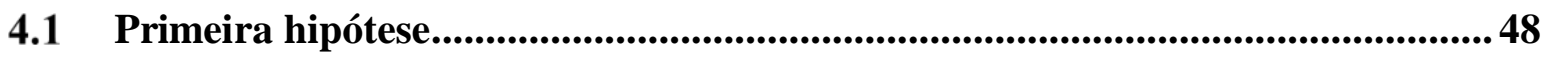

4.2 Segundo grupo de hipóteses ...................................................................................51

4.3 Terceira hipótese ..............................................................................................................58

4.4 Quarto grupo de hipóteses ......................................................................................60

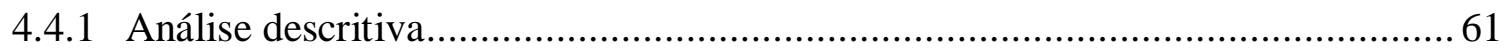

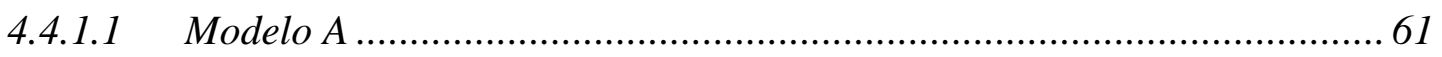

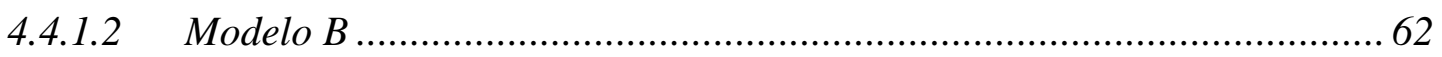

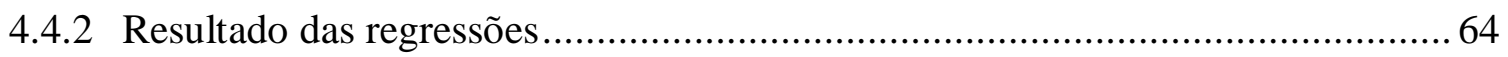

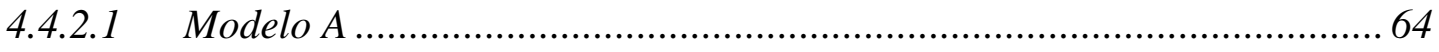

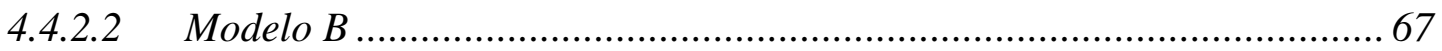

5 CONSIDERAÇÕES FINAIS ..................................................................................70

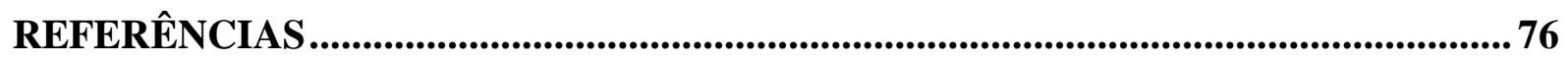

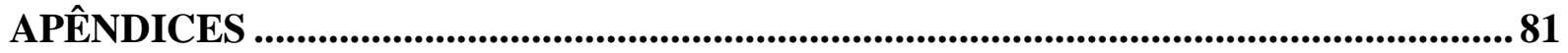

APÊNDICE A - Lista de empresas selecionadas ……………................................................. 81 
APÊNDICE B - Classificação conforme CPC 03, parágrafo 34A (por atividade na DFC, setor e ano) ..................................................................................................83

APÊNDICE C - Classificação conforme CPC 03, parágrafo 34A (por atividade na

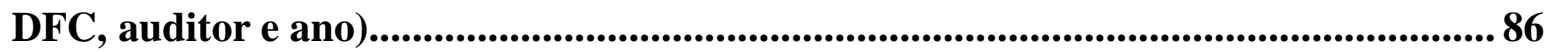
APENDICE D - Lista de empresas (Modelo A) ....................................................... 88

APÊNDICE E - Lista de empresas (Modelo B) ............................................................. 89

APÊNDICE F - Empresas com maiores diferenças entre o FCO divulgado e o FCO encorajado pelo CPC ........................................................................................................90 90

APÊNDICE G - Dados e coeficientes da regressão por efeitos fixos (Modelo A) ...... 92 APENDICE H - Dados e coeficientes da regressão por efeitos fixos (Modelo B) ...... 93 



\section{INTRODUÇÃo}

As normas brasileiras de contabilidade passaram por um processo de mudança e modernização, a fim de se equipararem às normas internacionais de contabilidade, International Financial Reporting Standards (IFRS), emitidas pelo International Accounting Standards Board (IASB). Na prática, esse processo foi iniciado em 2005, com a criação do Comitê de Pronunciamentos Contábeis (CPC), através da Resolução nº 1.055 do Conselho Federal de Contabilidade (CFC).

Em 2007, foi promulgada a Lei $n^{\circ} 11.638$, que alterou dispositivos da Lei $n^{\circ}$ 6.404/76 (Lei das Sociedades por Ações), iniciando-se oficialmente o processo de convergência às IFRS no Brasil. Através da referida lei, a Demonstração dos Fluxos de Caixa (DFC) tornou-se obrigatória já para os exercícios findos a partir de 2008. Nesse mesmo ano, o CPC emitiu o pronunciamento técnico CPC 03 (Demonstração dos Fluxos de Caixa), onde se estabeleceram regras de elaboração e divulgação da DFC, o qual está em conformidade com a norma internacional Statement of Cash Flows (IAS 7).

\subsection{Contextualização}

De maneira geral, o CPC 03 está alinhado com a IAS 7, os quais estabelecem Opções de Classificação na Demonstração dos Fluxos de Caixa (OCDFC), especificamente no que diz respeito aos fluxos de caixa relacionados aos juros, dividendos e juros sobre capital próprio (JCP), pagos e recebidos. Tais fluxos de caixa podem ser classificados na DFC em três diferentes atividades, dependendo do tipo de fluxo: operacionais (FCO), de investimento (FCI) ou de financiamento (FCF).

A exceção ocorre através da orientação adicional referente à classificação de juros, recebidos ou pagos, e de dividendos e JCP recebidos: a norma brasileira encoraja fortemente sua classificação como FCO; e os dividendos e JCP pagos têm sua classificação encorajada como FCF. A norma brasileira ainda ressalta que, caso a orientação não seja seguida, o fato deve ser evidenciado em nota explicativa. Essa orientação é dada pelo CPC 03, em seu parágrafo 34A, embora este não tenha correspondência com a IAS 7, norma originária e que serviu de base para a edição do CPC 03. Na realidade, o referido parágrafo está alinhado com a norma estadunidense Statement of Cash Flows (SFAS 95), emitida pelo FASB - Financial Accounting Standards Board, conforme os princípios contábeis geralmente aceitos nos Estados Unidos (United States Generally Accepted Accounting Principles - USGAAP). 
Mesmo em relação ao referido alinhamento entre CPC 03 e SFAS 95, há ainda uma diferença: a SFAS 95 requer a classificação dos fluxos tal qual a forma encorajada pelo CPC 03, no entanto, não exige a divulgação de justificativa se adotada outra forma de apresentação. Não há espaço nos USGAAP para escolhas contábeis na DFC. Se a classificação mandatória não for seguida, ocorrerá o descumprimento da norma. Isso significa dizer que não estão previstas OCDFC na norma contábil americana.

Conclui-se até aqui que tanto o CPC 03 quanto a IAS 7 permitem classificar os referidos itens (juros, dividendos e JCP) em mais de uma atividade na DFC. Assim, os preparadores podem escolher onde vão apresentar os itens mencionados, a fim de refletir a informação mais adequada para a realidade da empresa e, no contexto brasileiro, divulgando as devidas justificativas dessa escolha, caso não sigam a classificação fortemente encorajada pelo CPC 03.

Se, por um lado, essa flexibilidade prevista em norma permite que uma informação mais fidedigna seja apresentada, já que a apresentação da DFC poderá ser adaptada às circunstâncias específicas de cada empresa, por outro lado, essa mesma flexibilidade abre espaço para comportamentos oportunistas, ao permitir a escolha da opção que gere a informação mais conveniente.

Watts e Zimmerman (1990) afirmam que a contabilidade é uma atividade realizada por pessoas e, por esse motivo, não se pode gerar uma teoria que preveja e explique fenômenos contábeis ignorando os incentivos dos indivíduos. Pode-se então dizer que há incentivos que norteiam a escolha da classificação na DFC dos itens suscetíveis à flexibilidade. Tais incentivos podem estar relacionados à tentativa de divulgar a informação mais adequada ou podem ter relação com a necessidade de o gestor apresentar o melhor FCO possível, seja por interesse próprio (avaliação de desempenho, por exemplo), seja por interesse da empresa (melhor imagem para o mercado).

Com base nesse contexto, a presente pesquisa aborda os incentivos no âmbito da empresa, especificamente no que se refere a algumas de suas características, se as mesmas têm relação com a escolha de classificação na DFC. As características analisadas foram: segmento da indústria, firma de auditoria, endividamento, rentabilidade e se a empresa tem FCO negativo ao seguir o encorajamento do CPC 03 (FCO encorajado). 


\subsection{Questão da pesquisa e objetivo}

Tendo em vista o exposto, a questão da pesquisa está relacionada aos incentivos que definem a escolha das diferentes classificações na DFC dos juros, dividendos e JCP, pagos e recebidos, pelas empresas do mercado de capitais brasileiro.

Logo, o objetivo geral deste estudo é identificar as escolhas de classificação de juros, dividendos e JCP na DFC, por parte das empresas brasileiras, e as causas que motivam tais escolhas. Para atingir esse objetivo, as seguintes etapas foram seguidas:

1) Verificar se as classificações encorajadas pelo CPC 03 estão sendo seguidas, através do agrupamento das empresas de acordo com as opções de classificação adotadas;

2) Identificar fatores em comum (segmento e auditoria) nas empresas que adotam as mesmas opções de classificação;

3) Identificar as mudanças de classificação dos juros pagos de um período para o outro e verificar se há relação com a troca de auditor;

4) Analisar a correlação entre o efeito no FCO da opção adotada e características das empresas (endividamento, rentabilidade e FCO encorajado negativo).

\subsection{Hipóteses}

Considerando o objetivo proposto e as etapas da pesquisa, têm-se quatro hipóteses/grupo de hipóteses. A primeira está relacionada a um possível incentivo para seguir a classificação indicada pelo CPC 03, parágrafo 34A, que encoraja fortemente a classificação dos juros, recebidos ou pagos, os dividendos e JCP recebidos como FCO, e os dividendos e JCP pagos como FCF. Apesar de não haver uma exigência de se cumprir tal indicação, as empresas deverão divulgar em nota explicativa a justificativa para outras escolhas, demandando um trabalho adicional. Dessa forma, a seguinte hipótese foi construída:

$H_{1}$ : A maior parte das empresas brasileiras segue as classificações encorajadas pelo CPC 03, parágrafo $34 A$.

O segundo grupo de hipóteses dessa pesquisa refere-se à identificação de uma possível padronização das classificações de juros, JCP e dividendos na DFC, entre empresas com características semelhantes. 
H.a: Empresas do mesmo setor tendem a utilizar as mesmas classificações dos itens que possuem flexibilidade de apresentação na DFC.

Quanto ao segmento da indústria, espera-se um comportamento homogêneo na classificação das opções de apresentação na DFC, considerando-se o pressuposto de que a essência das transações precisa ser analisada em virtude de suas especificidades, e que empresas do mesmo segmento tendem a ter transações semelhantes. Em outras palavras, será avaliado se existe comportamento em grupo entre empresas brasileiras da mesma indústria, no que diz respeito às opções de classificação da DFC.

De acordo com Watts e Zimmerman (1986), pesquisadores notaram mudanças sistêmicas nos procedimentos contábeis de empresas da mesma indústria, as quais tendem a mudar de procedimentos no mesmo momento. Assim como em um determinado momento, empresas da mesma indústria tendem a usar os mesmos procedimentos. A pesquisa possibilitou verificar se esse comportamento sistêmico ocorre entre empresas brasileiras da mesma indústria, no que diz respeito às opções de classificação da DFC.

Outra explicação para a homogeneidade na classificação seria oriunda da influência exercida pelo auditor, o que explica a formulação da seguinte hipótese:

$H_{2} . b$ : Empresas que possuem os mesmos auditores tendem a utilizar as mesmas classificações dos itens que possuem flexibilidade de apresentação na DFC.

Segundo Scott (2014), os auditores atuam como intermediários no fluxo de informações entre a empresa e o usuário externo, ajudando a reduzir a assimetria informacional e aumentando a confiabilidade das demonstrações financeiras. A auditoria também é um mecanismo de enforcement, atestando o cumprimento das normas contábeis, as quais estão baseadas em uma estrutura conceitual que visam garantir a divulgação de informações relevantes.

Watts e Zimmerman (1986) abordam outro papel da auditoria relacionado à necessidade de monitoramento dos contratos, que são os compromissos representativos das relações entre os indivíduos externos e internos à empresa. Pelo fato das partes considerarem a probabilidade de quebra de contrato, o serviço de auditor é requerido, visando garantir que qualquer violação de contrato será reportada. $\mathrm{O}$ auditor é uma parte não envolvida no contrato e essa independência permite o cumprimento do seu papel, juntamente com a sua qualificação, ou seja, o auditor também precisa ser competente para identificar possíveis 
violações. A medida de independência e competência que o auditor tem vai determinar a sua reputação, a qual também influencia o grau de efetividade para exercer enforcement.

A criação de firmas de auditoria é um mecanismo para redução dos custos para se estabelecer uma boa reputação, considerando que tais instituições trabalham na capacitação e monitoramento dos seus auditores, por meio de exames de admissão, períodos de treinamento e comitê de ética (Watts \& Zimmerman, 1986). Essas sociedades profissionais tornaram-se marcas, reconhecidas pelos seus serviços de qualidade, e as grandes firmas de auditoria possuem vantagens em relação às demais, em virtude de terem uma estrutura que facilita a capacitação e monitoramento dos seus auditores.

As quatro maiores firmas de auditoria em âmbito internacional são chamadas de Big Four, são elas: PricewaterhouseCoopers International Limited (Price), Deloitte Touche Tohmatsu Limited (Deloitte), Ernst \& Young Global Limited (EY) e KPMG International Cooperative (KPMG). Para fins desta pesquisa, o grupo das Big Four é formado pelas entidades brasileiras, consideradas firmas-membro das respectivas entidades globais.

As empresas do mercado de capitais brasileiro, objeto de estudo dessa pesquisa, são obrigadas a contratar o serviço de auditoria de suas demonstrações financeiras, logo, não seria aplicável avaliar as diferenças de classificação na DFC, comparando-se empresas com ou sem auditoria. Entretanto, é possível comparar as práticas de empresas que contratam firmas de auditoria diferentes, pois, apesar da padronização que a própria natureza do serviço exige, pelo fato de seguirem as normas de auditoria, cada firma tem práticas e metodologias próprias, que diferenciam o seu serviço. Logo, uma possível influência pode ser exercida dado que a auditoria tem o papel de atestar o cumprimento das normas contábeis, e o faz a partir de seu julgamento acerca dos riscos que um potencial descumprimento destas pode trazer.

Assim, além da hipótese H2.b, que indica que empresas com os mesmos auditores tendem a utilizar as mesmas classificações dos itens que possuem flexibilidade de apresentação na DFC, uma terceira hipótese foi levantada:

$H_{3}$ : Mudanças de classificação de juros pagos ocorrem em função da mudança de auditor.

A referida hipótese foi direcionada aos juros pagos em função da possibilidade de a empresa aumentar o FCO, caso não seja seguida a classificação recomendada pelo CPC 03, algo que não ocorre para os demais itens suscetíveis à flexibilidade (juros recebidos, dividendos e JCP). 
O quarto grupo de hipóteses, de forma semelhante à pesquisa de Gordon, Henry, Jorgensen, e Linthicum (2013) e Silva, Martins, e Lima (2014), engloba a correlação entre o efeito no FCO da escolha de classificação na DFC e características financeiras e de desempenho das empresas, conforme abaixo:

H4.a: Empresas com elevado grau de endividamento tendem a escolher a classificação que aumente o FCO.

$H_{4 . b}$ : Empresas com menor rentabilidade tendem a escolher a classificação que aumente o FCO.

H4.c: Empresas com FCO negativo de acordo com o encorajamento do CPC 03 tendem a escolher a classificação que aumente o FCO.

As proxies das variáveis explicativas, utilizadas para representar as características das empresas e os fatores existentes na escolha de classificações que afetam o FCO, estão apresentadas a seguir.

No que se refere à medição do grau de endividamento, foi utilizado o índice de endividamento geral, calculado dividindo-se o total de passivos, circulante e não circulante, pelo total de ativos e multiplicando-se por 100. Empresas que possuem contratos e custos envolvidos em renegociações procuram informar um FCO mais elevado, de acordo com Gordon et al. (2013).

Para se calcular a rentabilidade da empresa, dividiu-se o resultado líquido do exercício pelo montante de ativo total e multiplicou-se por 100, apurando-se o retorno do ativo em percentual. Esse índice também captura se a empresa está com lucro ou prejuízo no período. Espera-se que empresas com uma maior rentabilidade sejam menos propensas a gerenciar um aumento do FCO, uma vez que possuem um lucro líquido elevado a seu favor. Essa questão está alinhada com a própria formação do resultado, apresentada anteriormente, da qual se pode afirmar que o FCO refere-se ao resultado menos as provisões.

No caso das empresas que reportariam FCO negativo ao seguir o encorajamento do CPC 03, considerou-se que as mesmas possuem incentivos para atenuar essa situação ou até para invertê-la. Por esta razão, espera-se que se o FCO encorajado for negativo, maior a chance de se gerenciar um aumento no FCO divulgado. Essa lógica é utilizada por analogia 
aos casos envolvendo incentivos para reportar resultados positivos em vez de negativos, de acordo com a pesquisa de Burgstahler e Dichev (1997).

\subsection{Justificativas e Contribuições}

Em primeiro lugar, verifica-se que há uma vasta literatura que examina a classificação de contas no balanço patrimonial e demonstração do resultado do exercício, todavia, pouca atenção tem sido dada às variações de classificação na DFC, de acordo com McVay (2006).

Como segundo ponto, destaca-se a importância de se entender o critério de classificação dos fluxos de caixa, pois a DFC, juntamente com as demais demonstrações contábeis, permite ao usuário, dentre outras possibilidades, prever os fluxos de caixa futuros, base para avaliação de empresas e análises financeiras. Nesse sentido, vale lembrar que Hendriksen e Breda (1999) afirmam que conhecer os fluxos de caixa futuros esperados é o que permite ao mercado fixar os preços das ações de uma empresa.

De acordo com Watts e Zimmerman (1986), uma forma de se estimar fluxos de caixa futuros é utilizar como referência os fluxos de caixa presentes. Beaver (1973) defende que os investidores estão apenas interessados em fluxo de caixa e dividendos. Outra questão abordada por Beaver (1973) refere-se à implicação na hipótese de mercados eficientes (HME) de que os investidores utilizarão toda a informação disponível para melhorar suas predições. Sem se aprofundar na discussão sobre a HME, seus méritos e limitações, o levantamento das opções de classificação relacionadas à DFC permitirá a identificação das escolhas que estão sendo efetuadas pelas empresas do mercado de capitais brasileiro, uma vez que tais escolhas podem impactar as informações apresentadas na DFC, interferindo na análise, predição e consequente decisão dos usuários.

As relações entre os indivíduos externos e internos à empresa são representadas por compromissos entre as partes, ou seja, por contratos. Segundo Watts e Zimmerman (1986), esse processo contratual trata-se de uma teoria econômica também chamada de direitos de propriedade, devido à sua ênfase nos direitos estabelecidos pelos contratos, os quais especificam a distribuição do fluxo de caixa da empresa. Adicionalmente, o conjunto de contratos que sobreviver ao longo do tempo são eficientes em termos de maximização do valor da empresa.

Scott (2014) afirma que um contrato eficiente minimiza custos relacionados ao risco moral por motivar o gestor a agir em favor do melhor interesse dos acionistas. Como a contabilidade integra contratos entre diversas partes, a presente pesquisa aborda 
especificamente a relação entre os preparadores das demonstrações contábeis e os seus usuários externos. Tais usuários querem usufruir do direito de ter acesso a informações úteis e confiáveis, uma vez que estão interessados em saber como a empresa está no momento e em entender suas perspectivas de negócios, de forma que possam tomar decisões com segurança.

Dada a possibilidade de os preparadores classificarem itens na DFC, conforme CPC 03 e IAS 7, e considerando que o FCO é a base para cálculos de valuation (Damodaran, 2006), que incluem a projeção dos fluxos de caixa futuros, para contratação (Dichev \& Skinner, 2002) e para análises financeiras (Estridge \& Lougee, 2007), várias podem ser as motivações para que o preparador escolha determinada classificação para obtenção de vantagens, ao contrário do que se espera com tal liberdade, que é o espaço necessário para exercício de julgamento visando a divulgação de informações verdadeiras e adequadas.

Essa pesquisa avalia se há incentivos para que o FCO seja afetado, e esta informação, se não apresentada de forma adequada, poderá prejudicar o entendimento dos usuários externos quanto à composição dos fluxos de caixa da empresa e à determinação do seu valor. Embora tamanha importância, menos atenção tem sido dada às variações de classificação de itens da DFC (Gordon et al., 2013).

Afora tal importância, esta pesquisa contribui para o desenvolvimento da teoria das escolhas contábeis no cenário brasileiro, expandindo o estudo efetuado por Silva et al. (2014), por abordar certas características das empresas que podem determinar as escolhas de classificação na DFC, de acordo com as opções previstas no CPC e nas IFRS. Além da utilização de uma amostra maior, tanto em quantidade de empresas como de períodos, a presente pesquisa inclui uma análise das classificações na DFC por setores e firmas de auditoria.

Em complemento, a presente pesquisa faz uma análise das mudanças de classificação dos juros pagos de um período para o outro e se essa mudança está relacionada com a troca de auditor. $\mathrm{O}$ foco nos juros pagos ocorre por ser esse o componente que aumenta o valor do FCO, caso não seja seguida a classificação encorajada pelo CPC 03. Outro diferencial deste trabalho refere-se ao uso de duas regressões: uma tendo como variável dependente a diferença em reais entre o FCO divulgado e o valor que seria o FCO ao seguir as opções encorajadas pelo CPC 03; e outra regressão com a escolha de classificação dos juros pagos (dummy), tendo em vista o impacto que esse item pode gerar no FCO, conforme mencionado. Silva et al. (2014) utilizaram apenas a classificação dos juros pagos como variável dependente.

Adicionalmente, este trabalho tem o potencial de trazer evidências do poder discricionário dos gestores através do relato de medidas de fluxos de caixa, quando optam por 
uma das alternativas de classificação na DFC, o que, aliás, é algo pouco pesquisado, uma vez que o resultado do exercício costuma ser a medida de referência para análise em pesquisas envolvendo gerenciamento de resultados. Conforme Scott (2014), o resultado contábil é formado pelo FCO somando-se ou reduzindo-se as acumulações (accruals) líquidas, as quais possuem níveis de discricionariedade e por isso são base dos modelos para se medir o nível de gerenciamento de resultados. Por outro lado, o FCO apurado de acordo com o CPC e as IFRS também está passível à discricionariedade, logo, medidas diferentes de FCO impactariam na mensuração das accruals e, consequentemente, no nível de gerenciamento de resultados calculado, distorcendo os achados e as possíveis comparações com outras empresas.

Não obstante a importância para a academia destaca-se a relevância deste trabalho para usuários e normatizadores, os quais obterão um melhor entendimento de como as empresas brasileiras têm utilizado a flexibilidade prevista no CPC 03 e IAS 7, e que fatores estão relacionados às suas escolhas, ajudando assim a direcionar novas pesquisas, além de prover informação relevante para análise das empresas e para emissão e/ou revisão das normas contábeis brasileiras e internacionais.

\subsection{Delimitações da pesquisa}

Conforme já mencionado, a questão da pesquisa está relacionada aos incentivos que definem a escolha das diferentes classificações na DFC dos juros, dividendos e JCP, pagos e recebidos, pelas empresas do mercado de capitais brasileiro. Além dos incentivos, um outro fator que interfere no processo de tomada de decisão dos indivíduos refere-se ao seu julgamento.

Bonner (2007) apresentou um framework relacionado à pesquisa envolvendo julgamento e tomada de decisão em contabilidade, definindo julgamento como o ato de formar ideia, opinião ou estimativa a respeito de algo, enquanto decisão se refere à "mente em ação", uma escolha baseada em julgamento e preferência. A referida autora mostrou a importância de se pesquisar o tema em questão, pois este traz consequências aos indivíduos envolvidos, seus pares e sociedade, destacando que há uma relação estreita da contabilidade com a psicologia. Apesar de ser algo relevante, essa área não foi abordada.

Esta pesquisa foca na observação das exigências do CPC 03 e da IAS 7, no que tange à flexibilidade de classificação dos juros, dividendos e JCP na DFC, independentemente do método de elaboração da referida demonstração financeira (direto ou indireto). Caso a empresa opte por apresentar a DFC pelo método direto, conforme parágrafo $20 \mathrm{~A}$ do CPC 03 , 
deverá fornecer em nota explicativa a conciliação entre o lucro líquido e fluxo de caixa líquido das atividades operacionais, ou seja, deverá apresentar informações equivalentes ao método indireto. Essa conciliação entre lucro e FCO é uma informação relevante, entretanto, o método de elaboração da DFC adotado pela empresa não influencia na pesquisa, tendo em vista que os montantes de juros, dividendos e JCP, pagos ou recebidos, devem ser apresentados separadamente nos dois métodos.

Apesar do CPC 03 ser aplicável às entidades em geral, o estudo não engloba as instituições financeiras, as quais, além de possuírem normatização contábil específica, costumam classificar os juros, pagos e recebidos, e os dividendos e JCP recebidos como fluxos de caixa operacionais, em virtude da natureza de suas operações, realidade inclusive mencionada na IAS 7 e no CPC 03. Não há, todavia, esse consenso de classificação para as demais entidades.

A pesquisa está direcionada à DFC consolidada, quando aplicável, das empresas abertas, uma vez que em IFRS não há requerimento de apresentação de demonstrações individuais. A DFC individual foi utilizada apenas quando a entidade não apresentou demonstrações consolidadas. As notas explicativas não foram consultadas, pois o foco da pesquisa está no critério de divulgação da própria DFC que as empresas brasileiras ${ }^{1}$ têm adotado.

O período analisado foi de 2008 a 2014, compreendendo o período a partir da divulgação compulsória da DFC no Brasil até o último exercício social passível de observação para consecução da pesquisa. Importante ressaltar que a utilização de vários períodos permite a análise de situações financeiras e de desempenho diferentes, bem como a mudança de auditores de uma mesma empresa, independentemente dos fatores que influenciaram tais mudanças, sejam crises da economia ou do setor, ou consequências de decisões internas, por exemplo.

\subsection{Estrutura do Trabalho}

Este trabalho está dividido em cinco capítulos, conforme a seguir:

Capítulo 1 - Introdução: apresenta a contextualização da questão de pesquisa, seu objetivo, etapas, hipóteses, justificativas, contribuições e delimitações.

\footnotetext{
${ }^{1}$ Entenda-se como empresas brasileiras, do mercado de capitais brasileiro, abertas ou de capital aberto, aquelas cujas ações são negociadas na Bolsa de Valores de São Paulo, a BM\&FBOVESPA (Bolsa de Valores, Mercadorias e Futuros), e que são regulamentadas pela CVM (Comissão de Valores Mobiliários).
} 
Capítulo 2 - Referencial Teórico: neste capítulo é apresentado o arcabouço teórico que serviu de suporte para este estudo. Os assuntos abordados são: a demonstração dos fluxos de caixa; estudos anteriores; escolhas contábeis; teoria de gerenciamento de resultados; teoria de investimento e estrutura conceitual.

Capítulo 3 - Metodologia: neste capítulo são apresentados: classificação da pesquisa; levantamento dos dados e critérios de classificação; amostra e critérios de seleção; procedimentos e análise dos dados.

Capítulo 4 - Resultados: apresenta os resultados obtidos e análise dos dados levantados.

Capítulo 5 - Considerações finais: capítulo que apresenta as conclusões, implicações do estudo e limitações da pesquisa.

Ao longo desse trabalho, serão utilizados alguns termos com significados específicos, conforme definido pelo Pronunciamento Técnico CPC 03 e IAS 07:

a) Caixa: numerário em espécie e depósitos bancários disponíveis.

b) Equivalentes de caixa: aplicações financeiras de curto prazo, de alta liquidez, que são prontamente conversíveis em um montante conhecido de caixa e que estão sujeitas a um insignificante risco de mudança de valor.

c) Fluxos de caixa: entradas e saídas de disponibilidades.

d) Atividades operacionais: principais atividades geradoras de receita da entidade e outras atividades diferentes das de investimento e de financiamento.

e) Atividades de investimento: referentes à aquisição e à venda de ativos de longo prazo e de outros investimentos não incluídos nos equivalentes de caixa.

f) Atividades de financiamento: resultam em mudanças no tamanho e na composição do capital próprio e no endividamento da entidade, não classificadas como atividade operacional.

Outro conceito que também será utilizado nesse trabalho é o de disponibilidades, que é o somatório dos saldos de caixa e equivalentes de caixa. 


\section{REFERENCIAL TEÓRICO}

Neste capítulo, são apresentados a utilidade e importância da DFC, o histórico de divulgação no Brasil, esclarecimentos sobre o método indireto de apresentação da DFC e a divisão por atividades, a qual caracteriza a estrutura da referida demonstração financeira.

$\mathrm{Na}$ sequência, estudos anteriores a respeito do tema da pesquisa e as principais teorias envolvidas são discorridos.

\subsection{A Demonstração dos Fluxos de Caixa}

O objetivo da DFC é fornecer informações acerca das alterações nas contas de caixa e equivalentes de caixa de uma entidade, em um determinado período, classificando tais fluxos de caixa em atividades operacionais, de investimento e de financiamento.

A DFC é considerada uma demonstração relevante para a tomada de decisões, pois por meio dela é possível identificar a escassez ou excedente de recursos da entidade analisada em determinado período, indicando a origem de todo numerário que entrou no caixa, bem como a sua aplicação e, ainda, o resultado do fluxo financeiro. Especificamente através da DFC pelo método indireto, é possível, dentre outras análises, conciliar o lucro contábil com o fluxo de caixa operacional líquido, por esse motivo ele também é chamado de método da conciliação, como explicado por Martins, Gelbcke, Santos, e Iudícibus (2013).

As entidades necessitam de caixa essencialmente pelas mesmas razões, por mais diferentes que sejam as suas principais atividades geradoras de receita. $\mathrm{Na}$ prática, as entidades precisam dos recursos de caixa para efetuar suas operações, pagar suas obrigações e prover um retorno para seus investidores. Nesse contexto, as informações dos fluxos de caixa de uma entidade são úteis para proporcionar aos usuários das demonstrações contábeis uma base para avaliar a capacidade de a entidade gerar caixa e equivalentes de caixa, bem como suas necessidades de liquidez. A DFC, quando utilizada em conjunto com as demais demonstrações contábeis, proporciona informações que habilitam os usuários a avaliar as mudanças nos ativos e passivos líquidos de uma entidade e sua estrutura financeira.

O IASB e o FASB consideram em sua estrutura conceitual ${ }^{2}$ que a decisão primária do usuário é a de investimento na empresa, destacando que o grupo principal de usuários das

\footnotetext{
2 IASB: "The Conceptual Framework for Financial Reporting"

FASB: "Statement of Financial Accounting Concepts No. 8 - Conceptual Framework for Financial Reporting"
} 
demonstrações contábeis, formado por investidores e credores, precisa de informações sobre montante, tempestividade e incerteza dos fluxos de caixa futuros. A referência à incerteza assume considerar que o investidor é avesso ao risco, conforme Scott (2014), o que implica dizer que ele está em busca de informações confiáveis e úteis que o ajudem a medir os fluxos de caixa futuros, por isso a importância do FCO apresentado na DFC, por ser um componente informacional relevante nesse processo.

Uma outra qualidade acerca do FCO, mencionada por Scott (2014), refere-se ao fato de que é mais provável que um montante de FCO de um determinado período se repita no período seguinte comparando-se com o comportamento das accruals. O referido autor também menciona que as accruals deverão afetar o resultado de forma reversa no futuro. Tais comportamentos indicam que o fluxo de caixa é mais persistente que as accruals. Essa característica de persistência facilita a previsão dos fluxos de caixa futuros da empresa, por oferecer uma informação precisa, tanto em termos de valores quanto de tempestividade.

\subsubsection{Histórico de divulgação no Brasil}

A DFC substituiu a Demonstração de Origens e Aplicações de Recursos (DOAR) e sua obrigatoriedade entrou em vigor a partir de 01.01.2008 pela Lei $n^{\circ} 11.638 / 2007$, a qual teve como objetivo fundamental atualizar as regras contábeis brasileiras e aprofundar a harmonização destas regras com os pronunciamentos internacionais, emitidos pelo IASB. A Lei $n^{\circ}$ 11.638/2007, art. 1º , deu nova redação ao inciso IV do art. 176 da Lei no 6.404/1976, Lei das Sociedade por Ações, substituindo assim a DOAR pela DFC. A CVM, como órgão regulamentador das empresas abertas brasileiras, disciplinou a referida lei através da Deliberação CVM n 547/2008, a qual aprovou o Pronunciamento Técnico CPC 03, que, por sua vez, trata da DFC.

A Lei $n^{\circ} 11.638 / 2007$ também deu nova redação ao art. 188 da Lei ${ }^{\circ}$ 6.404/1976, estabelecendo que a DFC deverá indicar, no mínimo, as alterações ocorridas, durante o exercício, no saldo de caixa e equivalentes de caixa, segregando-se essas alterações em, no mínimo, três fluxos: das operações; dos financiamentos; e, dos investimentos.

As mudanças promovidas pela Lei $\mathrm{n}^{\circ} 11.638 / 2007$ foram diversas e incluem a obrigatoriedade de elaboração da DFC também para as empresas de grande porte, ainda que não constituídas sob a forma de sociedades por ações. Para esse fim, considera-se de grande porte a sociedade ou o conjunto de sociedades sob controle comum que tiver, no exercício 
social anterior, ativo total superior a 240 milhões de reais ou receita bruta anual superior a 300 milhões de reais.

\subsubsection{Métodos de apresentação}

A DFC poderá ser elaborada e apresentada por um dos 2 métodos existentes: o método direto e o método indireto. Ressalta-se que este último tem sido o mais utilizado pelas empresas do mercado de capitais brasileiro (Scherer, Teodoro, Anjos, \& Kos, 2012; Silva et al., 2014) ${ }^{3}$. Martínez, Martínez, e Diazaraque (2011) identificaram que, no mercado espanhol, 89\% das empresas utilizaram o método indireto no primeiro ano de adoção das IFRS.

Ambos os métodos possuem uma característica comum, representada pela divisão em três fluxos: operacional, investimento e financiamento. A principal diferença entre eles reside na apresentação do FCO. O método direto inicia a sua demonstração com todas as movimentações ocorridas no caixa e equivalentes (todos os recebimentos e pagamentos que passaram por eles), as quais foram classificadas na atividade operacional. No método indireto, inicia-se com o lucro ou prejuízo líquido do período para, em seguida, fazer uma série de ajustes nesse lucro ou prejuízo e assim apurar o FCO.

Dessa forma, pode-se dizer que o FCO irá apresentar um resultado operacional por regime de caixa, pois os efeitos das accruals são anulados e os eventos referentes às outras atividades são reclassificados para seus respectivos grupos (Martins et al., 2013). Esses ajustes ao lucro ou prejuízo líquido devem-se ao fato de a Demonstração do Resultado do Exercício (DRE) ser elaborada com base no regime de competência. Isso significa dizer que em tal resultado foram consideradas as despesas e as receitas incorridas, mas que ainda não foram efetivamente realizadas (pagas ou recebidas). Em outras palavras, através da DFC pelo método indireto, é possível conciliar o resultado líquido com o FCO, ou seja, caixa líquido gerado ou aplicado nas atividades operacionais e, através dessa conciliação, os itens que compõem a diferença entre os regimes de competência e de caixa são destacados.

Outra diferença entre os dois métodos de elaboração da DFC é que o método indireto não relata as movimentações ocorridas no caixa e equivalentes, mas apresenta o fluxo de caixa das atividades através da movimentação das demais contas do balanço patrimonial, ou

\footnotetext{
${ }^{3}$ Scherer et al. (2012) analisaram 67 empresas que constituíam o índice IBOVESPA, e Silva et al. (2014) analisaram 109 empresas não financeiras integrantes do Novo Mercado. Das 352 empresas selecionadas na presente pesquisa, apenas 6 empresas divulgaram a DFC pelo método direto, das quais apenas 2 apresentaram em todos os anos (de 2008 a 2014), ambas do segmento de energia elétrica. As demais apresentaram pelo método direto em um ou mais anos, mas nos últimos anos passaram a divulgar pelo método indireto.
} 
seja, o efeito na variação de caixa e equivalentes de caixa é apurado indiretamente. A elaboração pelo método direto, por sua vez, é totalmente dependente de uma análise criteriosa de todas as transações que passaram pelo caixa e equivalentes durante o período em análise. Independentemente do método utilizado, os valores de fluxos de caixa das atividades operacionais, de investimento e de financiamento são os mesmos.

\subsubsection{Divisão por atividades}

De acordo com o CPC 03 e IAS 7, a entidade deverá classificar na DFC os fluxos de caixa entre as atividades operacionais, de investimento e de financiamento.

A classificação por atividade proporciona informações que permitem aos usuários avaliar o impacto de tais atividades sobre a posição financeira da entidade e o montante de seu caixa e equivalentes. Essas informações podem também ser usadas para avaliar a relação entres as três atividades.

Ressalta-se que

uma única transação pode incluir fluxos de caixa classificados em mais de uma atividade. Por exemplo, o desembolso de caixa para pagamento de um empréstimo inclui tanto os juros como o principal, a parte dos juros pode ser classificada como atividade operacional, mas a parte do principal deve ser classificada como atividade de financiamento.

Cada atividade da DFC será apresentada a seguir de forma resumida, de acordo com o CPC 03 e IAS 7.

O montante dos fluxos de caixa decorrente das atividades operacionais possibilita verificar se as operações da entidade têm gerado fluxos de caixa suficientes para pagamento de dívidas e para fazer investimentos, sem recorrer a fontes externas de financiamento, ou seja, para se autofinanciar, o que demonstra a capacidade operacional da entidade.

Os fluxos de caixa decorrentes das atividades operacionais são derivados das principais atividades geradoras de receita da entidade. Transações de venda de ativo imobilizado podem resultar em ganho ou perda, que compõe o lucro ou prejuízo líquido, e por isso tal resultado é anulado das atividades operacionais na DFC, uma vez que os fluxos de caixa relativos a tais transações são provenientes de atividades de investimento e assim são classificados na DFC.

A importância de se destacar os fluxos de caixa oriundos das atividades de investimento está relacionada à informação do montante de caixa que foi gerado ou aplicado no período pelos investimentos, os quais tem a finalidade de gerar resultados e fluxos de caixa no futuro. De acordo com a CPC 03, são exemplo de fluxos de caixa advindos das atividades de investimento: 
(a) pagamentos em caixa para aquisição de ativo imobilizado, intangíveis e outros ativos de longo prazo. Esses pagamentos incluem aqueles relacionados aos custos de desenvolvimento ativados e aos ativos imobilizados de construção própria;

(b) recebimentos de caixa resultantes da venda de ativo imobilizado, intangíveis e outros ativos de longo prazo;

(c) pagamentos em caixa para aquisição de instrumentos patrimoniais ou instrumentos de dívida de outras entidades e participações societárias em joint ventures (exceto aqueles pagamentos referentes a títulos considerados como equivalentes de caixa ou aqueles mantidos para negociação imediata ou futura);

(d) recebimentos de caixa provenientes da venda de instrumentos patrimoniais ou instrumentos de dívida de outras entidades e participações societárias em joint ventures (exceto aqueles recebimentos referentes aos títulos considerados como equivalentes de caixa e aqueles mantidos para negociação imediata ou futura);

(e) adiantamentos em caixa e empréstimos feitos a terceiros (exceto aqueles adiantamentos e empréstimos feitos por instituição financeira);

(f) recebimentos de caixa pela liquidação de adiantamentos ou amortização de empréstimos concedidos a terceiros (exceto aqueles adiantamentos e empréstimos de instituição financeira);

(g) pagamentos em caixa por contratos futuros, a termo, de opção e swap, exceto quando tais contratos forem mantidos para negociação imediata ou futura, ou os pagamentos forem classificados como atividades de financiamento; e

(h) recebimentos de caixa por contratos futuros, a termo, de opção e swap, exceto quando tais contratos forem mantidos para negociação imediata ou venda futura, ou os recebimentos forem classificados como atividades de financiamento.

A segregação dos fluxos de caixa advindos das atividades de financiamento é relevante para prever as exigências sobre fluxos de caixa futuros pelos fornecedores de capital à entidade. São exemplos de fluxos de caixa decorrentes das atividades de financiamento:

(a) caixa recebido pela emissão de ações ou outros instrumentos patrimoniais;

(b) pagamentos de caixa a investidores para adquirir ou resgatar ações da entidade;

(c) caixa recebido proveniente da emissão de debêntures, empréstimos, títulos e valores, hipotecas e outros empréstimos de curto e longo prazos;

(d) amortização de empréstimos e financiamentos, [incluindo debêntures emitidas, hipotecas, mútuos e outros empréstimos de curto e longo prazos]; e

(e) pagamentos de caixa por arrendatário para redução do passivo relativo a arrendamento mercantil financeiro.

\subsection{Estudos anteriores}

Estudos anteriores apresentam evidências variadas da percepção do investidor sobre informações contábeis divulgadas em diferentes classificações nas demonstrações financeiras. Alguns desses estudos focam na divulgação em notas explicativas: Ahmed, Kilic, e Lobo (2006); Cotter e Zimmer (2003); Davis-Friday, Folami, Liu, e Mittelstaedt (1999); Espahbodi, Espahbodi, Rezaee, e Tehranian (2002); Al Jifri e Citron (2009) e; Niu e Xu (2009). Outros poucos estudos abordam a análise da informação contábil apresentada em diferentes 
classificações na mesma demonstração financeira: Cahan, Courtenay, Gronnewoller, e Upton (2000); Lopes, Lourenço, e Soliman (2013) e; So e Smith (2009).

Gordon et al. (2013) pesquisaram a flexibilidade da escolha de classificação na DFC de acordo com as IFRS, em empresas de treze países europeus, para os exercícios fiscais de 2005 a 2008, e identificaram fatores determinantes para escolhas de classificação que aumentam o FCO, relacionados a características das empresas, dentre eles, rentabilidade e endividamento. Os autores mensuraram o efeito da flexibilidade de classificações na DFC usando como referência a SFAS 95, que estabelece a classificação dos juros, dividendos e JCP de forma semelhante ao que é encorajado pelo CPC 03, parágrafo 34A. Em função dessa similaridade, o presente estudo seguirá o desenho elaborado por Gordon et al. (2013), conforme detalhado mais adiante nas seções 3 e 4, adaptado de forma a responder a questões específicas da pesquisa.

Baik, Cho, Choi, e Lee (2013) examinaram a mudança de classificação na DFC em empresas que adotaram IFRS na Coréia, especificamente, os fatores determinantes e consequências econômicas da mudança de classificação dos juros pagos. Foi observado que empresas com alto endividamento e de grande porte, por exemplo, tendem a reclassificar o montante de juros pagos da atividade operacional para a atividade de financiamento, aumentando assim o valor do FCO divulgado.

Uma das características identificadas por Lee (2012), que tem associação com incentivos para inflar o FCO, foi a probabilidade de falência das empresas do mercado de capitais estadunidense, no período de 1988 a 2008. O referido estudo examinou incentivos para inflar FCO na DFC e mecanismos para gerenciar o FCO, ou seja, observou o gerenciamento do FCO (GFCO), o qual se distingue de gerenciamento de resultados, conforme indicado pela autora. O GFCO não afeta o resultado do período, ou seja, ele se mantém constante, assim como o fluxo de caixa agregado, que é a soma dos fluxos de caixa das atividades operacionais, de investimento e de financiamento.

Scherer et al. (2012), em seu estudo sobre as diferenças de procedimentos de divulgação da DFC entre empresas listadas nas bolsas de valores de São Paulo, Frankfurt, Milão e Londres, também abordam a classificação dos juros, dividendos e JCP pagos e recebidos na DFC, porém a um conjunto limitado de entidades, as que formam o índice IBOVESPA $^{4}$, e a um único período, 2009. Quando aplicável, 86\% das empresas brasileiras

\footnotetext{
${ }^{4}$ O IBOVESPA é o indicador do desempenho médio das cotações dos ativos de maior negociabilidade e representatividade do mercado de ações brasileiro (http://www.bmfbovespa.com.br/indices/ResumoIndice. aspx?Indice=IBOVESPA\&idioma=pt-br).
} 
selecionadas classificaram os juros pagos como FCO; juros recebidos foram classificados como FCO em 98\% da amostra; dividendos/JCP pagos como FCF em 98\% dessas empresas; e, dividendos/JCP recebidos como FCO em $48 \%$ e como FCI em 52\% das empresas selecionadas. Os resultados mostraram que a maioria das empresas seguiu a recomendação do CPC 03, parágrafo 34A, com exceção dos dividendos/JCP recebidos, pois apenas $48 \%$ das empresas os classificaram na atividade operacional.

Silva et al. (2014) investigaram as escolhas contábeis na evidenciação da DFC, do ano de 2010, das empresas brasileiras listadas no Novo Mercado da BM\&FBOVESPA, que estabelece um padrão de governança corporativa mais elevado, totalizando uma amostra de 107 empresas. Em linha com a presente pesquisa, consideraram a classificação dos juros pagos e recebidos, e dividendos/JCP pagos e recebidos, com o objetivo de identificar fatores que explicassem tais escolhas. Foram analisados aspectos relacionados a endividamento, rentabilidade, FCO negativo, porte da empresa e oportunidades de crescimento como incentivos para escolhas que aumentam o FCO.

Os resultados da pesquisa de Silva et al. (2014) não indicaram que as escolhas contábeis na DFC estavam relacionadas a algum desses fatores, o que evidenciaria um possível gerenciamento de fluxos de caixa. Com relação à classificação adotada pelas empresas, 45,7\% delas classificaram juros pagos como FCO; juros recebidos foram classificados como FCO em 6 do total de 8 empresas; dividendos/JCP pagos como FCF em todas as 84 empresas; e, dividendos/JCP recebidos como FCO em apenas 8 das 25 empresas que divulgaram essa informação. Com base na DFC de 2010 das empresas brasileiras listadas no Novo Mercado, concluiu-se que a maioria dessas empresas não seguiu a recomendação do CPC 03, parágrafo 34A, para classificação dos juros pagos (FCO) e dos dividendos/JCP recebidos (FCO).

Outros estudos envolvendo a DFC e o mercado de capitais brasileiros foram efetuados. Braga e Marques (2001) demonstraram a viabilidade de uma análise financeira através do cálculo e interpretação de índices extraídos da DFC, utilizando duas empresas que a divulgaram voluntariamente, de 1997 a 1999.

Salotti (2008) pesquisou sobre os motivos de divulgação voluntária da DFC no período de 2000 a 2004, identificando, dentre outras, correlação positiva com a importância dada pela empresa às percepções dos outsiders e com o desempenho da empresa, e correlação negativa com os custos de divulgação e com o nível de assimetria informacional.

Lustosa e Santos (2006) verificaram a reação do mercado de ações ao FCO e a relação entre o lucro contábil e o FCO, para 88 empresas não-financeiras, de 1995 a 2004. Destaca-se 
que, na ocasião de tais estudos, a divulgação da DFC não era compulsória e, além de reforçarem a importância dessa demonstração, levantaram questões a serem consideradas na elaboração da respectiva norma contábil, que acabou sendo emitida posteriormente, CPC 03 em 2008, de acordo com as IFRS, diferenciando-se dos USGAAP em virtude das opções previstas de classificação dos juros, dividendos e JCP, tema dessa pesquisa.

\subsection{Escolhas contábeis}

Conforme já mencionado, Salotti (2008) investigou os motivos de divulgação da DFC pelas empresas e/ou gestores, considerando os incentivos relacionados, uma vez que tal demonstração financeira não era compulsória no Brasil na época. No cenário atual, a divulgação da DFC não é mais uma escolha, todavia, pode-se escolher entre as opções de classificação dos juros, dividendos e JCP, de forma a seguir ou não o encorajamento apresentado pelo CPC 03, item 34A.

Com tais opções de classificação previstas na norma contábil, espera-se que cada empresa adote a classificação mais adequada, com o intuito de divulgar a melhor informação para auxiliar a tomada de decisão do investidor e demais usuários. Entretanto, fatores diversos podem influenciar a escolha da classificação. Considerando essa realidade, a presente pesquisa engloba escolhas contábeis especificamente na divulgação da DFC, não obstante esse tema ser bem mais abrangente.

Quagli e Avallone (2010) analisaram a influência dos três motivos da teoria das escolhas contábeis (assimetria informacional, custos de agência e oportunismo gerencial) defendidos por Holthausen (1990), a fim de explicar a escolha do critério de valor justo na mensuração de propriedade para investimento, uma das opções previstas pelo IAS 40. Tal análise envolveu as escolhas de empresas europeias do setor imobiliário na adoção das IFRS.

Martínez et al. (2011) examinaram relatórios anuais de empresas listadas no mercado de capitais espanhol que adotaram IFRS em 2005, a fim de identificar os critérios contábeis opcionais aplicados e as características das empresas que afetaram tais escolhas. Indústria, retorno sobre patrimônio líquido, tamanho e auditor influenciaram a escolha dos métodos contábeis utilizados na preparação das demonstrações financeiras, de acordo com a referida pesquisa.

Missonier-Piera (2004) investigou determinantes econômicos das escolhas de métodos contábeis e seu efeito no balanço patrimonial e na demonstração de resultado, de empresas do mercado de capitais suíço. As evidências mostraram que empresas que escolhem métodos 
contábeis que diminuem os índices de endividamento e que melhoram o resultado contábil foram as que mais se utilizam de empréstimos bancários para financiar as operações.

Murcia, Souza, Wuergues, e Duarte (2013) buscaram identificar os fatores determinantes da escolha realizada pelas companhias abertas no Brasil quanto ao tratamento dado à reserva de reavaliação, após o advento da Lei 11.638/07, a qual determinou que as empresas com saldo da referida reserva tinham a opção de estorná-lo ou mantê-lo para realização via depreciação ou alienação. Os fatores considerados para análise foram tamanho, rentabilidade, endividamento, governança corporativa, empresa de auditoria e valor da reserva de reavaliação. Quanto aos resultados, não foi identificada associação entre as decisões tomadas pelas empresas e o conjunto de variáveis explicativas, em função do modelo utilizado não ter sido significativo.

O tratamento dos saldos remanescentes de ativo diferido foi outra opção oriunda da Lei 11.638/07, os quais poderiam ser mantidos ou baixados. Lorencini e Costa (2012) procuraram avaliar quais características das companhias abertas estariam ligadas à tal escolha contábil. Foram identificadas duas características: 1) a participação em algum dos níveis diferenciados de governança corporativa - associada à escolha pela baixa dos saldos remanescentes; e, 2) o tamanho do saldo do ativo diferido - associado à escolha pela manutenção dos saldos.

Fields, Lys, e Vincent (2001) definem escolha contábil como qualquer decisão cujo propósito primário seja influenciar, em forma ou em substância, a saída do sistema contábil de uma forma particular, incluindo não apenas as demonstrações financeiras publicadas, mas também declarações fiscais e registros regulatórios.

Cabello (2012) afirma que a teoria das escolhas contábeis estuda o como e o porquê das escolhas, uma vez que o órgão regulador permite várias práticas contábeis para tratar de um mesmo evento econômico.

Para Watts (1992), escolha contábil inclui a escolha do gestor da empresa de um método contábil em detrimento a outro, como por exemplo, a escolha do método de depreciação linear em vez da depreciação acelerada, e considera que a teoria das escolhas contábeis é central no estudo e entendimento da contabilidade.

Francis (2001) apresenta a definição de escolha contábil de acordo com Fields et al. (2001) e abrange tal definição ao relacioná-la com a natureza dessa escolha, a qual inclui, dentre outras formas mencionadas pelos autores: regras igualmente aceitas (ex.: PEPS X UEPS); julgamentos e estimativas (ex.: estimativa de vida útil de ativos); decisões de divulgações (ex.: nível de detalhes na descrição de políticas contábeis); e, decisões de 
classificação. Esta última engloba a questão dessa pesquisa, que está relacionada a escolhas contábeis na DFC.

As pesquisas relacionadas a escolhas contábeis buscam identificar os fatores que as influenciam, considerando as possíveis motivações e consequências das mesmas. De acordo com Holthausen e Leftwich (1983), escolhas contábeis têm consequências econômicas se as mudanças nas regras utilizadas para calcular os números contábeis alteram a distribuição dos fluxos de caixa das empresas, ou alteram a riqueza das partes que usam tais números como base para definir contratos e para a tomada de decisão.

Considerando as decisões de classificação que uma escolha contábil pode envolver, não necessariamente haverá alteração nos fluxos de caixa efetivamente distribuídos e na riqueza das partes envolvidas, em função das mudanças nos números contábeis divulgados. Tomando-se como referência o tema da presente pesquisa, as escolhas contábeis na DFC não impactam o desembolso dos fluxos de caixa, mas interferem na informação sobre os tipos de fluxos de caixa (operacionais, de investimento e de financiamento) gerados ou utilizados pela empresa no período apresentado. Dessa forma, não é possível mensurar as consequências econômicas dessas escolhas, uma vez que as mesmas podem influenciar outros tipos de decisões, inclusive em períodos subsequentes.

Conforme já mencionado, Holthausen (1990) afirma que a teoria das escolhas contábeis engloba três motivos principais que direcionam essa escolha: assimetria informacional, custos de agência e oportunismo gerencial. Já de acordo com Watts e Zimmerman (1986), o gestor tem incentivos para usar procedimentos contábeis que aumentem os resultados divulgados, e defendem que nesse processo, os relatórios contábeis são usados para atender a três propósitos: contratos de débito, planos de compensação e custo político, e que esta pode ser uma decisão do gestor como indivíduo ou da empresa (grupo). Tudo isso reforça a complexidade que pode estar envolvida na escolha contábil, considerando o conjunto de procedimentos contábeis que os gestores têm a liberdade de decidir qual deles irão utilizar, a chamada discricionariedade.

Apesar das menções de Holthausen (1990), Watts e Zimmerman (1986, 1990) e Watts (1992) sobre uma teoria das escolhas contábeis e de diversas pesquisas que visam identificar fatores determinantes de tais escolhas, ainda não há uma teoria consolidada, conforme defendido por Silva et al. (2014), tendo em vista a diversidade de opções e fatores que podem se relacionar com as escolhas contábeis.

\subsection{Teoria de gerenciamento de resultados}


Cardoso (2005) conceitua o gerenciamento da informação contábil como a adoção de critérios discricionários sobre os números contábeis divulgados. Fields et al. (2001) defendem que, embora nem todas as escolhas contábeis envolvam gerenciamento de resultado, as implicações de tais escolhas para atingir um objetivo são consistentes com a ideia de gerenciamento de resultados.

De acordo com Scott (2014), a teoria de gerenciamento de resultados está relacionada à escolha pelo gestor de políticas contábeis ou ações reais, de forma a atingir um objetivo específico de reporte dos resultados. No caso das políticas contábeis, esse nível de liberdade de escolha permite que se opte por aquela que seja a mais adequada, aquela que melhor reflita as transações e suas características, por outro lado, também dá espaço para escolhas motivadas por interesses específicos.

De forma análoga, o GFCO ou o gerenciamento do resultado por regime de caixa, envolve a escolha da classificação dos juros, dividendos e JCP, pagos e recebidos, entre as três atividades da DFC, de forma que se apresente o FCO de acordo com o objetivo estabelecido. Esse objetivo pode ser, por exemplo, aumentar o FCO classificando os juros pagos na atividade de financiamento. Tal escolha pode ser motivada por incentivos internos ou externos. Lee (2012) menciona que o FCO também pode ser gerenciado através da negociação de prazos para pagamentos e recebimentos, o que geraria registros contábeis de transações que afetam o FCO. Esse tipo de GFCO, obtido através de ações reais, não será abordado na pesquisa, uma vez que não pode ser capturado através da análise da DFC.

Avaliação de desempenho e métricas para pagamento de bônus podem ser outros exemplos de motivos internos para GFCO, uma vez que, segundo Scott (2014), os gestores racionais buscam maximizar o seu benefício, todavia, essa abordagem não será foco da pesquisa.

Adicionalmente, diversas medidas representativas da prática de gerenciamento de resultados utilizam o FCO para se determinar o montante de accruals, algumas delas foram propostas por Leuz, Nanda, e Wysocki (2003). Goncharov e Zimmermann (2006) consideram a correlação entre a variação de accruals e a variação de FCO. Outra medida utiliza a magnitude das accruals como indicativo da extensão em que administradores exercem a discricionariedade na divulgação de lucros. O Lucro Não Discricionário, proposto por esses autores, é estimado pela adição das accruals não discricionárias ao FCO da empresa. Observa-se então que apesar de gerenciamento de resultados não se confundir com GFCO, 
uma medida indevida do FCO pode interferir na mensuração e consequentemente na análise do nível de gerenciamento de resultados da empresa.

\subsection{Teoria de investimento e Estrutura conceitual}

Watts e Zimmerman (1990) nomeiam as opções de escolha de procedimentos contábeis como "conjunto aceito" e afirmam que um dos fatores que irá influenciar na decisão são os custos e benefícios das restrições. Tais restrições produzem os melhores princípios contábeis, ou os princípios contábeis aceitos, os quais, por sua vez, buscam evitar um comportamento oportunista de gestores na escolha contábil. Watts e Zimmerman (1990) também mencionam o papel da auditoria externa no cumprimento das restrições, em linha com a menção de Watts (1992) sobre o uso da contabilidade e da auditoria para limitar as decisões dos gestores.

De acordo com Scott (2014), a utilidade da informação para fins de decisão é um aspecto abordado pela teoria de investimento. Conforme já mencionado, o IASB e o FASB consideram em sua estrutura conceitual que a decisão primária do usuário é a de investimento na empresa, e que o grupo principal de usuários das demonstrações contábeis é formado por investidores e credores.

Apesar da referência principal a investidores e credores, existem outros usuários externos e também internos à empresa, como fornecedores, entes públicos, acadêmicos, gestores, funcionários, dentre outros. Nota-se então que o uso da informação contábil é amplo e suas consequências ainda mais, considerando as inúmeras decisões que podem ser tomadas com base na análise das demonstrações financeiras.

As estruturas conceituais estabelecem conceitos, diretrizes e pressupostos para elaboração e apresentação das demonstrações financeiras, que por sua vez são base para emissão das normas. Beaver (1973) destaca o tipo de pensamento orientado à divulgação que envolve a adoção do critério de utilidade informacional nas estruturas conceituais, e aborda a necessidade de divulgar informação suficiente para que o grupo principal de usuários possa converter as demonstrações contábeis de uma política particular para outra.

O levantamento das escolhas de classificação da DFC divulgadas pelas empresas brasileiras permitirá identificar que informações estão sendo apresentadas ao investidor e demais usuários. E a análise de fatores que influenciam na escolha contábil pode servir como subsídio para se avaliar os riscos e benefícios do nível de discricionariedade previsto nas normas contábeis. 


\section{METODOLOGIA}

O presente capítulo contém esclarecimentos acerca da classificação da pesquisa, do levantamento de dados e dos critérios de classificação adotados, incluindo informações sobre a amostra, os critérios de seleção, os procedimentos efetuados e a análise dos dados.

\subsection{Classificação da pesquisa}

De acordo com os níveis básicos de pesquisa definidos por Bennett (citado em Smith, 2011), essa pesquisa é descritiva, classificativa e explicativa. Descritiva, em função da coleta e apresentação de dados, classificativa devido ao destaque de similaridades e agrupamento dos mesmos, e explicativa em virtude da tentativa de explicar as observações levantadas através da identificação de possíveis relações, baseadas em teoria.

Quanto aos procedimentos, essa pesquisa pode ser classificada como documental, pois se utilizou de documentos como DFCs, relatórios dos auditores e dados das empresas, para se realizar a análise e se chegar à conclusão. A vantagem da utilização de fontes documentais para essa pesquisa trata-se da informação objetiva da realidade, permitindo a observação e identificação de situações e comportamentos.

A pesquisa possui os enfoques quantitativo e qualitativo, uma vez que através da coleta de dados, foi possível identificar quantas empresas adotam um determinado tipo de classificação na DFC e se há uma consistência na apresentação no decorrer do período dos juros pagos. Em seguida, foi efetuada uma análise dos dados levantados, na tentativa de se identificar relações entre a escolha de classificação com certas características das empresas.

A análise dos dados levantados e suas relações permite avaliar se há incentivos para que o FCO seja afetado pela escolha de classificação dos juros, dividendos e JCP. O foco nos motivos para adoção de uma prática contábil particular e suas mudanças trata-se de uma das linhas da pesquisa contábil positiva.

\subsection{Levantamento dos dados}

Os valores de ativo total, FCO, retorno do ativo e endividamento geral, bem como o CNPJ (Cadastro Nacional da Pessoa Jurídica) das empresas selecionadas, foram obtidos através da base de dados Economatica ${ }^{\circledR}$. Os referidos dados financeiros e contábeis consideraram valores consolidados e do período de doze meses findo em 31 de dezembro. $\mathrm{O}$ 
relatório dos auditores independentes e DFC foram extraídos das Demonstrações Financeiras Anuais Completas (DFs anuais), constantes no site da CVM, através de busca pelo CNPJ. De forma aleatória, foram efetuadas algumas conferências dos valores obtidos da Economatica®, os quais foram confrontados com as demonstrações financeiras obtidas e não foram identificadas inconsistências. Alguns valores para certos períodos não constavam na base de dados, os quais foram adicionados de forma complementar, utilizando-se as DFs anuais.

Os relatórios dos auditores e DFC analisados tiveram os seguintes dados tabulados: nome da empresa, exercício, firma de auditora, e, quando disponível, classificação e valor dos juros pagos, dos juros recebidos, dos dividendos pagos, dos dividendos recebidos, dos JCP pagos e dos JCP recebidos.

Para fins de análise, foram considerados cinco grupos de auditores independentes: quatro dos grupos são compostos por cada uma das Big Four e o outro grupo é formado pelas demais firmas de auditoria. Esse agrupamento permite a identificação das semelhanças e diferenças de tratamento de cada uma das Big Four e dos demais auditores, no que diz respeito à sua concordância quanto à classificação na DFC dos juros, dividendos e JCP.

Lembrando que os valores considerados foram os da DFC consolidada, os valores individuais foram utilizados apenas quando a entidade não apresentou demonstrações consolidadas, conforme já mencionado na seção 1.5. Quando não havia valores na DFC consolidada para os itens sob análise, mas havia na controladora, apenas a classificação foi considerada, mantendo o saldo consolidado zerado, conforme divulgação.

Caso não constasse na DFC a indicação explícita de juros, dividendos ou JCP, pagos ou recebidos, foi considerado N/I (não informado), independentemente do motivo de não se apresentar tal informação, seja por não ser aplicável ou porque não foi destacada. Assim, tais casos não entraram na base de dados. Já nos casos em que não havia valores dos itens sob análise no exercício corrente, mas constava a informação na DFC do montante do exercício anterior comparativo, logo, a classificação foi tabulada e indicado zero como valor.

Os valores de juros pagos podem referir-se aos empréstimos e financiamentos, juros sobre debêntures, mútuos e outros. Quando o montante de juros pagos foi apresentado fora da DFC, geralmente abaixo da referida demonstração, apenas o valor foi considerado na tabulação dos dados e na classificação foi indicado N/I. Algumas empresas apresentavam o total de empréstimos e juros pagos em uma única linha, nesses casos, apenas a classificação dos juros pagos foi considerada, sem a indicação do valor.

$\mathrm{Na}$ determinação dos segmentos, utilizou-se a classificação setorial da Economatica®, composta por: Agro e Pesca; Alimentos e Bebidas; Comércio; Construção; Eletroeletrônicos; 
Energia Elétrica; Máquinas Industriais; Mineração; Minerais não Metais; Papel e Celulose; Petróleo e Gás; Química; Siderurgia e Metalurgia; Software e Dados; Telecomunicações; Têxtil; Transporte - Serviços; Veículos e Peças; e, Outros. Totalizando 19 setores.

Com a utilização de demonstrações financeiras consolidadas, diversos segmentos podem compor tais demonstrações. Todavia, considera-se a existência de um setor predominante no grupo de empresas que direcionou a classificação na Economatica®.

\subsection{Amostra e critérios de seleção}

A lista de empresas para análise dos respectivos dados foi levantada em 02 de março de 2015, através da Economatica ${ }^{\circledR}$. Foram utilizados os filtros de Brasil como país sede, empresa com status de ativa e ação mais movimentada, para não haver repetição de empresas. O filtro dos segmentos da indústria também foi utilizado e as empresas classificadas como "Finanças e Seguros" e "Fundos" foram excluídas da base, uma vez que as instituições financeiras não fazem parte do escopo da pesquisa. Dessa forma, foram selecionadas inicialmente 352 empresas. A Tabela 1 apresenta a quantidade de empresas selecionadas por setor e o Apêndice A apresenta a lista com o nome das referidas empresas.

Tabela 1

Quantidade de empresas por setor

\begin{tabular}{lc}
\multicolumn{1}{c}{ SETOR } & QUANTIDADE DE EMPRESAS \\
\hline Agro e Pesca & 4 \\
Alimentos e Bebidas & 16 \\
Comércio & 18 \\
Construção & 23 \\
Eletroeletrônicos & 7 \\
Energia Elétrica & 45 \\
Máquinas Industriais & 5 \\
Mineração & 6 \\
Minerais não Metais & 4 \\
Papel e Celulose & 5 \\
Petróleo e Gás & 8 \\
Química & 11 \\
Siderurgia e Metalurgia & 22 \\
Software e Dados & 5 \\
Telecomunicações & 14 \\
Têxtil & 25 \\
Transporte - Serviços & 19 \\
Veículos e Peças & 16 \\
Outros & 99 \\
TOTAL & $\mathbf{3 5 2}$
\end{tabular}


Em seguida, as DFs anuais de 2008 a 2014 de tais empresas foram obtidas. Algumas empresas divulgaram em apenas parte do período sob análise e ainda outras 17 empresas não haviam emitido as DFs anuais referentes ao exercício de 2014, até o encerramento do levantamento dos dados, em 05 de maio de 2015, totalizando 129 DFs anuais não divulgadas. Foram excluídas da amostra as empresas com exercício social findo em outros períodos que não fosse 31 de dezembro, tendo em vista que os dados financeiros e contábeis levantados foram com essa data de corte (total de 5 empresas e 26 DFs anuais excluídas). Os dados com inconsistência (ex.: juros pagos positivos, dividendos recebidos negativos, etc.) foram excluídos (total de 10 empresas e 12 DFs anuais excluídas). Também ocorreu da DFC não ser apresentada, não estar legível ou faltar alguma parte (7 empresas e DFs anuais).

A Tabela 2 apresenta a conciliação da diferença entre a quantidade prevista de DFs anuais que seriam analisadas, caso as 352 empresas selecionadas tivessem divulgação em todos os exercícios, e a quantidade final efetivamente utilizada na pesquisa. Tal diferença é resultante de DFs anuais que não foram utilizadas, em virtude de não se adequar às exigências da pesquisa, e de DFs anuais que não foram divulgadas, em função da empresa só ter divulgado demonstrações financeiras em parte dos anos.

Tabela 2

Conciliação da quantidade de DFs anuais (por ano)

\begin{tabular}{|c|c|c|c|c|c|c|c|c|}
\hline & 2008 & 2009 & 2010 & 2011 & 2012 & 2013 & 2014 & Total \\
\hline Previsão de DFs anuais das empresas selecionadas & 352 & 352 & 352 & 352 & 352 & 352 & 352 & 2.464 \\
\hline \multicolumn{9}{|l|}{ Exclusões: } \\
\hline - $\quad$ Outros exercícios sociais & -2 & -3 & -4 & -4 & -5 & -4 & -4 & -26 \\
\hline - Inconsistências dos dados & -1 & -2 & & -2 & -3 & -3 & -1 & -12 \\
\hline - $\quad$ DFC não apresentada, ilegível ou incompleta & & -1 & & -3 & -1 & -2 & & -7 \\
\hline - $\quad$ DFs anuais não divulgadas & -41 & -32 & -21 & -14 & -3 & -1 & -17 & -129 \\
\hline DFs anuais utilizadas na pesquisa & 308 & 314 & 327 & 329 & 340 & 342 & 330 & 2.290 \\
\hline
\end{tabular}

Através da análise das 2.290 DFs anuais, foram levantados os dados relacionados aos juros, dividendos e JCP das empresas. Considerando a semelhança de tratamento e de essência entre dividendos e JCP, os respectivos dados foram agrupados. A Tabela 3 indica um resumo da quantidade de dados levantados através da análise das DFs anuais. 
Tabela 3

Resumo dos dados levantados (por ano)

\begin{tabular}{lcccccccc}
\hline & $\mathbf{2 0 0 8}$ & $\mathbf{2 0 0 9}$ & $\mathbf{2 0 1 0}$ & $\mathbf{2 0 1 1}$ & $\mathbf{2 0 1 2}$ & $\mathbf{2 0 1 3}$ & $\mathbf{2 0 1 4}$ & Total \\
\hline Juros Pagos & 94 & 117 & 162 & 177 & 194 & 200 & 201 & 1.145 \\
Juros Recebidos & 9 & 13 & 15 & 16 & 16 & 15 & 13 & 97 \\
Dividendos/JCP pagos & 189 & 198 & 217 & 220 & 228 & 233 & 232 & 1.517 \\
Dividendos/JCP recebidos & 111 & 124 & 134 & 147 & 158 & 169 & 162 & 1.005 \\
\hline Dados totais levantados & $\mathbf{4 0 3}$ & $\mathbf{4 5 2}$ & $\mathbf{5 2 8}$ & $\mathbf{5 6 0}$ & $\mathbf{5 9 6}$ & $\mathbf{6 1 7}$ & $\mathbf{6 0 8}$ & $\mathbf{3 . 7 6 4}$ \\
\hline
\end{tabular}

Os dados indicados na Tabela 3 foram utilizados para direcionamento das hipóteses da pesquisa. A exceção ocorre para os dados indicados na primeira linha da referida tabela, pois do total de 1.145 dados sobre juros pagos 4 foram excluídos da base para efetuar a regressão que possui juros pagos como variável dependente (modelo B), resultando em 1.141 dados utilizados. Os dados excluídos referem-se a uma empresa cujos índices de rentabilidade e endividamento eram muito elevados, distorcendo as médias nas análises descritivas.

As Tabelas 4 e 5 apresentam um resumo ano a ano da quantidade de DFs anuais utilizadas na pesquisa, das quais foram consultados os relatórios dos auditores independentes e as DFCs, considerando as classificações por setores e por auditores, respectivamente.

Tabela 4

Quantidade de DFs anuais (por ano e setor)

\begin{tabular}{lccccccccc}
\hline Setores & $\mathbf{2 0 0 8}$ & $\mathbf{2 0 0 9}$ & $\mathbf{2 0 1 0}$ & $\mathbf{2 0 1 1}$ & $\mathbf{2 0 1 2}$ & $\mathbf{2 0 1 3}$ & $\mathbf{2 0 1 4}$ & Total & \% \\
\hline Agro e Pesca & 2 & 2 & 2 & 2 & 2 & 2 & 2 & 14 & $1 \%$ \\
Alimentos e Bebidas & 12 & 12 & 12 & 12 & 14 & 15 & 14 & 91 & $4 \%$ \\
Comércio & 14 & 15 & 18 & 18 & 18 & 18 & 17 & 118 & $5 \%$ \\
Construção & 23 & 23 & 23 & 22 & 23 & 22 & 20 & 156 & $7 \%$ \\
Eletroeletrônicos & 7 & 7 & 7 & 7 & 7 & 7 & 6 & 48 & $2 \%$ \\
Energia Elétrica & 42 & 41 & 44 & 45 & 45 & 45 & 45 & 307 & $13 \%$ \\
Máquinas Industriais & 5 & 5 & 5 & 5 & 5 & 5 & 5 & 35 & $2 \%$ \\
Mineração & 5 & 6 & 6 & 6 & 6 & 6 & 5 & 40 & $2 \%$ \\
Minerais não Metais & 4 & 4 & 4 & 3 & 3 & 3 & 3 & 24 & $1 \%$ \\
Papel e Celulose & 5 & 5 & 5 & 5 & 5 & 5 & 5 & 35 & $2 \%$ \\
Petróleo e Gás & 5 & 6 & 7 & 7 & 7 & 8 & 7 & 47 & $2 \%$ \\
Química & 9 & 9 & 9 & 9 & 10 & 10 & 11 & 67 & $3 \%$ \\
Siderurgia e Metalurgia & 20 & 20 & 21 & 21 & 22 & 21 & 21 & 146 & $6 \%$ \\
Software e Dados & 2 & 2 & 2 & 3 & 5 & 5 & 5 & 24 & $1 \%$ \\
Telecomunicações & 14 & 14 & 14 & 14 & 14 & 14 & 12 & 96 & $4 \%$ \\
Têxtil & 23 & 24 & 24 & 24 & 24 & 23 & 23 & 165 & $7 \%$ \\
Transporte-Serviços & 16 & 16 & 17 & 16 & 17 & 18 & 19 & 119 & $5 \%$ \\
Veículos e Peças & 16 & 16 & 16 & 15 & 16 & 16 & 14 & 109 & $5 \%$ \\
Outros & 84 & 87 & 91 & 95 & 97 & 99 & 96 & 649 & $28 \%$ \\
\hline Total & $\mathbf{3 0 8}$ & $\mathbf{3 1 4}$ & $\mathbf{3 2 7}$ & $\mathbf{3 2 9}$ & $\mathbf{3 4 0}$ & $\mathbf{3 4 2}$ & $\mathbf{3 3 0}$ & $\mathbf{2 . 2 9 0}$ & $\mathbf{1 0 0 \%}$ \\
\hline
\end{tabular}


A categoria "outros", indicada na Tabela 4, é composta por setores variados como, por exemplo, companhias de participação, dos ramos hoteleiro e imobiliário, e prestadoras de serviços diversos.

O grupo de auditores "outros", indicado na Tabela 5, é composto por 91 firmas de auditoria. Dentre elas, a BDO RCS emitiu relatório para um total de 173 DFs anuais, seguida pela BKR - Lopes, Machado Auditores, com 55 DFs anuais, e a Performance, com 51.

Tabela 5

Quantidade de DFs anuais (por ano e auditor)

\begin{tabular}{lccccccccc}
\hline Auditores & $\mathbf{2 0 0 8}$ & $\mathbf{2 0 0 9}$ & $\mathbf{2 0 1 0}$ & $\mathbf{2 0 1 1}$ & $\mathbf{2 0 1 2}$ & $\mathbf{2 0 1 3}$ & $\mathbf{2 0 1 4}$ & Total & \% \\
\hline Deloitte & 53 & 47 & 54 & 52 & 51 & 49 & 50 & 356 & $16 \%$ \\
EY & 34 & 46 & 72 & 77 & 69 & 58 & 53 & 409 & $18 \%$ \\
KPMG & 46 & 49 & 47 & 68 & 43 & 48 & 56 & 357 & $16 \%$ \\
Price & 34 & 38 & 45 & 50 & 69 & 77 & 71 & 384 & $17 \%$ \\
Outros & 141 & 134 & 109 & 82 & 108 & 110 & 100 & 784 & $34 \%$ \\
\hline Total & $\mathbf{3 0 8}$ & $\mathbf{3 1 4}$ & $\mathbf{3 2 7}$ & $\mathbf{3 2 9}$ & $\mathbf{3 4 0}$ & $\mathbf{3 4 2}$ & $\mathbf{3 3 0}$ & $\mathbf{2 . 2 9 0}$ & $\mathbf{1 0 0 \%}$ \\
\hline
\end{tabular}

Através da Tabela 5, observa-se que em torno de dois terços das empresas são auditadas pelas Big Four e que há entre essas firmas de auditoria uma distribuição equilibrada da quantidade de empresas que são seus clientes (18\% - EY; $17 \%$ - Price; 16\% - Deloitte e KPMG).

\subsection{Procedimentos e análise dos dados}

Quanto aos procedimentos que direcionam a primeira hipótese e o segundo grupo de hipóteses, as empresas foram agrupadas de acordo com as suas escolhas de classificação e então foi verificado se as mesmas seguiram a classificação encorajada pelo CPC 03, parágrafo 34A, indicada na Tabela 6. Em seguida, buscou-se identificar possíveis padrões de classificação, no que diz respeito ao setor de que fazem parte e aos seus auditores.

Tabela 6

Classificação encorajada pelo CPC 03, parágrafo 34A

\begin{tabular}{lcc} 
& FCO & FCF \\
\hline Juros pagos & $\mathrm{x}$ & \\
Juros recebidos & $\mathrm{x}$ & \\
Dividendos/JCP pagos & & $\mathrm{x}$ \\
Dividendos/JCP recebidos & $\mathrm{x}$ &
\end{tabular}

Nota. FCF = Fluxo de Caixa de Financiamento; FCO = Fluxo de Caixa Operacional. 
No que se refere à terceira hipótese, foram considerados os dados levantados sobre a classificação de juros pagos do período sob análise, de 2008 a 2014. Em seguida, identificouse as reclassificações entre as atividades de financiamento e operacional de um ano para o outro, resultando em 6 períodos observados, uma vez que 2008 foi o ano de partida da comparação. Na sequência, para as empresas e períodos que ocorreram reclassificações, foram identificados os auditores do ano atual e do ano anterior, a fim de verificar possíveis mudanças da firma de auditoria.

Com o intuito de se concluir sobre a rejeição ou não do quarto grupo de hipóteses, foram consideradas duas variáveis dependentes para análise do efeito no FCO decorrente da escolha de classificação: (1) a diferença em reais (R\$) entre o FCO divulgado e o valor que seria o FCO ao seguir as opções encorajadas pelo CPC 03 (FCO encorajado) e, (2) a escolha de classificação dos juros pagos. A primeira variável foi dividida pelo valor do ativo total, de forma a excluir o efeito de uma possível variabilidade em função do tamanho da empresa. A análise da segunda variável dependente foi direcionada aos juros pagos pois, caso sejam classificados na DFC como FCF (sem seguir a classificação recomendada pelo CPC), resultará em uma melhoria dos fluxos de caixa das atividades operacionais. Essa melhoria ao não seguir a recomendação do CPC não ocorre com as demais alternativas (juros recebidos, dividendos/JCP recebidos e pagos). Tal direcionamento foi estabelecido tomando-se por base o desenho da pesquisa de Gordon et al. (2013).

Por fim, a relação entre as variáveis dependentes e explicativas foi analisada utilizando-se dados em painel. A referida relação está apresentada na Tabela 7, a qual também indica as proxies utilizadas e o efeito esperado no FCO de cada uma delas.

Tabela 7

Modelos e variáveis referentes ao $4^{\circ}$ grupo de hipóteses

\begin{tabular}{|c|c|c|c|c|}
\hline Modelo & Variável dependente & $\begin{array}{c}\text { Variáveis } \\
\text { explicativas }\end{array}$ & Proxies & $\begin{array}{c}\text { Efeito esperado } \\
\text { no FCO }\end{array}$ \\
\hline \multirow{2}{*}{ A } & \multirow{2}{*}{$\begin{array}{l}\text { Diferença em R\$ entre o } \\
\text { FCO divulgado e FCO } \\
\text { encorajado, dividida pelo } \\
\text { valor do ativo total. }\end{array}$} & - Endividamento & $\begin{array}{l}\text { - Endividamento geral } \\
\text { (passivo total/ ativo } \\
\text { total*100) }\end{array}$ & + \\
\hline & & - Rentabilidade & $\begin{array}{l}\text { - Retorno do ativo } \\
\text { (resultado líquido/ ativo } \\
\text { total } * 100 \text { ) }\end{array}$ & - \\
\hline B & $\begin{array}{c}\text { Escolha de classificação dos } \\
\text { juros pagos }- \text { dummy, sendo } \\
1 \text { para classificação como } \\
\text { FCF e } 0 \text { se outra. }\end{array}$ & $\begin{array}{l}\text { - FCO } \\
\text { encorajado } \\
\text { negativo }\end{array}$ & $\begin{array}{l}\text { - FCO de acordo com } \\
\text { encorajamento do CPC } 03 \\
\text { (dummy, } 1 \text { se negativo e } 0 \\
\text { se positivo) }\end{array}$ & + \\
\hline
\end{tabular}


O efeito esperado no FCO está relacionado à necessidade de a empresa apresentar uma informação mais favorável de forma a compensar alguma situação insatisfatória. Por isso, quanto mais endividada estiver a empresa, quanto menos rentável ela for e se estiver com um FCO encorajado negativo, espera-se que as opções de classificações possam ser utilizadas para aumentar o montante de FCO apresentado.

\subsection{Dados em painel}

O efeito da escolha de classificação dos juros, dividendos e JCP na DFC sobre o FCO, de acordo com características financeiras e de desempenho das empresas, foi analisado através da utilização de dados em painel.

A análise com dados em painel compreende duas dimensões: uma transversal, representada pelas empresas e; uma longitudinal, representada pelo tempo. Assim, obteve-se informações de mais de um indivíduo ao longo de um período de tempo. Segundo Gujarati (2006), nos modelos estatísticos de dados em painel a mesma unidade de corte transversal é acompanhada ao longo do tempo (corte longitudinal).

Os modelos de séries temporais analisam apenas um elemento ao longo do tempo enquanto que os modelos de corte transversal consideram vários indivíduos em um dado momento. A utilização de dados em painel permite a observação de relações dinâmicas que não podem ser obtidas apenas com dados transversais (Baltagi citado em Gujarati, 2006). Além disso, permite controlar a heterogeneidade presente nos indivíduos, ou seja, controlar o efeito de variáveis não observadas.

A utilização de dados em painel permite ainda o uso de um número maior de observações do que seria possível se utilizássemos apenas dados transversais ou apenas dados longitudinais (Baltagi citado em Gujarati, 2006). No entanto, uma de suas limitações é que os dados em painel exigem um grande número de observações, sendo mais difíceis de serem implementados.

Nesta pesquisa, os indivíduos são representados por 171 empresas no modelo A e 234 empresas no modelo B, observadas ao longo de 7 anos (as listas das empresas utilizadas em cada modelo constam nos Apêndices D e E, respectivamente). Vale ressaltar que nem todas as empresas possuem dados em todos os anos, ou seja, trata-se de um painel desbalanceado.

De acordo com Lima (2007), a análise de dados em painel possui 3 abordagens: efeito pooling, efeitos fixos e efeitos aleatórios. No efeito pooling, também denominado de efeito combinado, tanto o intercepto quanto os coeficientes angulares são idênticos para todas as 
empresas durante todo o período de tempo, o que pode distorcer a verdadeira relação entre a variável dependente e a independente. Este modelo produz muitos coeficientes, tem pouca fiabilidade e não contempla a existência de interdependência entre as medidas individuais, isto é, não leva em consideração a presença de heterogeneidade não-observada (Marques, 2000). Todavia, na presente pesquisa, foi considerada a possibilidade de que características não observadas das empresas pudessem influenciar os regressores. Neste caso, as duas outras abordagens (modelo de efeitos fixos e modelo de efeitos aleatórios) são mais adequadas aos objetivos deste trabalho.

O objetivo do modelo de efeitos fixos é controlar os efeitos das variáveis omitidas que variam entre os indivíduos, mas que são constantes no tempo, isto é, ele é utilizado quando existem variáveis não observadas que provavelmente afetam o valor da variável dependente. Para verificar se as suposições sobre o modelo são adequadas, testa-se se os interceptos são diferentes entre os indivíduos, através da estatística F. O parâmetro de rejeição da hipótese nula adotado foi o nível de significância de 0,05 , ou seja, se o p-valor da estatística $F$ for inferior a 0,05 , conclui-se que os interceptos não são todos iguais, satisfazendo a suposição do modelo (Duarte, Lamounier, \& Takamatsu, 2007).

O modelo de efeitos aleatórios possui as mesmas suposições do modelo de efeitos fixos, mas há uma diferença em relação ao tratamento do intercepto. O modelo de efeitos aleatórios trata o intercepto como uma variável aleatória, ou seja, supõe-se que as empresas fazem parte de uma amostra aleatória da população total. Desta forma, o intercepto é composto por duas medidas: uma que capta a diferença entre as empresas (intercepto do modelo de efeitos fixos) e outra que reflete o intercepto populacional (Lima, 2007).

Para verificar se as suposições acerca do modelo são adequadas, utilizou-se o multiplicador de Lagrange de Breusch-Pagan. A hipótese nula deste teste é de que a variância da heterogeneidade não observada (heterocedasticidade dos termos de erro) é igual a zero. Caso a hipótese nula seja rejeitada, o modelo de efeitos aleatórios é adequado (Duarte et al., 2007).

Para se decidir entre o modelo de efeitos fixos e o de efeitos aleatórios, utiliza-se o teste de Hausman. A hipótese nula é de que o efeito não observado (intercepto do modelo de efeitos fixos) não está correlacionado com as variáveis explicativas. Caso a hipótese nula seja aceita, o melhor método é o de efeitos aleatórios.

Os resultados dos testes de Lagrange de Breusch-Pagan e de Hausman mostraram que o modelo de efeitos aleatórios foi o melhor para as duas regressões rodadas. Os referidos resultados constam na seção 4.4.2. 


\section{RESULTADOS}

A análise dos resultados obtidos será apresentada a seguir, de acordo com cada hipótese da pesquisa.

\subsection{Primeira hipótese}

Conforme apresentado na seção 1.3, a primeira hipótese da pesquisa está assim enunciada:

$H_{1}$ : A maior parte das empresas brasileiras segue as classificações encorajadas pelo СPC 03.

Com base nas DFCs analisadas, foi efetuado um levantamento das classificações dos juros e dividendos/JCP, pagos e recebidos, nas atividades de financiamento, investimento e operacional. Como não houve diferença de classificação entre dividendos e JCP, apenas dividendos serão mencionados como referência, inclusive por terem a mesma natureza dos JCP. A Tabela 8 apresenta um resumo da quantidade de dados levantados e das classificações adotadas ano a ano.

Tabela 8

Classificações na DFC (por ano e atividade)

\begin{tabular}{lccccccccc}
\hline & $\mathbf{2 0 0 8}$ & $\mathbf{2 0 0 9}$ & $\mathbf{2 0 1 0}$ & $\mathbf{2 0 1 1}$ & $\mathbf{2 0 1 2}$ & $\mathbf{2 0 1 3}$ & $\mathbf{2 0 1 4}$ & Total & \% \\
\hline $\begin{array}{l}\text { Total Geral } \\
\text { Juros Pagos }\end{array}$ & $\mathbf{3 0 8}$ & $\mathbf{3 1 4}$ & $\mathbf{3 2 7}$ & $\mathbf{3 2 9}$ & $\mathbf{3 4 0}$ & $\mathbf{3 4 2}$ & $\mathbf{3 3 0}$ & $\mathbf{2 . 2 9 0}$ & \\
$\quad$ (a) Financiamento & 41 & 47 & 61 & 65 & 75 & 75 & 78 & 442 & $39 \%$ \\
$\quad$ (b) Operacional & 53 & 70 & 101 & 112 & 119 & 125 & 123 & 703 & $61 \%$ \\
$\quad$ Total (a)+(b) & $\mathbf{9 4}$ & $\mathbf{1 1 7}$ & $\mathbf{1 6 2}$ & $\mathbf{1 7 7}$ & $\mathbf{1 9 4}$ & $\mathbf{2 0 0}$ & $\mathbf{2 0 1}$ & $\mathbf{1 . 1 4 5}$ & $50 \%$ \\
$\quad$ N/I & 214 & 197 & 165 & 152 & 146 & 142 & 129 & 1.145 & $50 \%$
\end{tabular}

Juros Recebidos

(a) Financiamento

(b) Operacional

(c) Investimento

Total $(a)+(b)+(c)$

$\mathrm{N} / \mathrm{I}$

$\begin{array}{lllllllll}2 & 2 & 2 & 2 & 3 & 3 & 3 & 17 & 18 \%\end{array}$

$\begin{array}{llllllllll}4 & 9 & 9 & 10 & 10 & 10 & 8 & 60 & 62 \%\end{array}$

$\begin{array}{lllllllll}3 & 2 & 4 & 4 & 3 & 2 & 2 & 20 & 21 \%\end{array}$

$\begin{array}{lllllllll}9 & 13 & 15 & 16 & 16 & 15 & 13 & 97 & 4 \%\end{array}$

$\begin{array}{lllllllll}299 & 301 & 312 & 313 & 324 & 327 & 317 & 2.193 & 96 \%\end{array}$

Dividendos pagos

(a) Financiamento

(b) Operacional

(c) Investimento

$\begin{array}{lllllllll}184 & 191 & 214 & 219 & 225 & 229 & 228 & 1.490 & 98 \%\end{array}$

$\begin{array}{lllllllll}3 & 6 & 3 & 1 & 3 & 4 & 3 & 23 & 2 \%\end{array}$

Total $(a)+(b)+(c)$

2

$\mathrm{N} / \mathrm{I}$

$\begin{array}{lllllllll}189 & 198 & 217 & 220 & 228 & 233 & 232 & 1.517 & 66 \%\end{array}$

$\begin{array}{lllllllll}119 & 116 & 110 & 109 & 112 & 109 & 98 & 773 & 34 \%\end{array}$

(Continua) 
Tabela 8

Classificações na DFC (por ano e atividade) (continuação)

\begin{tabular}{lccccccccc}
\hline & $\mathbf{2 0 0 8}$ & $\mathbf{2 0 0 9}$ & $\mathbf{2 0 1 0}$ & $\mathbf{2 0 1 1}$ & $\mathbf{2 0 1 2}$ & $\mathbf{2 0 1 3}$ & $\mathbf{2 0 1 4}$ & Total & $\mathbf{\%}$ \\
\hline $\begin{array}{c}\text { Dividendos recebidos } \\
\text { (a) Financiamento }\end{array}$ & 14 & 11 & 8 & 7 & 4 & 6 & 4 & 54 & $5 \%$ \\
(b) Operacional & 36 & 41 & 49 & 52 & 52 & 52 & 53 & 335 & $33 \%$ \\
(c) Investimento & 61 & 72 & 77 & 88 & 102 & 111 & 105 & 616 & $61 \%$ \\
Total (a)+(b)+(c) & $\mathbf{1 1 1}$ & $\mathbf{1 2 4}$ & $\mathbf{1 3 4}$ & $\mathbf{1 4 7}$ & $\mathbf{1 5 8}$ & $\mathbf{1 6 9}$ & $\mathbf{1 6 2}$ & $\mathbf{1 . 0 0 5}$ & $44 \%$ \\
N/I & 197 & 190 & 193 & 182 & 182 & 173 & 168 & 1.285 & $56 \%$ \\
\hline
\end{tabular}

Nota. $\mathrm{N} / \mathrm{I}=$ Não Informado.

${ }^{a}$ Quantidade total de relatórios dos auditores independentes e DFCs

Os dados totais classificados conforme encorajamento do CPC 03 estão destacados de cinza. Nota-se que apenas para dividendos recebidos não houve maioria na escolha da classificação encorajada pelo CPC 03, apenas 33\% das empresas classificaram tal item como FCO. Os demais itens tiveram as classificações encorajadas pelo CPC 03 como maioria dos dados (juros pagos - 61\%; juros recebidos - 62\%; dividendos pagos - 98\%). Entretanto, apenas os dividendos pagos tiveram uma homogeneidade de classificação, de acordo com o parágrafo 34A do CPC 03. Dessa forma, com base na análise efetuada, a hipótese H1 foi rejeitada apenas no que concerne aos dividendos recebidos.

Os resultados obtidos por Gordon et al. (2013), ao levantar a classificação dos juros pagos e recebidos e dividendos pagos e recebidos, para 13 países europeus, foram semelhantes aos resultados das empresas brasileiras nos seguintes aspectos:

- Juros pagos classificados como FCO pela maioria das empresas: Áustria (87\%); Bélgica (66\%); Dinamarca (99\%); Finlândia (100\%); França (67\%); Alemanha (68\%); Itália (85\%); Holanda (93\%); Noruega (76\%); Espanha (67\%); Suécia (96\%); e, Reino Unido (65\%). Apenas Portugal (19\%) não teve a maioria.

- Juros recebidos classificados como FCO pela maior parte das empresas: Áustria (80\%); Bélgica (49\%); Dinamarca (98\%); Finlândia (97\%); França (77\%); Alemanha (67\%); Itália (72\%); Holanda (61\%); Noruega (55\%); Suécia (93\%); e, Reino Unido (65\%). Portugal, Espanha e Reino Unido tiveram a maioria das empresas classificando como FCI $(91 \%, 52 \%$ e $61 \%$, respectivamente).

- Dividendos pagos como FCF pela maioria das empresas: em todos os países houve a maioria absoluta (99\%).

- Dividendos recebidos como FCI pela maior parte das empresas: Dinamarca (66\%); Holanda (57\%); Portugal (77\%); e, Reino Unido (59\%). Os demais países tiveram predominância da classificação dos dividendos recebidos como FCO: Áustria (91\%); Bélgica 
(50\%); Finlândia (70\%); França (55\%); Alemanha (67\%); Itália (56\%); Noruega (62\%); Espanha (58\%); e, Suécia (92\%).

A Tabela 9 resume o total das classificações por atividade e compara os resultados da presente pesquisa com os trabalhos de Scherer et al. (2012) e Silva et al. (2014), que também pesquisaram as classificações na DFC de empresas brasileiras, entretanto, consideraram apenas um período e uma quantidade menor de empresas.

Tabela 9

Comparativo dos resultados com pesquisas afins

\begin{tabular}{|c|c|c|c|c|c|c|}
\hline & \multicolumn{2}{|c|}{ Presente Estudo } & \multicolumn{2}{|c|}{$\begin{array}{c}\text { Scherer et al. } \\
\text { (2012) }\end{array}$} & \multicolumn{2}{|c|}{ Silva et al. (2014) } \\
\hline & Qtd. & $\%$ & Qtd. & $\%$ & Qtd. & $\%$ \\
\hline Períodos & \multicolumn{2}{|c|}{2008 a 2014} & \multicolumn{2}{|c|}{2009} & \multicolumn{2}{|c|}{2010} \\
\hline \multicolumn{7}{|l|}{ Juros Pagos } \\
\hline FCF & 442 & $39 \%$ & 7 & $12 \%$ & 58 & $54 \%$ \\
\hline FCI & & & 1 & $2 \%$ & & \\
\hline $\mathrm{FCO}$ & 703 & $61 \%$ & 51 & $86 \%$ & 49 & $46 \%$ \\
\hline Total & 1.145 & $100 \%$ & 59 & $100 \%$ & 107 & $100 \%$ \\
\hline \multicolumn{7}{|c|}{ Juros Recebidos } \\
\hline $\mathrm{FCF}$ & 17 & $18 \%$ & & & & \\
\hline FCI & 20 & $21 \%$ & 1 & $2 \%$ & 2 & $25 \%$ \\
\hline $\mathrm{FCO}$ & 60 & $62 \%$ & 58 & $98 \%$ & 6 & $75 \%$ \\
\hline Total & 97 & $100 \%$ & 59 & $100 \%$ & 8 & $100 \%$ \\
\hline \multicolumn{7}{|c|}{ Dividendos pagos } \\
\hline FCF & 1.490 & $98 \%$ & 53 & $98 \%$ & 84 & $100 \%$ \\
\hline FCI & 4 & $0 \%$ & 1 & $2 \%$ & & \\
\hline $\mathrm{FCO}$ & 23 & $2 \%$ & & & & \\
\hline Total & 1.517 & $100 \%$ & 54 & $100 \%$ & 84 & $100 \%$ \\
\hline \multicolumn{7}{|c|}{ Dividendos recebidos } \\
\hline FCF & 54 & $5 \%$ & & & & \\
\hline FCI & 616 & $61 \%$ & 11 & $52 \%$ & 17 & $68 \%$ \\
\hline FCO & 335 & $33 \%$ & 10 & $48 \%$ & 8 & $32 \%$ \\
\hline Total & 1.005 & $100 \%$ & 21 & $100 \%$ & 25 & $100 \%$ \\
\hline Dados Totais & 3.764 & & 193 & & 224 & \\
\hline
\end{tabular}

Nota . FCF = Fluxo de Caixa de Financiamento; FCO = Fluxo de Caixa Operacional; FCI = Fluxo de Caixa de Investimento.

No que diz respeito ao percentual de classificação de cada item entre as atividades, de acordo com a presente pesquisa, não houve mudanças significativas ao se analisar o período total e os anos de 2009 e $2010^{5}$, logo, para fins de comparação com as demais pesquisas, serão considerados os dados totais, de 2008 a 2014.

${ }^{5}$ Em 2009: 60\% dos juros pagos foram classificados como FCO; 69\% dos juros recebidos como FCO; $96 \%$ dos dividendos pagos como FCF; e, 33\% dos dividendos recebidos como FCO. 
Os juros pagos foram classificados como FCO em $61 \%$ do total dos dados levantados, em $86 \%$ das empresas que formavam o índice IBOVESPA (resultados de Scherer et al. (2012)) e em apenas 46\% das empresas do Novo Mercado (resultados de Silva et al. (2014)). Essas variações de percentuais indicam um comportamento diferenciado na classificação dos juros pagos entre as empresas que compõem o índice IBOVESPA, as listadas no Novo Mercado e as empresas não financeiras do mercado de capitais brasileiro.

Os juros recebidos foram classificados como FCO na maioria dos casos, considerando as amostras das três pesquisas sob comparação (62\% - Presente pesquisa; 75\% - Silva et al. (2014); 98\% - Scherer et al. (2012)). Nota-se que essa é uma informação pouco divulgada, seja por falha dos preparadores da DFC ou pelo fato da informação não ser quantitativamente relevante, ou até por não ser prática usual das empresas brasileiras cobrarem juros. Em função disso, os dados obtidos são poucos e não há base suficiente para se concluir sobre tais resultados.

No caso dos dividendos pagos, há quase uma unanimidade de classificação como FCF pelas empresas brasileiras, seguindo o encorajamento do CPC 03, conforme identificado através das três pesquisas (98\% - Presente pesquisa; 100\% - Silva et al. (2014); 98\% - Scherer et al. (2012)). Por outro lado, os dividendos recebidos prevaleceram com a classificação como FCI (61\% - Presente pesquisa; 68\% - Silva et al. (2014); 52\% - Scherer et al. (2012)), diferentemente da classificação como FCO encorajada pelas normas contábeis brasileiras.

\subsection{Segundo grupo de hipóteses}

O segundo grupo de hipóteses é composto primeiramente pela seguinte hipótese:

H2.a: Empresas do mesmo setor tendem a utilizar as mesmas classificações dos itens que possuem flexibilidade de apresentação na DFC.

A Tabela 10 resume a quantidade total de classificações de acordo com o encorajamento do CPC 03, parágrafo 34A, considerando o setor da empresa como fator comum. O detalhamento ano a ano por setor está apresentado no Apêndice B.

De forma geral, os setores que mais seguiram as classificações recomendadas pelo CPC 03 foram "Papel e Celulose", "Energia Elétrica" e "Agro e Pesca", com 87\%, 81\% e 
$80 \%$ dos dados totais divulgados, respectivamente. E os setores "Eletroeletrônicos" e "Mineração" foram os que tiveram um menor índice de cumprimento do parágrafo 34A, com $55 \%$ e $57 \%$ do total, respectivamente, ainda assim atingindo a maioria das classificações conforme encorajamento do CPC 03.

Com relação aos juros pagos, dois setores classificaram 100\% como FCO ("Agro e Pesca" e "Papel e Celulose"), seguidos por "Energia Elétrica" e "Minerais não Metais", ambos com $77 \%$ da classificação como FCO. O setor que menos seguiu o encorajamento do CPC 03 foi o de "Máquinas Industriais", com apenas 5\% do total de divulgações de juros pagos, seguido por "Mineração", com 26\%. Os demais setores oscilaram entre $45 \%$ e 74\%, rodeando a média de $61 \%$ do total de classificações de juros pagos como FCO.

Os juros recebidos foram classificados de forma predominante como FCO na maioria dos setores com tal informação divulgada, exceto os setores de "Eletroeletrônicos" (dos 6 dados, 5 foram classificados como FCF e 1 como FCI), "Têxtil” (1 como FCI), "Transporte Serviços" (7 como FCF) e, "Outros" (5 como FCF e 13 como FCI).

Em linha com o total de classificações (98\%), os dividendos pagos tiveram a classificação predominante como FCF em todos os setores. A menor representatividade de classificação, de acordo com o parágrafo 34A do CPC 03, foi atingida pelos setores de "Mineração" (83\%) e "Eletroeletrônicos" (84\%), tendo as demais classificações de dividendos pagos como FCO.

Os dividendos recebidos foram classificados como FCO na maioria dos casos pelos seguintes setores: "Energia Elétrica" e "Siderurgia e Metalurgia" (ambos com 59\%); "Mineração" e "Papel e Celulose" (ambos com 57\%); e "Telecomunicações" (52\%). Os setores de "Máquinas Industriais" e "Petróleo e Gás" não seguiram o encorajamento do CPC e classificaram os dividendos recebidos como FCI em vez de FCO, em todos os casos. Na sequência, o setor "Têxtil" foi o que menos classificou os dividendos recebidos como FCO, apenas $11 \%$ do total. Os demais setores oscilaram entre $21 \%$ e $48 \%$, rodeando a média de $33 \%$ do total de classificações em conformidade com o parágrafo 34A.

dividendos pagos como FCF; e, 37\% dos dividendos recebidos como FCO. 
Tabela 10

Classificações na DFC conforme encorajamento do CPC 03 (por setor)

\begin{tabular}{|c|c|c|c|c|c|c|c|c|c|c|c|c|c|c|c|}
\hline & \multicolumn{3}{|c|}{ Juros Pagos } & \multicolumn{3}{|c|}{ Juros Recebidos } & \multicolumn{3}{|c|}{ Dividendos Pagos } & \multicolumn{3}{|c|}{ Dividendos Recebidos } & \multicolumn{3}{|c|}{ Dados Totais ${ }^{\mathrm{a}}$} \\
\hline & FCO & $\%$ & Total & FCO & $\%$ & Total & FCF & $\%$ & Total & FCO & $\%$ & Total & Par.34A & $\%$ & Total \\
\hline Agro e Pesca & 3 & $100 \%$ & 3 & & & & 7 & $100 \%$ & 7 & 2 & $40 \%$ & 5 & 12 & $80 \%$ & 15 \\
\hline Alimentos e Bebidas & 23 & $72 \%$ & 32 & 5 & $100 \%$ & 5 & 52 & $100 \%$ & 52 & 12 & $38 \%$ & 32 & 92 & $76 \%$ & 121 \\
\hline Comércio & 26 & $45 \%$ & 58 & & & & 94 & $99 \%$ & 95 & 12 & $23 \%$ & 52 & 132 & $64 \%$ & 205 \\
\hline Construção & 51 & $64 \%$ & 80 & 3 & $100 \%$ & 3 & 104 & $99 \%$ & 105 & 16 & $22 \%$ & 73 & 174 & $67 \%$ & 261 \\
\hline Eletroeletrônicos & 9 & $50 \%$ & 18 & - & $0 \%$ & 6 & 31 & $84 \%$ & 37 & 11 & $35 \%$ & 31 & 51 & $55 \%$ & 92 \\
\hline Energia Elétrica & 153 & $77 \%$ & 200 & 16 & $80 \%$ & 20 & 243 & $97 \%$ & 251 & 79 & $59 \%$ & 135 & 491 & $81 \%$ & 606 \\
\hline Máquinas Industriais & 1 & $5 \%$ & 22 & & & & 26 & $100 \%$ & 26 & - & $0 \%$ & 11 & 27 & $46 \%$ & 59 \\
\hline Mineração & 5 & $26 \%$ & 19 & 3 & $100 \%$ & 3 & 15 & $83 \%$ & 18 & 13 & $57 \%$ & 23 & 36 & $57 \%$ & 63 \\
\hline Minerais não Metais & 10 & $77 \%$ & 13 & 3 & $100 \%$ & 3 & 16 & $100 \%$ & 16 & 4 & $40 \%$ & 10 & 33 & $79 \%$ & 42 \\
\hline Papel e Celulose & 27 & $100 \%$ & 27 & 6 & $100 \%$ & 6 & 24 & $96 \%$ & 25 & 12 & $57 \%$ & 21 & 69 & $87 \%$ & 79 \\
\hline Petróleo e Gás & 15 & $50 \%$ & 30 & & & & 26 & $100 \%$ & 26 & - & $0 \%$ & 11 & 41 & $61 \%$ & 67 \\
\hline Química & 26 & $57 \%$ & 46 & & & & 46 & $100 \%$ & 46 & 12 & $48 \%$ & 25 & 84 & $72 \%$ & 117 \\
\hline Siderurgia e Metalurgia & 47 & $60 \%$ & 78 & 7 & $100 \%$ & 7 & 97 & $100 \%$ & 97 & 36 & $59 \%$ & 61 & 187 & $77 \%$ & 243 \\
\hline Software e Dados & 10 & $71 \%$ & 14 & 5 & $100 \%$ & 5 & 24 & $100 \%$ & 24 & 6 & $35 \%$ & 17 & 45 & $75 \%$ & 60 \\
\hline Telecomunicações & 16 & $59 \%$ & 27 & 5 & $83 \%$ & 6 & 51 & $98 \%$ & 52 & 23 & $52 \%$ & 44 & 95 & $74 \%$ & 129 \\
\hline Têxtil & 73 & $74 \%$ & 99 & - & $0 \%$ & 1 & 110 & $99 \%$ & 111 & 7 & $11 \%$ & 65 & 190 & $69 \%$ & 276 \\
\hline Transporte - Serviços & 29 & $46 \%$ & 63 & 2 & $22 \%$ & 9 & 102 & $100 \%$ & 102 & 18 & $27 \%$ & 66 & 151 & $63 \%$ & 240 \\
\hline Veículos e Peças & 30 & $45 \%$ & 66 & & & & 64 & $100 \%$ & 64 & 12 & $29 \%$ & 41 & 106 & $62 \%$ & 171 \\
\hline Outros & 149 & $60 \%$ & 250 & 5 & $22 \%$ & 23 & 358 & $99 \%$ & 363 & 60 & $21 \%$ & 282 & 572 & $62 \%$ & 918 \\
\hline Total & 703 & $61 \%$ & 1.145 & 60 & $62 \%$ & 97 & 1.490 & $\mathbf{9 8 \%}$ & 1.517 & 335 & $33 \%$ & 1.005 & 2.588 & $69 \%$ & 3.764 \\
\hline
\end{tabular}

Nota . FCF = Fluxo de Caixa de Financiamento; FCO = Fluxo de Caixa Operacional.

${ }^{\text {a}}$ Total de de dados conforme classificação encorajada pelo CPC 03, parágrafo 34A. 
Considerando os resultados das classificações por setor apresentados na Tabela 10, a Tabela 11 demonstra, em percentuais, como os juros pagos e recebidos, e dividendos pagos e recebidos foram classificados no período total sob análise.

Tabela 11

Classificações na DFC (por setor)

\begin{tabular}{|c|c|c|c|c|c|c|c|c|c|c|c|}
\hline & \multicolumn{2}{|c|}{$\begin{array}{l}\text { Juros } \\
\text { Pagos }\end{array}$} & \multicolumn{3}{|c|}{$\begin{array}{c}\text { Juros } \\
\text { Recebidos }\end{array}$} & \multicolumn{3}{|c|}{$\begin{array}{l}\text { Dividendos } \\
\text { Pagos }\end{array}$} & \multicolumn{3}{|c|}{$\begin{array}{l}\text { Dividendos } \\
\text { Recebidos }\end{array}$} \\
\hline & FCF & FCO & FCF & FCI & FCO & FCF & FCI & FCO & FCF & FCI & FCO \\
\hline Agro e Pesca & $0 \%$ & $100 \%$ & & & & $100 \%$ & & & $60 \%$ & & $40 \%$ \\
\hline Alimentos e Bebidas & $28 \%$ & $72 \%$ & & & $100 \%$ & $100 \%$ & & & & $63 \%$ & $38 \%$ \\
\hline Comércio & $55 \%$ & $45 \%$ & & & & $99 \%$ & & $1 \%$ & $12 \%$ & $65 \%$ & $23 \%$ \\
\hline Construção & $36 \%$ & $64 \%$ & & & $100 \%$ & $99 \%$ & & $1 \%$ & $8 \%$ & $70 \%$ & $22 \%$ \\
\hline Eletroeletrônicos & $50 \%$ & $50 \%$ & $83 \%$ & $17 \%$ & $0 \%$ & $84 \%$ & & $16 \%$ & $29 \%$ & $35 \%$ & $35 \%$ \\
\hline Energia Elétrica & $24 \%$ & $77 \%$ & & $20 \%$ & $80 \%$ & $97 \%$ & $1 \%$ & $2 \%$ & $3 \%$ & $39 \%$ & $59 \%$ \\
\hline Máquinas Indust. & $95 \%$ & $5 \%$ & & & & $100 \%$ & & & & $100 \%$ & $0 \%$ \\
\hline Mineração & $74 \%$ & $26 \%$ & & & $100 \%$ & $83 \%$ & & $17 \%$ & & $43 \%$ & $57 \%$ \\
\hline Minerais não Metais & $23 \%$ & $77 \%$ & & & $100 \%$ & $100 \%$ & & & & $60 \%$ & $40 \%$ \\
\hline Papel e Celulose & $0 \%$ & $100 \%$ & & & $100 \%$ & $96 \%$ & & $4 \%$ & & $43 \%$ & $57 \%$ \\
\hline Petróleo e Gás & $50 \%$ & $50 \%$ & & & & $100 \%$ & & & & $100 \%$ & $0 \%$ \\
\hline Química & $43 \%$ & $57 \%$ & & & & $100 \%$ & & & $8 \%$ & $44 \%$ & $48 \%$ \\
\hline Siderurgia e Metal. & $40 \%$ & $60 \%$ & & & $100 \%$ & $100 \%$ & & & $2 \%$ & $39 \%$ & $59 \%$ \\
\hline Software e Dados & $29 \%$ & $71 \%$ & & & $100 \%$ & $100 \%$ & & & & $65 \%$ & $35 \%$ \\
\hline Telecomunicações & $41 \%$ & $59 \%$ & & $17 \%$ & $83 \%$ & $98 \%$ & $2 \%$ & & $2 \%$ & $45 \%$ & $52 \%$ \\
\hline Têxtil & $26 \%$ & $74 \%$ & & $100 \%$ & $0 \%$ & $99 \%$ & & $1 \%$ & $5 \%$ & $85 \%$ & $11 \%$ \\
\hline Transporte - Serv. & $54 \%$ & $46 \%$ & $78 \%$ & & $22 \%$ & $100 \%$ & & & $15 \%$ & $58 \%$ & $27 \%$ \\
\hline Veículos e Peças & $55 \%$ & $45 \%$ & & & & $100 \%$ & & & $7 \%$ & $63 \%$ & $29 \%$ \\
\hline Outros & $40 \%$ & $60 \%$ & $22 \%$ & $57 \%$ & $22 \%$ & $99 \%$ & $0 \%$ & $1 \%$ & $2 \%$ & $77 \%$ & $21 \%$ \\
\hline
\end{tabular}

Nota . FCF = Fluxo de Caixa de Financiamento; FCO = Fluxo de Caixa Operacional; FCI = Fluxo de

Caixa de Investimento.

Com exceção do setor "Outros", que por ser diversificado foi excluído da análise, estão destacados em cinza os percentuais que atingiram $70 \%{ }^{6}$ ou mais, a fim de identificar as classificações predominantes dos setores e, então, analisar a hipótese H2.a.

Os setores "Máquinas Industriais" e "Têxtil", foram os únicos que seguiram uma classificação predominante em todos os itens divulgados que possuem flexibilidade de apresentação na DFC. Os setores de "Alimentos e Bebidas", "Energia Elétrica", "Mineração", "Minerais não Metais", "Papel e Celulose" e "Software e Dados" tiveram classificação

${ }^{6}$ De uma forma mais conservadora, poder-se-ia considerar $90 \%$ ou mais como critério de predominância, e de forma oposta, $51 \%$ poderia ser considerado como maioria. Logo, adotou-se um critério intermediário de $70 \%$. 
predominante nos itens com flexibilidade, com exceção de dividendos recebidos. "Construção" foi o setor que classificou os itens com predominância de classificação, exceto os juros pagos.

Nota-se que para os itens juros recebidos e dividendos pagos houve sim uma predominância de classificação por parte de todos os setores em alguma atividade da DFC, mesmo que não seja aquela encorajada pelo CPC 03, como no caso dos juros recebidos nos segmentos de "Eletroeletrônicos", "Têxtil" e "Transporte - Serviços". Entretanto, os juros pagos seguiram uma tendência de classificação em 9 setores do total de 18 sob análise, e os dividendos recebidos em apenas 4 setores, logo, para tais itens, a hipótese H2.a foi rejeitada. A Tabela 12 apresenta um resumo das classificações predominantes por setor.

Tabela 12

Resumo das classificações predominantes (por setor)

\begin{tabular}{|c|c|c|c|}
\hline & \multicolumn{2}{|c|}{ Juros Pagos } & \multirow{2}{*}{$\begin{array}{c}\text { Dividendos Recebidos } \\
\text { FCI }\end{array}$} \\
\hline & FCF & FCO & \\
\hline Agro e Pesca & & $100 \%$ & \\
\hline Alimentos e Bebidas & & $72 \%$ & \\
\hline Construção & & & $70 \%$ \\
\hline Energia Elétrica & & $77 \%$ & \\
\hline Máquinas Industriais & $95 \%$ & & $100 \%$ \\
\hline Mineração & $74 \%$ & & \\
\hline Minerais não Metais & & $77 \%$ & \\
\hline Papel e Celulose & & $100 \%$ & \\
\hline Petróleo e Gás & & & $100 \%$ \\
\hline Software e Dados & & $71 \%$ & \\
\hline Têxtil & & $74 \%$ & $85 \%$ \\
\hline
\end{tabular}

Compondo ainda o segundo grupo de hipóteses, tem-se o seguinte:

$H_{2} . b$ : Empresas que possuem os mesmos auditores tendem a utilizar as mesmas classificações dos itens que possuem flexibilidade de apresentação na DFC.

Passando da análise por setor para analisar os dados por firma de auditoria, a Tabela 13 resume a quantidade total de classificações na DFC, de acordo com o encorajamento do CPC 03, considerando os auditores como fator comum. O detalhamento ano a ano por auditor está apresentado no Apêndice C. 
Tabela 13

Classificações na DFC conforme encorajamento do CPC 03 (por auditor)

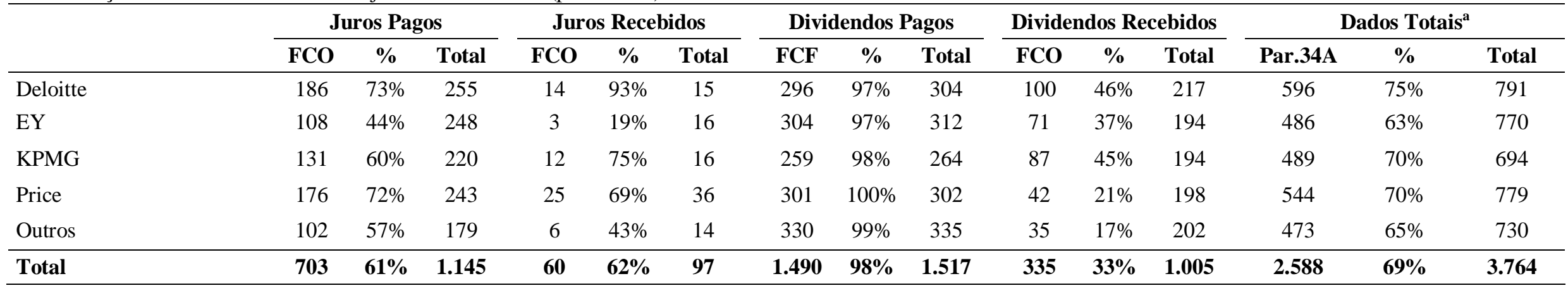

Nota . FCF = Fluxo de Caixa de Financiamento; FCO = Fluxo de Caixa Operacional

aTotal de de dados conforme classificação encorajada pelo CPC 03, parágrafo 34A. 
Dos cinco grupos de auditores segregados, nota-se que a Deloitte é a firma de auditoria que, de uma forma geral, mais emitiu opinião sobre DFCs com a classificação indicada no parágrafo 34A do CPC 03 (75\% do total dos dados divulgados). Na sequência, a KPMG e a Price opinaram sobre $70 \%$ dos dados de acordo com o parágrafo 34A. Por último, a EY emitiu relatório para $63 \%$ dos dados em conformidade com a classificação encorajada pelo CPC 03.

Seguindo com a análise dos resultados das classificações por auditor, a Tabela 14 demonstra, em percentuais, como os juros pagos e recebidos, e dividendos pagos e recebidos foram classificados no período total sob análise.

Tabela 14

Classificações na DFC (por auditor)

\begin{tabular}{|c|c|c|c|c|c|c|c|c|c|c|c|}
\hline & \multicolumn{2}{|c|}{$\begin{array}{l}\text { Juros } \\
\text { Pagos }\end{array}$} & \multicolumn{3}{|c|}{$\begin{array}{c}\text { Juros } \\
\text { Recebidos }\end{array}$} & \multicolumn{3}{|c|}{$\begin{array}{c}\text { Dividendos } \\
\text { Pagos }\end{array}$} & \multicolumn{3}{|c|}{$\begin{array}{l}\text { Dividendos } \\
\text { Recebidos }\end{array}$} \\
\hline & FCF & FCO & FCF & FCI & FCO & FCF & FCI & FCO & FCF & FCI & FCO \\
\hline Deloitte & $27 \%$ & $73 \%$ & $7 \%$ & & $93 \%$ & $97 \%$ & & $3 \%$ & $1 \%$ & $53 \%$ & $46 \%$ \\
\hline $\mathrm{EY}$ & $56 \%$ & $44 \%$ & $50 \%$ & $31 \%$ & $19 \%$ & $97 \%$ & & $3 \%$ & $8 \%$ & $56 \%$ & $37 \%$ \\
\hline KPMG & $40 \%$ & $60 \%$ & & $25 \%$ & $75 \%$ & $98 \%$ & $1 \%$ & $1 \%$ & $5 \%$ & $51 \%$ & $45 \%$ \\
\hline Price & $28 \%$ & $72 \%$ & $11 \%$ & $19 \%$ & $69 \%$ & $100 \%$ & & $0 \%$ & $2 \%$ & $77 \%$ & $21 \%$ \\
\hline Outros & $43 \%$ & $57 \%$ & $29 \%$ & $29 \%$ & $43 \%$ & $99 \%$ & $1 \%$ & $1 \%$ & $11 \%$ & $71 \%$ & $17 \%$ \\
\hline
\end{tabular}

Nota. FCF = Fluxo de Caixa de Financiamento; FCO = Fluxo de Caixa Operacional; FCI = Fluxo de Caixa de Investimento.

Com exceção do grupo "Outros”, que é diversificado e não fará parte da análise, estão destacados em cinza os percentuais superiores a $70 \%^{7}$, a fim de identificar as classificações predominantes por firma de auditoria, e então analisar a hipótese H2.b.

De acordo com as Tabela 13 e Tabela 14, as empresas auditadas pela Deloitte e pela Price predominaram com a classificação dos juros pagos como FCO, conforme encorajamento do parágrafo $34 \mathrm{~A}, 73 \%$ e $72 \%$, respectivamente, seguida pelas empresas auditadas pela KPMG, com 60\%, e por último as auditadas pela EY, com 44\%. De uma forma geral, a Deloitte e a Price foram os auditores cujos clientes adotaram uma classificação predominante em três dos quatro itens com flexibilidade de apresentação na DFC. No caso da Deloitte, dividendos recebidos não predominaram em uma determinada classificação, e no caso da Price, os juros recebidos. A EY foi a firma de auditoria com empresas auditadas que menos seguiram um padrão de classificação, apenas os dividendos pagos foram classificados de

\footnotetext{
${ }^{7}$ Vide nota de rodapé 6.
} 
forma predominante como FCF, assim como ocorreu com as demais, por se tratar de um item que tem uma classificação praticamente padronizada no mercado de capitais brasileiro.

O resumo dos resultados está apresentado na Tabela 15, com exceção do item dividendos pagos, em virtude de ser classificado de forma praticamente padronizada no mercado brasileiro.

Tabela 15

Resumo das classificações predominantes (por auditor)

\begin{tabular}{|c|c|c|c|}
\hline & $\begin{array}{l}\text { Juros } \\
\text { Pagos }\end{array}$ & $\begin{array}{c}\text { Juros } \\
\text { Recebidos }\end{array}$ & $\begin{array}{c}\text { Dividendos } \\
\text { Recebidos }\end{array}$ \\
\hline & FCO & FCO & FCI \\
\hline Deloitte & $73 \%$ & $93 \%$ & \\
\hline KPMG & & $75 \%$ & \\
\hline Price & $72 \%$ & & $77 \%$ \\
\hline
\end{tabular}

Considerando a análise dos dados efetuada, há indicações de influência da Deloitte e da Price na escolha das opções de classificação por parte das empresas auditadas, uma vez que tais firmas de auditoria costumam seguir uma certa classificação predominante. Assim, não se pode rejeitar a hipótese H2.b para essas firmas de auditoria. Por outro lado, para as outras duas Big Four (EY e KPMG), a hipótese H2.b foi rejeitada.

\subsection{Terceira hipótese}

Conforme indicado na seção 1.3, a terceira hipótese da pesquisa está assim enunciada:

H3: Mudanças de classificação de juros pagos ocorrem em função da mudança de auditor.

O montante de juros pagos pode aumentar o FCO caso não seja seguida a classificação recomendada pelo CPC 03, os demais encorajamentos previstos pela referida norma, envolvendo juros recebidos e dividendos/JCP, podem reduzir o FCO se não seguidos. Logo, uma análise das mudanças de classificação dos juros pagos de um exercício para o outro foi efetuada e os resultados alcançados constam na Tabela 16.

Entre os cinco grupos de auditores, a EY foi a firma de auditoria com uma menor representatividade de empresas classificando os juros pagos como FCO (44\%), conforme já mencionado (vide Tabela 14). Em linha com essa realidade, ela foi a auditoria com uma maior 
quantidade de empresas que reclassificaram os juros pagos de FCO para FCF (10 mudanças do total de 13), conforme indicado na Tabela 16, o que gera um aumento no FCO divulgado. Para as demais Big Four, predominaram as mudanças no sentido oposto, de FCF para FCO, de forma a seguir o encorajamento do CPC 03. Observa-se também que praticamente todas as mudanças de classificação foram entre as Big Four.

Tabela 16

Reclassificações de juros pagos (por auditor e atividades na DFC)

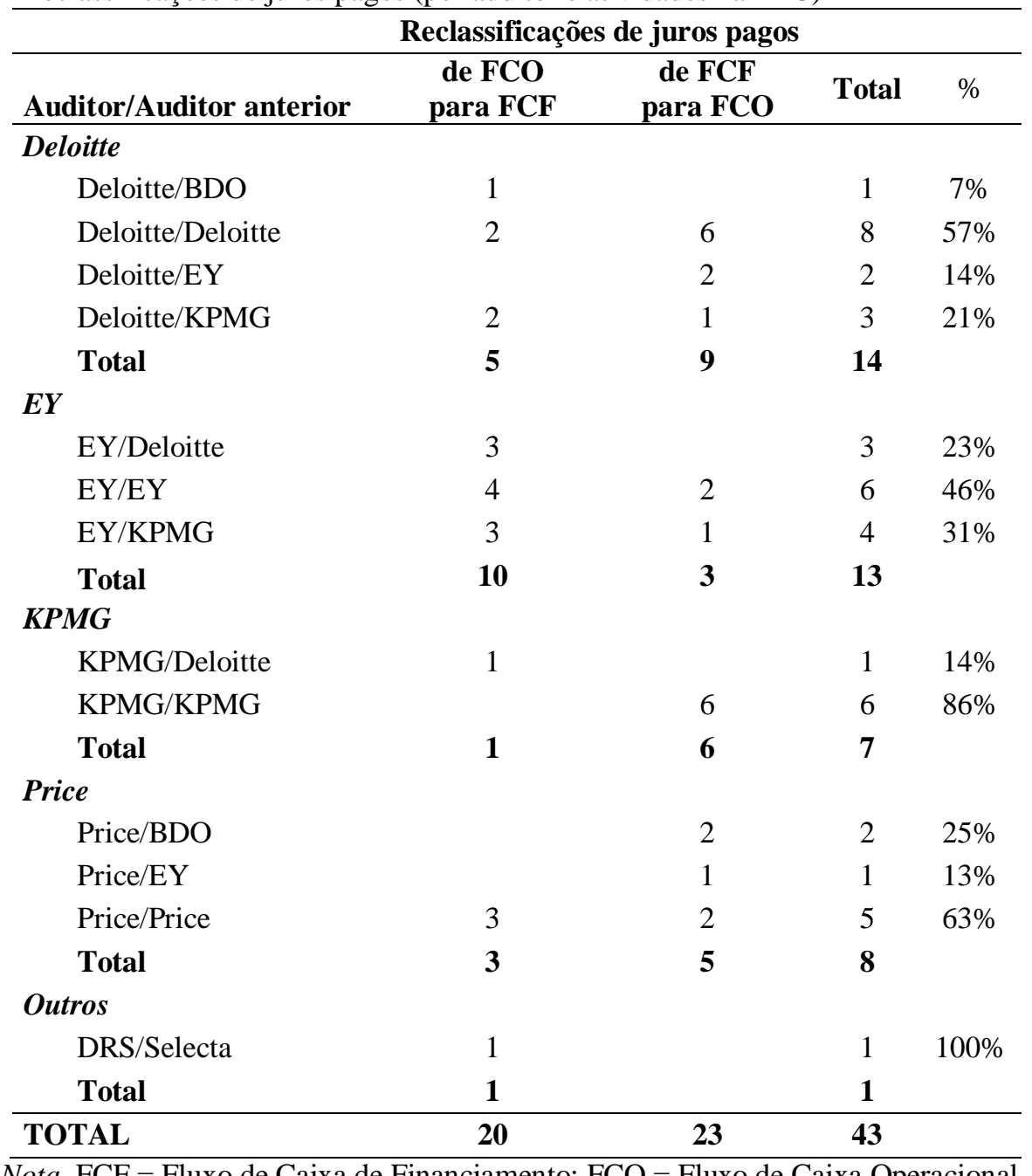

Com o intuito de identificar uma possível relação entre a reclassificação dos juros pagos e a mudança de auditor, a Tabela 17 resume o total de mudanças em virtude da situação da auditoria. Logo, se no ano anterior outro auditor prestava serviço, a auditoria foi iniciada, e se o mesmo auditor prestava serviço no ano anterior, trata-se de uma auditoria recorrente.

Interessante notar que parte considerável dessas mudanças ocorreu mesmo sem mudança da firma de auditoria (57\% - Deloitte; 46\% - EY; 86\% - KPMG; 63\% - Price). Para os 25 casos de auditoria recorrente, foram analisados os sócios que assinaram os relatórios, a 
fim de verificar se houve mudança do sócio responsável de um período para o outro. Em apenas 5 desses casos (20\%) houve mudança do sócio de auditoria. Verifica-se então que a mudança de classificação dos juros pagos ocorreu na maior parte dos casos, independentemente da mudança da firma de auditoria ou do auditor responsável, logo, as evidências apontam para a rejeição da hipótese H3.

Tabela 17

Resumo das reclassificações de juros pagos (por auditor e situação da auditoria)

\begin{tabular}{|c|c|c|c|c|c|}
\hline \multirow[b]{2}{*}{ Auditor } & \multicolumn{4}{|c|}{ Auditoria } & \multirow[b]{2}{*}{ Total } \\
\hline & Iniciada & $\%$ & Recorrente & $\%$ & \\
\hline Deloitte & 6 & $43 \%$ & 8 & $57 \%$ & 14 \\
\hline EY & 7 & $54 \%$ & 6 & $46 \%$ & 13 \\
\hline KPMG & 1 & $14 \%$ & 6 & $86 \%$ & 7 \\
\hline Price & 3 & $38 \%$ & 5 & $63 \%$ & 8 \\
\hline Outros & 1 & $100 \%$ & - & $0 \%$ & 1 \\
\hline Total & 18 & & 25 & & 43 \\
\hline
\end{tabular}

Na referida análise (Tabelas 16 e 17), foram considerados 1.051 dados sobre juros pagos de 2009 a 2014 (total de 1.145 subtraído 94 dados de 2008, ano de partida da comparação, conforme Tabela 8), e ocorreram apenas 43 mudanças de classificação, ou seja, apenas $4 \%$ da amostra. Isso pode representar uma preocupação por parte das empresas analisadas com a consistência de prática contábil, pode ser um reflexo de poucas mudanças no contexto operacional e financeiro das mesmas ou pode não haver uma análise criteriosa a cada divulgação para se concluir sobre a classificação mais adequada para a realidade da empresa.

\subsection{Quarto grupo de hipóteses}

Esta seção apresenta a análise descritiva e os resultados das regressões referentes ao quarto grupo de hipóteses, segregando-se os dois modelos de regressão utilizados, indicados como modelo A e modelo B.

Conforme indicado na Tabela 7, o modelo A possui "diferença" como variável dependente, que representa a diferença em $\mathrm{R} \$$ entre o FCO divulgado e o valor que seria o FCO ao seguir as opções encorajadas pelo CPC 03 (FCO encorajado), dividida pelo valor do ativo total. O modelo B possui "juros pagos" como variável dependente, que se refere à escolha de classificação dos juros pagos - variável dummy, sendo 1 para classificação como FCF e 0 se FCO. As variáveis explicativas (endividamento, rentabilidade e FCO encorajado) são as mesmas nos dois modelos. 


\title{
4.4.1 Análise descritiva
}

\author{
4.4.1.1 Modelo A
}

A Tabela 18 apresenta a média, frequência $(\mathrm{N})$, desvio padrão e mediana das variáveis utilizadas no modelo A de regressão em cada um dos anos, com exceção do FCO encorajado (variável dummy).

Tabela 18

Dados das variáveis do modelo A

\begin{tabular}{|c|c|c|c|c|c|}
\hline Variáveis & Exercício & Média & $\mathbf{N}$ & Desvio Padrão & Mediana \\
\hline \multirow{8}{*}{$\begin{array}{l}\text { VARIÁVEL DEPENDENTE } \\
\text { Diferença em R\$ entre o FCO } \\
\text { divulgado e FCO encorajado, } \\
\text { dividida pelo valor do ativo total. }\end{array}$} & 2008 & ,0081 & 64 & ,05748 & ,0000 \\
\hline & 2009 & ,0085 & 67 & ,04024 & ,0000 \\
\hline & 2010 & ,0014 & 70 & ,05552 & ,0100 \\
\hline & 2011 & 0140 & 81 & ,03467 & ,0200 \\
\hline & 2012 & ,0102 & 89 & ,02659 & ,0100 \\
\hline & 2013 & ,0084 & 108 & ,03030 & ,0100 \\
\hline & 2014 &,- 0029 & 106 & , 12704 & ,0100 \\
\hline & Total & ,0065 & 585 & ,06538 & ,0100 \\
\hline \multirow[t]{8}{*}{ Rentabilidade } & 2008 & $-3,7136$ & 64 & 43,74277 & 2,7000 \\
\hline & 2009 & 4,9388 & 67 & 10,92714 & 4,0000 \\
\hline & 2010 & 4,7869 & 70 & 10,16828 & 4,3000 \\
\hline & 2011 & 4,1981 & 81 & 8,89029 & 4,4000 \\
\hline & 2012 & ,3606 & 89 & 20,40381 & 2,8000 \\
\hline & 2013 & $-3,7185$ & 108 & 46,23418 & 2,8000 \\
\hline & 2014 & 72,4019 & 106 & 749,50581 & 3,2000 \\
\hline & Total & 13,8008 & 585 & 320,11134 & 3,3000 \\
\hline \multirow[t]{8}{*}{ Endividamento } & 2008 & 69,8545 & 64 & 79,70254 & 58,3000 \\
\hline & 2009 & 61,8191 & 67 & 57,81431 & 53,4000 \\
\hline & 2010 & 64,7869 & 70 & 64,15549 & 55,4000 \\
\hline & 2011 & 60,6677 & 81 & 43,69228 & 57,1000 \\
\hline & 2012 & 62,5588 & 89 & 59,24189 & 57,0000 \\
\hline & 2013 & 64,8224 & 108 & 63,80535 & 54,3500 \\
\hline & 2014 & 63,6726 & 106 & 51,78391 & 57,3500 \\
\hline & Total & 63,8967 & 585 & 59,78372 & 56,2000 \\
\hline
\end{tabular}

Conforme Tabela 18, a média da rentabilidade do conjunto de anos analisados foi de $13,8 \%$, enquanto que a média de endividamento esteve entre $60,7 \%$ e $69,9 \%$. 
A Tabela 19 apresenta a frequência para a variável FCO encorajado, utilizada no modelo A de regressão.

Tabela 19

Dados da variável FCO encorajado (modelo A)

\begin{tabular}{lcccc}
\hline $\begin{array}{c}\text { FCO } \\
\text { encorajado }\end{array}$ & $\begin{array}{c}\text { Positivo } \\
\mathbf{N}(\boldsymbol{\%})\end{array}$ & $\begin{array}{c}\text { Negativo } \\
\mathbf{N}(\boldsymbol{\%})\end{array}$ & $\begin{array}{c}\text { Em branco } \\
\mathbf{N}(\boldsymbol{\%})\end{array}$ & $\begin{array}{c}\text { Total } \\
\mathbf{N}(\boldsymbol{\%})\end{array}$ \\
\hline 2008 & $47(27,5)$ & $17(9,9)$ & $107(62,6)$ & $171(100)$ \\
2009 & $55(32,2)$ & $12(7,0)$ & $104(60,8)$ & $171(100)$ \\
2010 & $54(31,6)$ & $16(9,4)$ & $101(59,1)$ & $171(100)$ \\
2011 & $59(34,5)$ & $22(12,9)$ & $90(52,6)$ & $171(100)$ \\
2012 & $74(43,3)$ & $15(8,8)$ & $82(48,0)$ & $171(100)$ \\
2013 & $85(49,7)$ & $23(13,5)$ & $63(36,8)$ & $171(100)$ \\
2014 & $87(50,9)$ & $19(11,1)$ & $65(38,0)$ & $171(100)$ \\
\hline Total & $\mathbf{4 6 1 ( 3 8 , 5 )}$ & $\mathbf{1 2 4}(\mathbf{1 0 , 4 )}$ & $\mathbf{6 1 2}(\mathbf{5 1 , 1 )}$ & $\mathbf{1 . 1 9 7 ( 1 0 0 )}$ \\
\hline
\end{tabular}

$\mathrm{Na}$ Tabela 19, somando-se o total de dados de FCO encorajado positivo e FCO encorajado negativo, chega-se ao total de 585 dados utilizados na regressão. Como apenas parte das 171 empresas divulgou o FCO diferente daquele encorajado pelo CPC 03 (diferença que corresponde à variável dependente do modelo) e algumas empresas não têm dados em todos os anos, há uma quantidade indicada como "em branco", que se refere ao desbalanceamento do painel de dados.

Dos 585 dados considerados no modelo, $461(78,8 \%)$ tratavam-se de FCO encorajado positivo e $124(21,2 \%)$ de FCO encorajado negativo. Este último refere-se à variável independente que se esperava influenciar na diferença entre o valor do FCO divulgado e do FCO encorajado pelo CPC 03.

\subsubsection{Modelo B}

A Tabela 20 apresenta a média, frequência $(\mathrm{N})$, desvio padrão e mediana das variáveis rentabilidade e endividamento, utilizadas no modelo B de regressão, em cada um dos anos. Juros pagos e FCO encorajado, por serem variáveis dummy, constam na Tabela 20.

Tabela 20

Dados das variáveis do modelo B

\begin{tabular}{cccccc}
\hline Variáveis & Exercício & Média & N & Desvio Padrão & Mediana \\
\hline Rentabilidade & 2008 & $-4,2227$ & 94 & 44,82704 & 3,7500 \\
& 2009 & 4,0619 & 117 & 14,63133 & 5,0000 \\
2010 & 4,7793 & 162 & 11,29089 & 5,4500 \\
2011 & 4,1024 & 176 & 9,35835 & 4,5000 \\
& 2012 & 2,8272 & 193 & 9,20505 & 3,3000 \\
& 2013 &,- 3005 & 199 & 34,65555 & 3,1000 \\
& 2014 & 41,5440 & 200 & 544,52614 & 3,3000 \\
& Total & $\mathbf{9 , 0 8 7 8}$ & $\mathbf{1 . 1 4 1}$ & $\mathbf{2 2 8 , 9 7 4 9 1}$ & $\mathbf{3 , 9 0 0 0}$ \\
& & & & & \\
& & & & &
\end{tabular}


Tabela 20

Dados das variáveis do modelo B (Continuação)

\begin{tabular}{cccccc}
\hline Variáveis & Exercício & Média & N & Desvio Padrão & Mediana \\
\hline Endividamento & 2008 & 76,7962 & 94 & 75,71170 & 62,2500 \\
& 2009 & 74,9369 & 117 & 76,77536 & 59,8000 \\
& 2010 & 62,1357 & 162 & 46,13040 & 57,4400 \\
2011 & 61,9335 & 176 & 44,07944 & 57,9900 \\
& 2012 & 61,1641 & 193 & 30,35689 & 58,9000 \\
& 2013 & 63,4889 & 199 & 36,79917 & 57,5000 \\
& 2014 & 61,4030 & 200 & 24,88416 & 59,3000 \\
& Total & $\mathbf{6 4 , 5 6 8 2}$ & $\mathbf{1 . 1 4 1}$ & $\mathbf{4 6 , 8 3 9 2 7}$ & $\mathbf{5 8 , 5 0 0 0}$ \\
\hline
\end{tabular}

Conforme Tabela 20, a média da rentabilidade do conjunto de anos analisados foi de $9,09 \%$, enquanto que a média de endividamento esteve entre $61,2 \%$ e $76,8 \%$.

A Tabela 21 apresenta a frequência para as variáveis juros pagos (variável dependente) e FCO encorajado, utilizadas no modelo B de regressão.

Tabela 21

Dados das variáveis Juros pagos e FCO encorajado (modelo B)

\begin{tabular}{|c|c|c|c|c|}
\hline JUROS PAGOS & $\begin{array}{c}\text { 0 - FCO } \\
\text { N }(\%)\end{array}$ & $\begin{array}{c}1 \text { - FCF } \\
\text { N }(\%)\end{array}$ & $\begin{array}{c}\text { Em branco } \\
\mathbf{N}(\%)\end{array}$ & $\begin{array}{l}\text { Total } \\
\text { N }(\%)\end{array}$ \\
\hline 2008 & $53(22,6)$ & $41(17,5)$ & $140(59,8)$ & $234(100)$ \\
\hline 2009 & $70(29,9)$ & $47(20,1)$ & $117(50,0)$ & $234(100)$ \\
\hline 2010 & $101(43,2)$ & $61(26,1)$ & $72(30,8)$ & 234 (100) \\
\hline 2011 & $112(47,9)$ & $64(27,4)$ & $58(24,8)$ & $234(100)$ \\
\hline 2012 & $119(50,9)$ & $74(31,6)$ & $41(17,5)$ & $234(100)$ \\
\hline 2013 & $125(53,4)$ & $74(31,6)$ & $35(15,0)$ & $234(100)$ \\
\hline 2014 & $123(52,6)$ & $77(32,9)$ & $34(14,5)$ & $234(100)$ \\
\hline Total & $703(42,9)$ & $438(26,7)$ & $497(30,4)$ & $1.638(100)$ \\
\hline FCO ENCORAJADO & $\begin{array}{c}\text { Positivo } \\
\text { N }(\%)\end{array}$ & $\begin{array}{c}\text { Negativo } \\
\mathbf{N}(\%)\end{array}$ & $\begin{array}{c}\text { Em branco } \\
\mathbf{N}(\%)\end{array}$ & $\begin{array}{c}\text { Total } \\
\text { N }(\%)\end{array}$ \\
\hline 2008 & $72(30,8)$ & $22(9,4)$ & $140(59,8)$ & $234(100)$ \\
\hline 2009 & $100(42,7)$ & $17(7,3)$ & $117(50,0)$ & $234(100)$ \\
\hline 2010 & $131(56,0)$ & $31(13,2)$ & $72(30,8)$ & $234(100)$ \\
\hline 2011 & $141(60,3)$ & $35(15,0)$ & $58(24,8)$ & $234(100)$ \\
\hline 2012 & $158(67,5)$ & $35(15,0)$ & $41(17,5)$ & $234(100)$ \\
\hline 2013 & $158(67,5)$ & $41(17,5)$ & $35(15,0)$ & $234(100)$ \\
\hline 2014 & $166(70,9)$ & $34(14,5)$ & $34(14,5)$ & 234 (100) \\
\hline Total & $926(56,5)$ & $215(13,1)$ & $497(30,4)$ & $1.638(100)$ \\
\hline
\end{tabular}

As Tabelas 20 e 21 mostram que foram utilizados 1.141 dados na regressão. Isso indica que apenas parte das 234 empresas divulgou valores de juros pagos na DFC (variável dependente do modelo) e que algumas empresas não têm dados em todos os anos, por isso há uma quantidade indicada como "em branco", que se refere ao desbalanceamento do painel de dados. 
Conforme Tabela 21, dos 1.141 dados de juros pagos utilizados no modelo, 703 $(61,6 \%)$ foram classificados como FCO e 438 (38,4\%) classificados como FCF (vide abertura por setor e auditor nos Apêndices B e C, respectivamente). Lembrando que juros pagos é a variável dependente do modelo (dummy, 1 se classificados como FCF e 0 se FCO). Quanto aos dados relacionados ao FCO encorajado, 926 (81,2\%) se referiam a FCO encorajado positivo e $215(18,8 \%)$ a FCO encorajado negativo. Este último refere-se à variável independente que se esperava influenciar na classificação dos juros pagos (dummy 1).

\subsubsection{Resultado das regressões}

A seguir serão apresentados os resultados das regressões realizadas. Cada regressão foi testada através do modelo de efeitos fixos e do modelo de efeitos aleatórios. Todos os modelos foram estimados considerando a inclusão de 6 variáveis dummy correspondentes aos anos pesquisados. Foram incluídas 6 variáveis (e não 7, de 2008 a 2014) para evitar o problema da multicolinearidade e foi utilizado o teste de Wald para verificar a relevância de tais variáveis no modelo. O objetivo do referido teste é verificar se os parâmetros das variáveis dummy são conjuntamente iguais a zero, o que indicaria não haver importância estatística para mantê-las no modelo.

A significância do teste de Wald resultou em valor superior a 0,05 em todos os casos, indicando que os parâmetros das variáveis dummy são conjuntamente iguais a zero e, portanto, devem ser excluídas do modelo. Ou seja, estas variáveis não foram capazes de capturar fatores macroeconômicos que poderiam ter afetado as empresas no período analisado. Isso indica que em nenhum ano foi identificado um comportamento destoante dos demais, o qual poderia estar relacionado a fatores externos relevantes de determinado ano, como por exemplo, uma grave crise ou eventos econômicos específicos.

\subsubsection{Modelo A}

Para efetuar a regressão, foram considerados apenas os períodos das empresas em que havia diferença entre o montante de FCO divulgado e o FCO encorajado, resultando na utilização de 171 empresas e 585 dados. A lista das empresas utilizadas consta no Apêndice D. 
Para avaliar qual dos modelos (efeitos fixos ou efeitos aleatórios) é o mais adequado, foram utilizados dois testes: o multiplicador de Lagrange de Breusch-Pagan (teste LM de Breusch-Pagan) e o teste de Hausman. Seus resultados encontram-se nas Tabelas 22 e 23, respectivamente.

Tabela 22

Teste LM de Breusch-Pagan (modelo A)

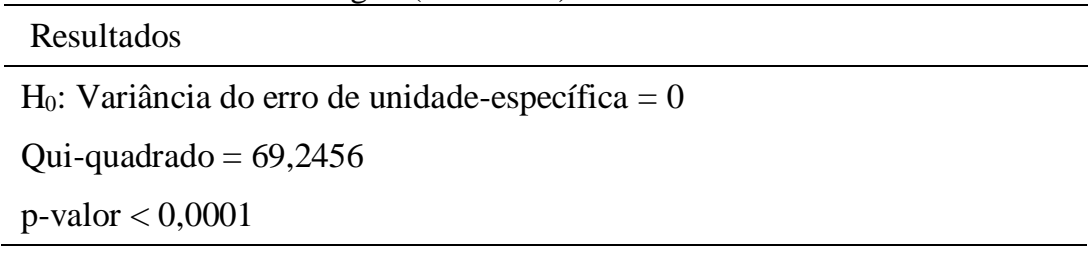

Tabela 23

Teste de Hausman (modelo A)

\begin{tabular}{l} 
Resultados \\
\hline $\mathrm{H}_{0}:$ As estimativas do modelo de efeitos aleatórios são consistentes \\
Qui-quadrado $=6,57293$ \\
p-valor $=0,0868303$ \\
\hline
\end{tabular}

Como a significância (p-valor) do teste de Breusch-Pagan foi inferior a 0,05, concluise que o modelo de efeitos aleatórios é o mais adequado. Esta conclusão é corroborada pelo teste de Hausman, uma vez que o p-valor deste teste $(>0,05)$ não foi significativo (Gujarati, 2006; Lima, 2007).

O modelo A foi estimado conforme a equação abaixo, através do modelo de efeitos fixos e de efeitos aleatórios.

Diferença $_{i, t}=\beta_{0}+\beta_{1}$ End $_{i, t}+\beta_{2}$ Rent $_{i, t}+\beta_{3} \mathrm{FCO}_{i, t}+\varepsilon$

Em que:

Diferença $=$ Diferença em reais entre o FCO divulgado e o FCO encorajado, dividida pelo valor do ativo total, da empresa $i$ no ano $t$

$\beta_{0}=$ Constante

$\beta_{1}, \beta_{2}, \beta_{3}=$ Estimadores

End $=$ Endividamento da empresa $i$ no ano $t$

Rent $=$ Rentabilidade da empresa $i$ no ano $t$

FCO $=$ Fluxo de Caixa Operacional encorajado da empresa $i$ no ano $t$ (dummy, 1 se negativo e 0 se positivo)

$\varepsilon=$ Termo de erro do modelo 
O Apêndice $\mathrm{G}$ apresenta os dados da regressão e os coeficientes obtidos, através do modelo de efeitos fixos. As Tabelas 24 e 25 mostram os dados da regressão e os coeficientes obtidos, através do modelo de efeitos aleatórios.

Tabela 24

Sumário do modelo A (efeitos aleatórios)

\begin{tabular}{ll}
\hline Dados & Quantidade/Valor \\
\hline Seção cruzada & 171 unidades \\
Série temporal & Mínimo de 1/ Máximo de 7 \\
"Por dentro" da variância & 0,00344 \\
"Por entre" a variância & 0,00185 \\
Erro padrão & 0,064115 \\
\hline
\end{tabular}

Tabela 25

Coeficientes do modelo A (efeitos aleatórios)

\begin{tabular}{lcccc}
\hline Variáveis & Coeficientes & Erro padrão & t & p-valor \\
\hline$\beta_{0}$ & $-0,008122$ & 0,004318 & $-1,881$ & $0,0605^{*}$ \\
End & 0,00019 & $4,718 \times 10^{-5}$ & 4,035 & $<0,0001^{* * *}$ \\
Rent & $1,0847 \times 10^{-5}$ & $8,089 \times 10^{-6}$ & 1,341 & 0,1805 \\
FCO & 0,011341 & 0,006576 & 1,725 & $0,0851^{*}$ \\
\hline
\end{tabular}

* p-valor $<0,10 ; * * *$ p-valor $<0,01$

Pela Tabela 25, constata-se que apenas endividamento possui coeficiente significante (p-valor < 0,05) (Fávero, 2015; Gujarati, 2006). Desta forma, endividamento é a única variável que influencia de forma direta (coeficiente positivo) a diferença em R\$ entre o FCO divulgado e o FCO encorajado pelo CPC 03, ou seja, quanto maior o endividamento, maior a diferença. Tais resultados apontam que uma situação desfavorável de alto endividamento influencia a divulgação de um FCO maior, em linha com a direção esperada do efeito dessa variável no FCO (vide Tabela 7). O Apêndice F contém as empresas e períodos com as maiores diferenças entre o FCO divulgado e o FCO encorajado pelo CPC, em milhares de reais e divididas pelo ativo total.

Gordon et al. (2013) identificaram rentabilidade e endividamento como variáveis significantes influenciando a diferença entre o FCO divulgado e o valor que seria o FCO seguindo a SFAS 95, a qual indica as mesmas classificações encorajadas pelo CPC 03. A explicação apresentada para a relação direta entre maior rentabilidade e maior FCO divulgado refere-se a um possível reforço da avaliação de rentabilidade da empresa (Silva et al., 2014). Em outras palavras, empresas mais rentáveis podem escolher a classificação que aumente o FCO para refletir um melhor desempenho de fluxo de caixa em linha com o desempenho do resultado contábil (Gordon et al., 2013). Por outro lado, os resultados do estudo de Gordon et 
al. (2013) quanto à variável endividamento mostraram um comportamento conforme era esperado: quanto maior o endividamento, maior a diferença.

Baik et al. (2013) identificaram que firmas coreanas com maior endividamento tendem a mudar a classificação dos juros pagos de FCO para FCF, evidenciando que tal situação é um incentivo para divulgar um melhor FCO. Entretanto, variáveis relacionadas à rentabilidade não foram estatisticamente significantes.

\subsubsection{Modelo B}

Para efetuar a regressão do modelo $\mathrm{B}$, foram considerados apenas os períodos das empresas em que havia divulgação dos juros pagos, resultando na utilização de 234 empresas e 1.141 dados. Vide lista das empresas utilizadas no Apêndice E.

Para avaliar qual dos modelos (efeitos fixos ou efeitos aleatórios) é o mais adequado, foram utilizados dois testes: o multiplicador de Lagrange de Breusch-Pagan (teste LM de Breusch-Pagan) e o teste de Hausman. Seus resultados encontram-se nas Tabelas 26 e 27, respectivamente.

Tabela 26

Teste LM de Breusch-Pagan (modelo B)

\begin{tabular}{l}
\hline Resultados \\
\hline $\mathrm{H}_{0}:$ Variância do erro de unidade-específica $=0$ \\
Qui-quadrado $=1478,38$ \\
p-valor $=0$
\end{tabular}

Tabela 27

Teste de Hausman (modelo B)

\begin{tabular}{l} 
Resultados \\
$\mathrm{H}_{0}:$ As estimativas do modelo de efeitos aleatórios são consistentes \\
Qui-quadrado $=1,73626$ \\
p-valor $=0,628902$ \\
\hline
\end{tabular}

Como a significância (p-valor) do teste de Breusch-Pagan foi inferior a 0,05, concluise que o modelo de efeitos aleatórios é o mais adequado. Esta conclusão é corroborada pelo teste de Hausman, uma vez que o p-valor deste teste $(>0,05)$ não foi significativo.

O modelo B foi estimado conforme a equação abaixo, através do modelo de efeitos fixos e de efeitos aleatórios.

$$
\text { Juros pagos }_{i, t}=\beta_{0}+\beta_{1} \text { End }_{i, t}+\beta_{2} \text { Rent }_{i, t}+\beta_{3} F C O_{i, t}+\varepsilon
$$

Em que: 
Juros pagos $\rightarrow$ Classificação dos juros pagos da empresa $i$ no ano $t$ (dummy, 1 se classificados como FCF e 0 se FCO)

$\beta_{0}=$ Constante

$\beta_{1}, \beta_{2,} \beta_{3}=$ Estimadores

End $=$ Endividamento da empresa $i$ no ano $t$

Rent $=$ Rentabilidade da empresa $i$ no ano $t$

FCO = Fluxo de Caixa Operacional encorajado da empresa $i$ no ano $t$ (dummy, 1 se negativo e 0 se positivo)

$\varepsilon=$ Termo de erro do modelo

O Apêndice $\mathrm{H}$ apresenta os dados da regressão e os coeficientes obtidos, através do modelo de efeitos fixos. As Tabelas 28 e 29 mostram os dados da regressão e os coeficientes obtidos, através do modelo de efeitos aleatórios.

Tabela 28

Sumário do modelo B (efeitos aleatórios)

\begin{tabular}{ll}
\hline Dados & Quantidade/Valor \\
\hline Seção cruzada & 234 unidades \\
Série temporal & Mínimo de 1/ Máximo de 7 \\
"Por dentro" da variância & 0,0527752 \\
"Por entre" a variância & 0,205589 \\
Erro padrão & 0,484090 \\
\hline
\end{tabular}

Tabela 29

Coeficientes do modelo B (efeitos aleatórios)

\begin{tabular}{lcccc}
\hline Variáveis & Coeficientes & Erro padrão & t & p-valor \\
\hline$\beta 0$ & 0,333561 & 0,0365495 & 9,126 & $<0,0001^{* * *}$ \\
End & 0,000916 & 0,0003136 & 2,923 & $0,0035^{* * *}$ \\
Rent & $8,95039 \times 10-6$ & $3,3592 \times 10-5$ & 0,2664 & 0,7899 \\
FCO & 0,0117908 & 0,0235521 & 0,5006 & 0,6167 \\
\hline
\end{tabular}

Nota. $* * *$ p-valor $<0,01$

Pela Tabela 29, constata-se que apenas a variável endividamento possui coeficiente significante ( $\mathrm{p}$-valor $<0,05)$, indicando há uma relação direta entre o endividamento e a classificação dos juros pagos como FCF, o que, por sua vez, gera aumento no FCO divulgado. Assim como no modelo A, o resultado está de acordo com o efeito esperado (Tabela 7).

Gordon et al. (2013) não identificaram variáveis que influenciam a classificação dos juros pagos na DFC na amostra de empresas europeias. Esses resultados estão em linha com o estudo de Silva et al. (2014), que considerou as variáveis endividamento, rentabilidade e FCO negativo no seu modelo de regressão, e tais variáveis não foram significantes na amostra de 
empresas brasileiras. Ambos os estudos utilizaram a classificação de juros pagos como variável dependente. A diferença das proxies do estudo de Silva et al. (2014) para as da presente pesquisa está na utilização do retorno sobre patrimônio líquido como índice de rentabilidade em vez do retorno do ativo, e do FCO divulgado em vez do FCO encorajado. 


\section{CONSIDERAÇÕES FINAIS}

Tendo em vista as opções de classificação na DFC oferecidas pelas normas contábeis brasileiras e internacionais, os preparadores da referida demonstração podem escolher em que atividade apresentar os juros, dividendos e JCP, pagos e recebidos, a fim de refletir a informação mais adequada sobre a realidade da empresa. Além disso, no contexto brasileiro, deverão divulgar as justificativas dessa escolha, caso não sigam a classificação fortemente encorajada pelo CPC 03. Tal flexibilidade prevista em norma permite que uma informação mais fidedigna seja divulgada, uma vez que a apresentação da DFC poderá ser adaptada à realidade de cada empresa, entretanto, abre espaço para comportamentos oportunistas, ao permitir a escolha da classificação que gere a informação mais conveniente, de acordo com os interesses do gestor e/ou da empresa.

A possibilidade de se optar por uma classificação na DFC dentre várias remete aos incentivos que definem a escolha das diferentes classificações na DFC dos juros, dividendos e JCP, pagos e recebidos, pelas empresas do mercado de capitais brasileiro, questão desta pesquisa. Dessa forma, buscou-se identificar incentivos que influenciam a escolha de classificação na DFC, incentivos esses relacionados a características das empresas brasileiras (segmento da indústria, firma de auditoria, endividamento, rentabilidade e se a empresa tem FCO encorajado negativo), sendo o objetivo geral deste estudo.

Com o intuito de responder à questão de pesquisa e atingir o objetivo geral, foram desenvolvidas quatro etapas e respectivas hipóteses, relacionadas às empresas não financeiras do mercado de capitais brasileiro. Utilizou-se de uma amostra final de 352 empresas, 2.290 demonstrações financeiras anuais, que continham o relatório dos auditores independentes e a DFC, e 3.764 dados sobre juros e dividendos/JCP, pagos e recebidos, referentes ao período de 2008 a 2014.

A seguir estão apresentadas as evidências alcançadas para cada etapa e sua(s) respectiva(s) hipótese(s) e, na sequência, as implicações do estudo e as limitações da pesquisa.

A primeira etapa da pesquisa consistiu em verificar se as classificações encorajadas pelo CPC 03 estavam sendo seguidas, através do agrupamento das empresas de acordo com as OCDFC adotadas. Para isso, criou-se a primeira hipótese $\left(\mathrm{H}_{1}\right)$ : A maior parte das empresas brasileiras segue as classificações encorajadas pelo CPC 03, parágrafo 34A. Verificou-se que apenas dividendos/JCP recebidos não foram classificados pela maioria das empresas conforme o encorajamento do CPC 03, assim rejeitou-se a hipótese quanto a esse item. 
$\mathrm{Na}$ segunda etapa, procurou-se identificar fatores em comum (segmento e auditoria) nas empresas que adotam as mesmas opções de classificação.

Assim, criou-se a hipótese $\mathrm{H}_{2}$.a: Empresas do mesmo setor tendem a utilizar as mesmas classificações dos itens que possuem flexibilidade de apresentação na DFC. Foi possível identificar que alguns segmentos seguiram uma classificação predominante em todos ou parte dos itens que possuem flexibilidade de apresentação na DFC. Os setores "Máquinas Industriais" e "Têxtil" foram os únicos que seguiram uma classificação predominante em todos os itens com OCDFC. Para os itens juros recebidos e dividendos pagos, confirmou-se a predominância de classificação por parte de todos os setores em alguma atividade da DFC, mesmo não sendo a encorajada pelo CPC 03. Todavia, os juros pagos e os dividendos recebidos tiveram uma classificação predominante em apenas alguns segmentos. Dessa forma, a hipótese de relação entre setor e classificação conforme encorajamento do CPC não foi rejeitada para os setores "Máquinas Industriais" e "Têxtil", e foi rejeitada para os itens juros pagos e dividendos recebidos, uma vez que apenas parte dos setores seguiu uma classificação predominante.

Similarmente, criou-se a hipótese $\mathrm{H}_{2}$.b: Empresas que possuem os mesmos auditores tendem a utilizar as mesmas classificações dos itens que possuem flexibilidade de apresentação na DFC. Os resultados mostraram que algumas firmas de auditoria seguiram certas classificações de forma predominante. Apenas os dividendos pagos foram classificados de forma predominante como FCF por todas as Big Four, item que tem uma classificação praticamente padronizada no mercado de capitais brasileiro. Assim, a hipótese de relação entre auditor e classificação conforme encorajamento do CPC foi rejeitada para a firma de auditoria EY, que não teve predominância de classificação para todos os itens suscetíveis à flexibilidade.

A terceira etapa objetivou identificar as mudanças de classificação dos juros pagos de um período para o outro e verificar se há relação com a troca de auditor e, para isso, elaborouse a hipótese $\mathrm{H}_{3}$ : Mudanças de classificação de juros pagos ocorrem em função da mudança de auditor. Foi verificado que as mudanças identificadas ocorreram mesmo quando não houve troca de auditor, assim, rejeitou-se a hipótese de que a mudança de classificação está relacionada com a alteração de auditor.

Por fim, a quarta e última etapa pretendeu analisar a correlação entre o efeito no FCO da opção adotada e características das empresas (endividamento, rentabilidade e FCO encorajado negativo). Para isso, elaborou-se três hipóteses: 
H4.a: Empresas com elevado grau de endividamento tendem a escolher a classificação que aumente o FCO.

$H_{4 . b}$ : Empresas com menor rentabilidade tendem a escolher a classificação que aumente o FCO.

H.c: Empresas com FCO negativo de acordo com o encorajamento do CPC 03 tendem a escolher a classificação que aumente o FCO.

Os resultados das regressões mostraram que o endividamento influencia a diferença entre o FCO divulgado e o valor que seria o FCO ao seguir as opções encorajadas pelo CPC 03, bem como a classificação de juros pagos como FCF. Identificou-se que quanto maior o endividamento, maior a diferença, ou seja, maior o valor do FCO divulgado em relação ao FCO encorajado pelo CPC 03; e que, há uma relação direta (coeficiente positivo) entre o endividamento e a classificação de juros pagos como FCF. Esse comportamento pode indicar que empresas com situação financeira desfavorável tendem a escolher a classificação que aumente o FCO. Dessa forma, a hipótese $\mathrm{H}_{4}$.a não pode ser rejeitada. Quanto às hipóteses $\mathrm{H}_{4}$.b e $\mathrm{H}_{4}$.c, ambas foram rejeitadas, uma vez que as variáveis rentabilidade e FCO encorajado não foram significantes nos resultados das regressões.

De uma forma geral, foram identificados incentivos relacionados às características das empresas do mercado de capitais brasileiro que influenciam as escolhas de classificação na DFC, seja por fazerem parte de um determinado segmento, por serem auditadas pela mesma firma de auditoria ou pela situação financeira das mesmas.

Os resultados do presente estudo apresentam contribuições, tanto para consolidação de teorias, quanto para aperfeiçoamento da prática contábil, uma vez que existe uma complementariedade entre teoria e prática, fazendo com que o conhecimento se amplie e os procedimentos sejam aperfeiçoados.

A contribuição relacionada à teoria das escolhas contábeis envolve a identificação de evidências e indícios no cenário brasileiro de incentivos que direcionam a escolha de classificações na DFC. Incentivos esses relacionados à situação financeira, segmento a que a empresa pertence e a firma de auditoria que foi contratada.

No âmbito dos usuários das demonstrações financeiras, conhecer as escolhas e fatores relacionados à classificação dos juros e dividendos na DFC é um auxílio para que a correta análise dessa demonstração, e das demais em conjunto, seja efetuada. No caso de investidores e credores, conscientes do uso dessa discricionariedade e dos incentivos que podem afetar o FCO, os mesmos podem utilizar a medida adequada de FCO para estimar os fluxos de caixa futuros, seja para fins de avaliação de empresas ou análises financeiras. 
O entendimento da discricionariedade envolvida na DFC, além de permitir uma comparação adequada entre empresas, possibilita o alinhamento da mensuração do FCO para que a consequente mensuração das accruals seja efetuada corretamente, para fins de determinação do nível de gerenciamento de resultados.

Outra implicação desse estudo refere-se à sua relevância para normatizadores, os quais podem emitir e/ou revisar normas contábeis em função das escolhas que as empresas brasileiras têm efetuado, no âmbito da DFC, e o impacto das mesmas. Adicionalmente, este trabalho possibilita o entendimento acerca da recomendação adicional do $\mathrm{CPC}$ em relação às IFRS, na tentativa de padronizar a apresentação da DFC, assim como ocorre nos USGAAP. Cientes desse cenário, os normatizadores poderão avaliar até que ponto é benéfico permitir ou não a flexibilidade de classificação na DFC.

Apesar das diversas contribuições, a presente pesquisa tem algumas limitações. O propósito de se padronizar a DFC, dentre outros aspectos, é aumentar o seu grau de comparabilidade entre as empresas, em detrimento a um maior poder informativo que a escolha da classificação mais adequada resultaria.

A Estrutura Conceitual CPC 00 indica a comparabilidade como característica qualitativa de melhoria da informação contábil-financeira e altamente desejável. Lemes, Santos, e Rodrigues (2013) avaliaram o nível de comparabilidade do resultado e do patrimônio líquido de empresas financeiras do mercado de capitais brasileiro, algo que não foi efetuado para a DFC pela presente pesquisa. Além de não ter avaliado o nível de comparabilidade da DFC, o presente estudo também não envolveu a análise dos custos e benefícios dessa característica qualitativa, os quais foram abordados por De Franco, Kothari, e Verdi (2011).

Uma outra característica relacionada à comparabilidade refere-se à consistência da informação divulgada. A Estrutura Conceitual CPC 00 esclarece que a consistência trata-se do uso dos mesmos métodos para os mesmos itens e que auxilia a alcançar o objetivo da comparabilidade. Dessa forma, não deveria haver variabilidade das classificações de um período para o outro sem uma mudança de cenário que a justificasse. Essa variabilidade restrita em função da exigência normativa pode limitar o uso das regressões. De qualquer forma, mesmo com pouca variabilidade pode-se ter um comportamento contínuo da classificação em virtude da situação da empresa, algo identificado nessa pesquisa no que se refere à característica de endividamento, conforme apresentado nos resultados.

Telles e Salotti (2015) mencionam o desafio de se dimensionar a qualidade e a quantidade de informações que possam atender as necessidades dos usuários das 
demonstrações financeiras. De forma semelhante, pode existir uma relação entre quantidade de escolhas contábeis e qualidade da informação, algo que não foi abordado pela presente pesquisa.

Por fim, quando se menciona a utilização da flexibilidade de classificação na DFC como subsídio para um possível comportamento oportunista, trata-se da busca por evidências de, por exemplo, uma situação específica, como o nível de endividamento, fator identificado neste estudo, ou a influência de certas características (setor e auditoria). Todavia, não é possível afirmar que, em todos os casos com tais evidências identificadas, a liberdade de escolha foi utilizada para gerar a informação mais conveniente. Essa impossibilidade ocorre uma vez que pode haver situações de empresas que classificam os itens na DFC da forma considerada como a mais correta no seu ponto de vista, independentemente do cenário econômico-financeiro em que se encontra, ou podem existir outros incentivos que influenciam a referida escolha não explorados nesta pesquisa. 


\section{REFERÊNCIAS}

Ahmed, A. S., Kilic, E., \& Lobo, G. J. (2006). Does recognition versus disclosure matter? Evidence from value-relevance of banks' recognized and disclosed derivative financial instruments. The Accounting Review, 81(3), 567-588.

Al Jifri, K., \& Citron, D. (2009). The value-relevance of financial statement recognition versus note disclosure: Evidence from goodwill accounting. European Accounting Review, 18(1), 123-140.

Baik, B., Cho, H., Choi, W., \& Lee, K. (2013). Who Classify Interest Payments as Financing Activities? An Analysis of Classification Shifting in the Statement of Cash Flows at the Adoption of IFRS. Anais do Instituto de Contabilidade da Coréia, (chamada única), 1106-1136.

Beaver, W. H. (1973). What shoud be the FASB's objectives? Journal of Accountancy, $136(2), 49$.

Bonner, S. E. (2007). Judgement and Decision Making in Accounting. New Jersey: Prentice Hall.

Braga, R., \& Marques, J. A. V. da C. (2001). Avaliação da liquidez das empresas através da análise da demonstração de fluxos de caixa. Revista Contabilidade \& Finanças, $12(25), 6-23$.

Burgstahler, D., \& Dichev, I. (1997). Earnings management to avoid earnings decreases and losses. Journal of Accounting and Economics, 24(1), 99-126.

Cabello, O. G. (2012). Análise dos efeitos das práticas de tributação do lucro na Effective Tax Rate (ETR) das companhias abertas brasileiras: uma abordagem da teoria das escolhas contábeis (Tese de doutorado, Universidade de São Paulo, São Paulo, Brasil). Recuperado de http://www.teses.usp.br/teses/disponiveis/12/12136/tde-14022013161843/pt-br.php

Cahan, S. F., Courtenay, S. M., Gronnewoller, P. L., \& Upton, D. R. (2000). Value relevance of mandated comprehensive income disclosures. Journal of Business Finance \& Accounting, 27(9-10), 1233-1265.

Cardoso, R. L. (2005). Regulação econômica e escolhas de práticas contábeis: Evidências no mercado de saúde suplementar brasileiro (Tese de doutorado, Universidade de São Paulo, São Paulo, Brasil). Recuperado de http://www.teses.usp.br/teses/disponiveis/12/12136/tde-18122008-121952/pt-br.php

Cotter, J., \& Zimmer, I. (2003). Disclosure versus recognition: The case of asset revaluations. Asia-Pacific Journal of Accounting \& Economics, 10(1), 81-99.

CPC-00 (R1). (2011). Estrutura Conceitual para Elaboração e Divulgação do Relatório Contábil-Financeiro. Brasília: CPC. Recuperado de:

http://www.cpc.org.br/CPC/Documentos-Emitidos/Pronunciamentos/Pronunciamento ?Id $=80$ 
CPC-03 (R2). (2010). Demonstração dos Fluxos de Caixa. Brasília: CPC. Recuperado de: http://www.cpc.org.br/CPC/Documentos-Emitidos/Pronunciamentos/Pronunciamento? $\mathrm{Id}=34$.

Damodaran, A. (2006). Damodaran on Valuation: Security Analysis for Investment and Corporate Finance (2nd ed.). New Jersey: Wiley.

Davis-Friday, P. Y., Folami, L. B., Liu, C.-S., \& Mittelstaedt, H. F. (1999). The value relevance of financial statement recognition vs. disclosure: Evidence from SFAS No. 106. The Accounting Review, 74(4), 403-423.

De Franco, G., Kothari, S. P., \& Verdi, R. S. (2011). The benefits of financial statement comparability. Journal of Accounting Research, 49(4), 895-931.

Dichev, I. D., \& Skinner, D. J. (2002). Large-sample evidence on the debt covenant hypothesis. Journal of Accounting Research, 40(4), 1091-1123.

Duarte, P. C., Lamounier, W. M., \& Takamatsu, R. T. (2007). Modelos econométricos para dados em painel: Aspectos teóricos e exemplos de aplicação à pesquisa em contabilidade e finanças. Artigo apresentado no $7^{\circ}$ Congresso USP de Controladoria e Contabilidade, São Paulo, Brasil.

Espahbodi, H., Espahbodi, P., Rezaee, Z., \& Tehranian, H. (2002). Stock price reaction and value relevance of recognition versus disclosure: The case of stock-based compensation. Journal of Accounting and Economics, 33(3), 343-373.

Estridge, J., \& Lougee, B. (2007). Measuring Free Cash Flows for Equity Valuation: Pitfalls and Possible Solutions. Journal of Applied Corporate Finance, 19(2), 60-71.

Fávero, L. P. L. (2015). Análise de Dados: Modelos de Regressão com Excel®, Stata®e SPSS®. Rio de Janeiro: Campus/Elsevier.

Fields, T. D., Lys, T. Z., \& Vincent, L. (2001). Empirical research on accounting choice. Journal of Accounting and Economics, 31(1), 255-307.

Francis, J. (2001). Discussion of empirical research on accounting choice. Journal of Accounting and Economics, 31(1), 309-319.

Goncharov, I., \& Zimmermann, J. (2006). Do accounting standards influence the level of earnings management? Evidence from Germany. Recuperado em 25 de junho de 2015, de http://ssrn.com/abstract=386521

Gordon, E. A., Henry, E., Jorgensen, B., \& Linthicum, C. L. (2013). Flexibility in cash flow reporting classification choices under IFRS. Recuperado em 25 de junho de 2015, de http://ssrn.com/abstract=2439383

Gujarati, D. N. (2006). Econometria básica. Rio de Janeiro: Elsevier.

Hendriksen, E. S., \& Breda, M. F. V. (1999). Teoria da contabilidade. São Paulo: Atlas. 
Holthausen, R. W. (1990). Accounting method choice: Opportunistic behavior, efficient contracting, and information perspectives. Journal of Accounting and Economics, 12(1), 207-218.

Holthausen, R. W., \& Leftwich, R. W. (1983). The economic consequences of accounting choice implications of costly contracting and monitoring. Journal of Accounting and Economics, 5, 77-117.

Jamal, K., \& Tan, H.-T. (2010). Joint effects of principles-based versus rules-based standards and auditor type in constraining financial managers' aggressive reporting. The Accounting Review, 85(4), 1325-1346.

Lee, L. F. (2012). Incentives to inflate reported cash from operations using classification and timing. The Accounting Review, 87(1), 1-33.

Lemes, S., Santos, L. A. A., \& Rodrigues, N. A. (2013). Financial Statement Comparability: Empirical Evidence From Brazil. Journal of Modern Accounting and Auditing, 9(5), 587-601.

Leuz, C., Nanda, D., \& Wysocki, P. D. (2003). Earnings management and investor protection: an international comparison. Journal of Financial Economics, 69(3), 505-527.

Lima, G. A. S. F. (2007). Utilização da teoria da divulgação para avaliação da relação do nível de disclosure com o custo da dívida das empresas brasileiras (Tese de doutorado, Universidade de São Paulo, São Paulo, Brasil). Recuperado de http://www.teses.usp.br/teses/disponiveis/12/12136/tde-26112007-165145/pt-br.php

Lopes, A. I., Lourenço, I., \& Soliman, M. (2013). Do alternative methods of reporting noncontrolling interests really matter? Australian Journal of Management, 38(1), 7-30.

Lorencini, F. D., \& Costa, F. M. (2012). Escolhas contábeis no Brasil: Identificação das características das companhias que optaram pela manutenção versus baixa dos saldos do ativo diferido. Revista Contabilidade \& Finanças, 23(58), 52-64.

Lustosa, P. R. B., \& Santos, A. (2006). Importância relativa do ajuste no fluxo de caixa das operações para o mercado de capitais brasileiro. Artigo apresentado no $6^{\circ}$ Congresso USP de Controladoria e Contabilidade, São Paulo, Brasil.

Marques, L. D. (2000). Modelos dinâmicos com dados em painel: Revisão de literatura. Recuperado de http://www.fep.up.pt/investigacao/workingpapers/wp100.PDF

Martínez, J. A., Martínez, F. G., \& Diazaraque, J. M. M. (2011). Optional accounting criteria under IFRSs and corporate characteristics: evidence from spain. Revista de Contabilidad, 14(1), 59-85.

Martins, E., Gelbcke, E. R., Santos, A., \& Iudícibus, S. (2013). Manual de Contabilidade Societária: Aplicável a todas as Sociedades (2nd ed.). São Paulo: Atlas.

McVay, S. E. (2006). Earnings management using classification shifting: An examination of core earnings and special items. The Accounting Review, 81(3), 501-531. 
Missonier-Piera, F. (2004). Economic determinants of multiple accounting method choices in a Swiss context. Journal of International Financial Management \& Accounting, 15(2), $118-144$.

Murcia, F. D.-R., Souza, M. M. de, Wuergues, A. F. E., \& Duarte, G. (2013). Realização ou estorno da reserva de reavaliação: Fatores determinantes da escolha das companhias abertas no Brasil após o advento da Lei 11.638/07. Advances in Scientific and Applied Accounting, 6(1), 112-133.

Niu, F., \& Xu, B. (2009). Does recognition versus disclosure really matter? Evidence from the market valuation of recognition of employee stock option expenses. Asia-Pacific Journal of Accounting \& Economics, 16(2), 215-233.

Nobes, C. W. (2005). Rules-based standards and the lack of principles in accounting. Accounting Horizons, 19(1), 25-34.

Quagli, A., \& Avallone, F. (2010). Fair value or cost model? Drivers of choice for IAS 40 in the real estate industry. European Accounting Review, 19(3), 461-493.

Salotti, B. M., \& Yamamoto, M. M. (2008). Divulgação voluntária da demonstração dos fluxos de caixa no mercado de capitais brasileiro. Revista Contabilidade \& Finanças, $48,37-49$.

Scherer, L. M., Teodoro, J. D., Anjos, R. P., \& Kos, S. R. (2012). Demonstração dos fluxos de caixa: Análise de diferenças de procedimentos de divulgação entre empresas listadas nas bolsas de valores de São Paulo, Frankfurt, Milão e Londres. Revista Contabilidade e Controladoria, 4(2), 37-51.

Scott, W. R. (2014). Financial accounting theory (7th ed.). Toronto: Pearson Education.

Silva, D. M., Martins, V. A., \& Lima, F. G. (2014). Escolhas Contábeis na Evidenciação da Demonstração dos Fluxos de Caixa. Artigo apresentado no $37^{\circ}$ Encontro da ANPAD, Rio de Janeiro, Brasil. Recuperado de http://www.anpad.org.br/admin/pdf/2014_EnANPAD_CON1524.pdf

Smith, M. (2011). Research methods in accounting (2nd ed.). London: Sage.

So, S., \& Smith, M. (2009). Value Relevance of IAS 27 (2003) Revision on Presentation of Non-Controlling Interest: Evidence From Hong Kong. Journal of International Financial Management \& Accounting, 20(2), 166-198.

Telles, S. V., \& Salotti, B. M. (2015). Divulgação da informação contábil sobre depreciação: O antes e o depois da adoção das IFRS. Revista Universo Contábil, 11(2), 153-173.

Watts, R. L. (1992). Accounting choice theory and market-based research in accounting. The British Accounting Review, 24(3), 235-267.

Watts, R. L., \& Zimmerman, J. L. (1986). Positive accounting theory. New Jersey: PrenticeHall Inc.

Watts, R. L., \& Zimmerman, J. L. (1990). Positive accounting theory: a ten year perspective. Accounting Review, 65(1), 131-156. 


\section{APÊNDICES}

\section{APÊNDICE A - Lista de empresas selecionadas}

\begin{tabular}{|c|c|c|c|c|}
\hline \multicolumn{5}{|c|}{ Empresas selecionadas para o estudo } \\
\hline Abril Educa & Cemat & Fras-Le & Mendes Jr & Sao Carlos \\
\hline Aco Altona & Cemepe & Futuretel & Menezes Cort & Sao Martinho \\
\hline AES Elpa & Cemig & Gafisa & Met Duque & Saraiva Livr \\
\hline AES Tiete & Cesp & Gama Part & Metal Iguacu & Sauipe \\
\hline Afluente & Chiarelli & Generalshopp & Metal Leve & Schlosser \\
\hline Afluente $\mathrm{T}$ & Cia Hering & Ger Paranap & Metalfrio & Schulz \\
\hline AGconcessoes & Cielo & Gerdau & Metisa & Selectpart \\
\hline Agpart & Cims & Gerdau Met & Millennium & Senior Sol \\
\hline Alef S/A & Cobrasma & Gol & Mills & Ser Educa \\
\hline Alfa Consorc & Coelba & GPC Part & Minasmaquinas & Sid Nacional \\
\hline Alfa Holding & Coelce & Grazziotin & Minerva & Sierrabrasil \\
\hline Aliansce & Comgas & Grendene & Minupar & SLC Agricola \\
\hline Aliperti & Conc Rio Ter & Grucai & MMX Miner & Smiles \\
\hline All Amer Lat & Const A Lind & Guararapes & Mont Aranha & Sondotecnica \\
\hline All Norte & Const Beter & Habitasul & Mrs Logist & Souza Cruz \\
\hline All Ore & Contax & Haga SA & MRV & Springer \\
\hline Allis Part & Copasa & Harpia Part & Multiplan & Springs \\
\hline Alpargatas & Copel & Helbor & Multiplus & SPturis \\
\hline Altus S/A & Cor Ribeiro & Hercules & Mundial & Sudeste \\
\hline Alupar & Cosan & Hoteis Othon & Nadir Figuei & Sul 116 Part \\
\hline Ambev S/A & Cosan Log & Hrt Petroleo & Natura & Sultepa \\
\hline Ampla Energ & Cosern & Hypermarcas & Neoenergia & Suzano Hold \\
\hline Anima & Coteminas & Ideiasnet & Net & Suzano Papel \\
\hline Arezzo Co & CPFL Energia & IGB SA & Newtel Part & Taesa \\
\hline Arteris & CPFL Renovav & Iguatemi & Nordon Met & Tec Blumenau \\
\hline Azevedo & $\mathrm{Cr} 2$ & Imc Holdings & Nortcquimica & Tecel S Jose \\
\hline B2W Digital & Cremer & Ind Cataguas & Nova Oleo & Technos \\
\hline Bahema & Csu Cardsyst & Inds Romi & Nutriplant & Tecnisa \\
\hline Bardella & Cvc Brasil & Inepar & Oderich & Tecnosolo \\
\hline Battistella & Cyre Com-Ccp & Inepar Tel & Odontoprev & Tectoy \\
\hline Baumer & Cyrela Realt & Invepar & OGX Petroleo & Tegma \\
\hline Belapart & Daleth Part & Invest Bemge & Oi & Teka \\
\hline Bematech & Dasa & Iochp-Maxion & Opport Energ & Tekno \\
\hline BHG & Desenvix & Itaitinga & OSX Brasil & Telebras \\
\hline Bic Monark & DHB & Itausa & Ourofino SA & Telef Brasil \\
\hline Biomm & Dimed & Itautec & P.Acucar-Cbd & Telinvest \\
\hline Biosev & Direcional & J B Duarte & Panatlantica & Tempo Part \\
\hline Bombril & Doc Imbituba & JBS & Par Al Bahia & Tereos \\
\hline Bonaire Part & Dohler & Jereissati & Paranapanema & Tex Renaux \\
\hline BR Brokers & Dommo Empr & JHSF Part & PDG Realt & Tim Part S/A \\
\hline BR Malls Par & Dtcom Direct & Joao Fortes & Pet Manguinh & Time For Fun \\
\hline BR Pharma & Duratex & Josapar & Petrobras & Totvs \\
\hline BR Propert & Ecorodovias & JSL & Pettenati & Tractebel \\
\hline Bradespar & Elekeiroz & Karsten & Plascar Part & Tran Paulist \\
\hline Brasilagro & Elektro & Kepler Weber & Polpar & Trevisa \\
\hline Braskem & Eletrobras & Klabin SA & Portobello & Trisul \\
\hline Brasmotor & Eletron & Kroton & Positivo Inf & Triunfo Part \\
\hline BRF SA & Eletropar & La Fonte Tel & Pq Hopi Hari & Tupy \\
\hline Brookfield & Eletropaulo & Le Lis Blanc & Profarma & Ultrapar \\
\hline Buettner & Emae & Light SA & Prompt & Unicasa \\
\hline
\end{tabular}


(Continuação)

\begin{tabular}{ccccc}
\hline & \multicolumn{2}{c}{ Empresas selecionadas para o estudo } & Unipar \\
\hline Cabambiental & Embraer & Linx & Providencia & Untick \\
Cabinda Part & Embratel Part & Litel & Prumo & Usiminas \\
Cacique & Encorpar & Lix da Cunha & Qgep Part & Qualicorp \\
Caconde Part & Energias BR & Localiza & V-Agro \\
Caianda Part & Energisa & Locamerica & Quality Soft & Vale \\
Cambuci & Eneva & Log-In & RaiaDrogasil & Valetron \\
Capitalpart & Equatorial & Lojas Americ & Randon Part & Valid \\
Casan & Estacio Part & Lojas Hering & Recrusul & Viavarejo \\
CCR SA & Estrela & Lojas Marisa & Rede Energia & Vigor Food \\
Ccx Carvao & Eternit & Lojas Renner & Redentor & Viver \\
Ceb & Eucatex & Longdis & Renar & Vulcabras \\
Cedro & Even & Lopes Brasil & Renova & Weg \\
Ceee-D & Evora & Lupatech & Ret Part & Wembley \\
Ceee-Gt & Excelsior & M.Diasbranco & Riosulense & Wetzel S/A \\
Ceg & Eztec & Magaz Luiza & Rodobensimob & Whirlpool \\
Celesc & Fer Heringer & Magnesita SA & Rossi Resid & Wlm Ind Com \\
Celgpar & Ferbasa & Mangels Indl & Sabesp & Zain Part \\
Celpa & Fibam & Maori & Sanepar & \\
Celpe & Fibria & Marcopolo & Sansuy & \\
Celul Irani & Fleury & Marfrig & Santanense & \\
Cemar & Forja Taurus & Melhor SP & Santos Brp & \\
& & & &
\end{tabular}


APÊNDICE B - Classificação conforme CPC 03, parágrafo 34A (por atividade na DFC, setor e ano)

\begin{tabular}{lcccccccccc}
\hline & \multicolumn{7}{c}{ JUROS PAGOS - FCO } & & & \\
\cline { 2 - 10 } & $\mathbf{2 0 0 8}$ & $\mathbf{2 0 0 9}$ & $\mathbf{2 0 1 0}$ & $\mathbf{2 0 1 1}$ & $\mathbf{2 0 1 2}$ & $\mathbf{2 0 1 3}$ & $\mathbf{2 0 1 4}$ & $\begin{array}{c}\text { Total } \\
\text { FCO }\end{array}$ & $\begin{array}{c}\text { Total } \\
\text { Geral }\end{array}$ \\
\hline Agro e Pesca & & & & & 1 & 1 & 1 & 3 & $100 \%$ & 3 \\
Alimentos e Bebidas & 1 & 1 & 4 & 4 & 5 & 4 & 4 & 23 & $72 \%$ & 32 \\
Comércio & & 2 & 5 & 5 & 5 & 5 & 4 & 26 & $45 \%$ & 58 \\
Construção & 2 & 4 & 7 & 6 & 9 & 11 & 12 & 51 & $64 \%$ & 80 \\
Eletroeletrônicos & & 1 & 1 & 1 & 2 & 2 & 2 & 9 & $50 \%$ & 18 \\
Energia Elétrica & 11 & 13 & 21 & 26 & 28 & 28 & 26 & 153 & $77 \%$ & 200 \\
Máquinas Industriais & 1 & & & & & & & 1 & $5 \%$ & 22 \\
Mineração & & 1 & 1 & 2 & & 1 & & 5 & $26 \%$ & 19 \\
Minerais não Metais & & & 2 & 2 & 2 & 2 & 2 & 10 & $77 \%$ & 13 \\
Papel e Celulose & 3 & 4 & 4 & 4 & 4 & 4 & 4 & 27 & $100 \%$ & 27 \\
Petróleo e Gás & 1 & 1 & 2 & 2 & 3 & 3 & 3 & 15 & $50 \%$ & 30 \\
Química & 3 & 3 & 3 & 4 & 4 & 4 & 5 & 26 & $57 \%$ & 46 \\
Siderurgia e Metalurgia & 6 & 7 & 8 & 8 & 6 & 6 & 6 & 47 & $60 \%$ & 78 \\
Software e Dados & 1 & 1 & 1 & 1 & 2 & 2 & 2 & 10 & $71 \%$ & 14 \\
Telecomunicações & 2 & 2 & 3 & 3 & 3 & 2 & 1 & 16 & $59 \%$ & 27 \\
Têxtil & 8 & 10 & 11 & 10 & 11 & 11 & 12 & 73 & $74 \%$ & 99 \\
Transporte - Serviços & 2 & 3 & 5 & 6 & 5 & 4 & 4 & 29 & $46 \%$ & 63 \\
Veículos e Peças & 2 & 3 & 4 & 4 & 5 & 6 & 6 & 30 & $45 \%$ & 66 \\
Outros & 10 & 14 & 19 & 24 & 24 & 29 & 29 & 149 & $60 \%$ & 250 \\
\hline Total & $\mathbf{5 3}$ & $\mathbf{7 0}$ & $\mathbf{1 0 1}$ & $\mathbf{1 1 2}$ & $\mathbf{1 1 9}$ & $\mathbf{1 2 5}$ & $\mathbf{1 2 3}$ & $\mathbf{7 0 3}$ & $\mathbf{6 1 \%}$ & $\mathbf{1 . 1 4 5}$ \\
\hline \% & $\mathbf{5 6 \%}$ & $\mathbf{6 0 \%}$ & $\mathbf{6 2 \%}$ & $\mathbf{6 3 \%}$ & $\mathbf{6 1 \%}$ & $\mathbf{6 3 \%}$ & $\mathbf{6 1 \%}$ & $\mathbf{6 1 \%}$ & & \\
\hline Dados Totais & $\mathbf{9 4}$ & $\mathbf{1 1 7}$ & $\mathbf{1 6 2}$ & $\mathbf{1 7 7}$ & $\mathbf{1 9 4}$ & $\mathbf{2 0 0}$ & $\mathbf{2 0 1}$ & $\mathbf{1 . 1 4 5}$ & & \\
\hline & & & & & & & & & & \\
\hline
\end{tabular}

\begin{tabular}{|c|c|c|c|c|c|c|c|c|c|c|}
\hline \multicolumn{11}{|c|}{ JUROS RECEBIDOS - FCO } \\
\hline & 2008 & 2009 & 2010 & 2011 & 2012 & 2013 & 2014 & $\begin{array}{l}\text { Total } \\
\text { FCO }\end{array}$ & $\%$ & $\begin{array}{l}\text { Total } \\
\text { Geral }\end{array}$ \\
\hline Agro e Pesca & 1 & 1 & & & 1 & 1 & 1 & 5 & $100 \%$ & 5 \\
\hline Alimentos e Bebidas & & & & & 1 & 1 & 1 & 3 & $100 \%$ & 3 \\
\hline Comércio & & & & & & & & - & $0 \%$ & 6 \\
\hline Construção & & 2 & 2 & 3 & 3 & 3 & 3 & 16 & $80 \%$ & 20 \\
\hline Eletroeletrônicos & & & & 1 & 1 & 1 & & 3 & $100 \%$ & 3 \\
\hline Energia Elétrica & & 1 & 1 & 1 & & & & 3 & $100 \%$ & 3 \\
\hline Máquinas Industriais & & 1 & 1 & 1 & 1 & 1 & 1 & 6 & $100 \%$ & 6 \\
\hline Mineração & 1 & & 1 & 1 & 1 & 2 & 1 & 7 & $100 \%$ & 7 \\
\hline Minerais não Metais & 1 & 1 & 1 & 1 & 1 & & & 5 & $100 \%$ & 5 \\
\hline Papel e Celulose & 1 & 3 & 1 & & & & & 5 & $83 \%$ & 6 \\
\hline Petróleo e Gás & & & & & & & & - & $0 \%$ & 1 \\
\hline Química & & & 1 & 1 & & & & 2 & $22 \%$ & 9 \\
\hline Siderurgia e Metalurgia & & & $\underline{1}$ & $\underline{1}$ & $\underline{1}$ & $\underline{1}$ & $\underline{1}$ & $\underline{5}$ & $22 \%$ & $\underline{23}$ \\
\hline
\end{tabular}


(Continuação)

\begin{tabular}{lcccccccccc}
\hline & \multicolumn{7}{c}{ JUROS RECEBIDOS - FCO } \\
\cline { 2 - 11 } & $\mathbf{2 0 0 8}$ & $\mathbf{2 0 0 9}$ & $\mathbf{2 0 1 0}$ & $\mathbf{2 0 1 1}$ & $\mathbf{2 0 1 2}$ & $\mathbf{2 0 1 3}$ & $\mathbf{2 0 1 4}$ & $\begin{array}{c}\text { Total } \\
\text { FCO }\end{array}$ & $\begin{array}{c}\text { \% } \\
\text { Total } \\
\text { Geral }\end{array}$ \\
\hline Software e Dados & $\mathbf{4}$ & $\mathbf{9}$ & $\mathbf{9}$ & $\mathbf{1 0}$ & $\mathbf{1 0}$ & $\mathbf{1 0}$ & $\mathbf{8}$ & $\mathbf{6 0}$ & $62 \%$ & $\mathbf{9 7}$ \\
Telecomunicações & $44 \%$ & $69 \%$ & $60 \%$ & $63 \%$ & $63 \%$ & $67 \%$ & $62 \%$ & $62 \%$ & & \\
Têxtil & $\mathbf{9}$ & $\mathbf{1 3}$ & $\mathbf{1 5}$ & $\mathbf{1 6}$ & $\mathbf{1 6}$ & $\mathbf{1 5}$ & $\mathbf{1 3}$ & $\mathbf{9 7}$ & & \\
Transporte- Serviços & 1 & 1 & & & 1 & 1 & 1 & 5 & $100 \%$ & 5 \\
Veículos e Peças & & & & & 1 & 1 & 1 & 3 & $100 \%$ & 3 \\
Outros & & & & & & & & - & $0 \%$ & 6 \\
\hline Total & & $\mathbf{2}$ & $\mathbf{2}$ & $\mathbf{3}$ & $\mathbf{3}$ & $\mathbf{3}$ & $\mathbf{3}$ & $\mathbf{1 6}$ & $\mathbf{8 0 \%}$ & $\mathbf{2 0}$ \\
\hline \% & & & & $\mathbf{1}$ & $\mathbf{1}$ & $\mathbf{1}$ & & $\mathbf{3}$ & $\mathbf{1 0 0 \%}$ & $\mathbf{3}$ \\
\hline Dados Totais & & $\mathbf{1}$ & $\mathbf{1}$ & $\mathbf{1}$ & & & & $\mathbf{3}$ & $\mathbf{1 0 0 \%}$ & $\mathbf{3}$ \\
\hline
\end{tabular}

\begin{tabular}{|c|c|c|c|c|c|c|c|c|c|c|}
\hline \multicolumn{11}{|c|}{ DIVIDENDOS PAGOS - FCF } \\
\hline & 2008 & 2009 & 2010 & 2011 & 2012 & 2013 & 2014 & $\begin{array}{l}\text { Total } \\
\text { FCO }\end{array}$ & $\%$ & $\begin{array}{l}\text { Total } \\
\text { Geral }\end{array}$ \\
\hline Agro e Pesca & 1 & 1 & 1 & 1 & 1 & 1 & 1 & 7 & $100 \%$ & 7 \\
\hline Alimentos e Bebidas & 8 & 6 & 7 & 6 & 7 & 9 & 9 & 52 & $100 \%$ & 52 \\
\hline Comércio & 13 & 12 & 14 & 13 & 14 & 15 & 13 & 94 & $99 \%$ & 95 \\
\hline Construção & 12 & 14 & 15 & 17 & 16 & 16 & 14 & 104 & $99 \%$ & 105 \\
\hline Eletroeletrônicos & 5 & 5 & 5 & 4 & 4 & 4 & 4 & 31 & $84 \%$ & 37 \\
\hline Energia Elétrica & 29 & 31 & 35 & 38 & 38 & 35 & 37 & 243 & $97 \%$ & 251 \\
\hline Máquinas Industriais & 4 & 4 & 4 & 4 & 4 & 3 & 3 & 26 & $100 \%$ & 26 \\
\hline Mineração & 2 & 2 & 2 & 3 & 2 & 2 & 2 & 15 & $83 \%$ & 18 \\
\hline Minerais não Metais & 2 & 2 & 2 & 2 & 2 & 3 & 3 & 16 & $100 \%$ & 16 \\
\hline Papel e Celulose & 4 & 4 & 3 & 4 & 3 & 3 & 3 & 24 & $96 \%$ & 25 \\
\hline Petróleo e Gás & 3 & 3 & 4 & 4 & 4 & 4 & 4 & 26 & $100 \%$ & 26 \\
\hline Química & 6 & 6 & 7 & 6 & 7 & 7 & 7 & 46 & $100 \%$ & 46 \\
\hline Siderurgia e Metalurgia & 12 & 13 & 15 & 15 & 13 & 14 & 15 & 97 & $100 \%$ & 97 \\
\hline Software e Dados & 2 & 2 & 2 & 3 & 5 & 5 & 5 & 24 & $100 \%$ & 24 \\
\hline Telecomunicações & 7 & 8 & 8 & 8 & 7 & 7 & 6 & 51 & $98 \%$ & 52 \\
\hline Têxtil & 12 & 16 & 17 & 17 & 17 & 16 & 15 & 110 & $99 \%$ & 111 \\
\hline Transporte - Serviços & 14 & 13 & 15 & 13 & 14 & 15 & 18 & 102 & $100 \%$ & 102 \\
\hline Veículos e Peças & 9 & 9 & 9 & 8 & 10 & 10 & 9 & 64 & $100 \%$ & 64 \\
\hline Outros & 39 & 40 & 49 & 53 & 57 & 60 & 60 & 358 & $99 \%$ & 363 \\
\hline Total & 184 & 191 & 214 & 219 & 225 & 229 & 228 & 1.490 & $98 \%$ & $\mathbf{1 . 5 1 7}$ \\
\hline$\%$ & $97 \%$ & $96 \%$ & $99 \%$ & $100 \%$ & $99 \%$ & $98 \%$ & $98 \%$ & $98 \%$ & & \\
\hline Dados Totais & 189 & 198 & 217 & 220 & 228 & 233 & 232 & 1.517 & & \\
\hline
\end{tabular}




\begin{tabular}{|c|c|c|c|c|c|c|c|c|c|c|}
\hline \multicolumn{11}{|c|}{ DIVIDENDOS RECEBIDOS - FCO } \\
\hline & 2008 & 2009 & 2010 & 2011 & 2012 & 2013 & 2014 & $\begin{array}{l}\text { Total } \\
\text { FCO }\end{array}$ & $\%$ & $\begin{array}{l}\text { Total } \\
\text { Geral }\end{array}$ \\
\hline Agro e Pesca & & & & & & 1 & 1 & 2 & $40 \%$ & 5 \\
\hline Alimentos e Bebidas & & & 2 & 2 & 3 & 3 & 2 & 12 & $38 \%$ & 32 \\
\hline Comércio & 1 & 1 & 1 & 2 & 2 & 2 & 3 & 12 & $23 \%$ & 52 \\
\hline Construção & 2 & 3 & 3 & 4 & 2 & 1 & 1 & 16 & $22 \%$ & 73 \\
\hline Eletroeletrônicos & & 1 & 2 & 2 & 2 & 2 & 2 & 11 & $35 \%$ & 31 \\
\hline Energia Elétrica & 8 & 8 & 9 & 13 & 14 & 14 & 13 & 79 & $59 \%$ & 135 \\
\hline Máquinas Industriais & & & & & & & & - & $0 \%$ & 11 \\
\hline Mineração & 2 & 2 & 2 & 2 & 1 & 1 & 3 & 13 & $57 \%$ & 23 \\
\hline Minerais não Metais & & & & 1 & 1 & 1 & 1 & 4 & $40 \%$ & 10 \\
\hline Papel e Celulose & 2 & 3 & 2 & 2 & 1 & 1 & 1 & 12 & $57 \%$ & 21 \\
\hline Petróleo e Gás & & & & & & & & - & $0 \%$ & 11 \\
\hline Química & 2 & 2 & 1 & 1 & 2 & 2 & 2 & 12 & $48 \%$ & 25 \\
\hline Siderurgia e Metalurgia & 4 & 4 & 6 & 6 & 5 & 5 & 6 & 36 & $59 \%$ & 61 \\
\hline Software e Dados & 1 & 2 & 2 & 1 & & & & 6 & $35 \%$ & 17 \\
\hline Telecomunicações & 1 & 4 & 4 & 3 & 4 & 4 & 3 & 23 & $52 \%$ & 44 \\
\hline Têxtil & 1 & & 1 & & 2 & 2 & 1 & 7 & $11 \%$ & 65 \\
\hline Transporte - Serviços & 3 & 2 & 3 & 2 & 1 & 3 & 4 & 18 & $27 \%$ & 66 \\
\hline Veículos e Peças & 3 & 3 & 2 & 2 & 2 & & & 12 & $29 \%$ & 41 \\
\hline Outros & 6 & 6 & 9 & 9 & 10 & 10 & 10 & 60 & $21 \%$ & 282 \\
\hline Total & 36 & 41 & 49 & 52 & 52 & 52 & 53 & 335 & $33 \%$ & 1.005 \\
\hline$\%$ & $32 \%$ & $33 \%$ & $37 \%$ & $35 \%$ & $33 \%$ & $31 \%$ & $33 \%$ & $33 \%$ & & \\
\hline Dados Totais & 111 & 124 & 134 & 147 & 158 & 169 & 162 & 1.005 & & \\
\hline
\end{tabular}


APÊNDICE C - Classificação conforme CPC 03, parágrafo 34A (por atividade na DFC, auditor e ano)

\begin{tabular}{lcccccccccc}
\hline & \multicolumn{10}{c}{ JUROS PAGOS -FCO } \\
\cline { 2 - 12 } & $\mathbf{2 0 0 8}$ & $\mathbf{2 0 0 9}$ & $\mathbf{2 0 1 0}$ & $\mathbf{2 0 1 1}$ & $\mathbf{2 0 1 2}$ & $\mathbf{2 0 1 3}$ & $\mathbf{2 0 1 4}$ & $\begin{array}{c}\text { Total } \\
\text { FCO }\end{array}$ & $\boldsymbol{\%}$ & $\begin{array}{c}\text { Total } \\
\text { Geral }\end{array}$ \\
\hline Deloitte & 10 & 19 & 39 & 40 & 25 & 26 & 27 & 186 & $73 \%$ & 255 \\
EY & 6 & 6 & 11 & 18 & 20 & 22 & 25 & 108 & $44 \%$ & 248 \\
KPMG & 7 & 11 & 20 & 24 & 22 & 24 & 23 & 131 & $60 \%$ & 220 \\
Price & 12 & 15 & 19 & 24 & 35 & 37 & 34 & 176 & $72 \%$ & 243 \\
Outros & 18 & 19 & 12 & 6 & 17 & 16 & 14 & 102 & $57 \%$ & 179 \\
\hline Total & $\mathbf{5 3}$ & $\mathbf{7 0}$ & $\mathbf{1 0 1}$ & $\mathbf{1 1 2}$ & $\mathbf{1 1 9}$ & $\mathbf{1 2 5}$ & $\mathbf{1 2 3}$ & $\mathbf{7 0 3}$ & $\mathbf{6 1 \%}$ & $\mathbf{1 . 1 4 5}$ \\
\hline \% & $\mathbf{5 6 \%}$ & $\mathbf{6 0 \%}$ & $\mathbf{6 2 \%}$ & $\mathbf{6 3 \%}$ & $\mathbf{6 1 \%}$ & $\mathbf{6 3 \%}$ & $\mathbf{6 1 \%}$ & $\mathbf{6 1 \%}$ & & \\
\hline Dados Totais & $\mathbf{9 4}$ & $\mathbf{1 1 7}$ & $\mathbf{1 6 2}$ & $\mathbf{1 7 7}$ & $\mathbf{1 9 4}$ & $\mathbf{2 0 0}$ & $\mathbf{2 0 1}$ & $\mathbf{1 . 1 4 5}$ & & \\
\hline
\end{tabular}

\begin{tabular}{lcccccccccc}
\hline & \multicolumn{10}{c}{ JUROS RECEBIDOS -FCO } \\
\cline { 2 - 11 } & $\mathbf{2 0 0 8}$ & $\mathbf{2 0 0 9}$ & $\mathbf{2 0 1 0}$ & $\mathbf{2 0 1 1}$ & $\mathbf{2 0 1 2}$ & $\mathbf{2 0 1 3}$ & $\mathbf{2 0 1 4}$ & $\begin{array}{c}\text { Total } \\
\text { FCO }\end{array}$ & $\mathbf{\%}$ & $\begin{array}{c}\text { Total } \\
\text { Geral }\end{array}$ \\
\hline Deloitte & 2 & 2 & 4 & 3 & 1 & 1 & 1 & 14 & $93 \%$ & 15 \\
EY & & & 1 & 2 & & & & 3 & $19 \%$ & 16 \\
KPMG & 1 & 2 & & & 2 & 3 & 4 & 12 & $75 \%$ & 16 \\
Price & & 1 & 3 & 5 & 7 & 6 & 3 & 25 & $69 \%$ & 36 \\
Outros & 1 & 4 & 1 & & & & & 6 & $43 \%$ & 14 \\
\hline Total & $\mathbf{4}$ & $\mathbf{9}$ & $\mathbf{9}$ & $\mathbf{1 0}$ & $\mathbf{1 0}$ & $\mathbf{1 0}$ & $\mathbf{8}$ & $\mathbf{6 0}$ & $\mathbf{6 2 \%}$ & $\mathbf{9 7}$ \\
\hline \% & $\mathbf{4 4 \%}$ & $\mathbf{6 9 \%}$ & $\mathbf{6 0 \%}$ & $\mathbf{6 3 \%}$ & $\mathbf{6 3 \%}$ & $\mathbf{6 7 \%}$ & $\mathbf{6 2 \%}$ & $\mathbf{6 2 \%}$ & & \\
\hline Dados Totais & $\mathbf{9}$ & $\mathbf{1 3}$ & $\mathbf{1 5}$ & $\mathbf{1 6}$ & $\mathbf{1 6}$ & $\mathbf{1 5}$ & $\mathbf{1 3}$ & $\mathbf{9 7}$ & & \\
\hline
\end{tabular}

\begin{tabular}{lcccccccccc}
\hline & \multicolumn{10}{c}{ DIVIDENTOS PAGOS -FCF } \\
\cline { 2 - 11 } & $\mathbf{2 0 0 8}$ & $\mathbf{2 0 0 9}$ & $\mathbf{2 0 1 0}$ & $\mathbf{2 0 1 1}$ & $\mathbf{2 0 1 2}$ & $\mathbf{2 0 1 3}$ & $\mathbf{2 0 1 4}$ & $\begin{array}{c}\text { Total } \\
\text { FCO }\end{array}$ & $\boldsymbol{\%}$ & $\begin{array}{c}\text { Total } \\
\text { Geral }\end{array}$ \\
\hline Deloitte & 43 & 38 & 47 & 42 & 41 & 41 & 44 & 296 & $97 \%$ & 304 \\
EY & 26 & 35 & 54 & 58 & 49 & 42 & 40 & 304 & $97 \%$ & 312 \\
KPMG & 34 & 32 & 33 & 43 & 32 & 37 & 48 & 259 & $98 \%$ & 264 \\
Price & 23 & 27 & 37 & 45 & 54 & 62 & 53 & 301 & $100 \%$ & 302 \\
Outros & & & & & & & & & & \\
\hline Total & $\mathbf{5 8}$ & $\mathbf{5 9}$ & $\mathbf{4 3}$ & $\mathbf{3 1}$ & $\mathbf{4 9}$ & $\mathbf{4 7}$ & $\mathbf{4 3}$ & $\mathbf{3 3 0}$ & $\mathbf{9 9 \%}$ & $\mathbf{3 3 5}$ \\
\hline \% & $\mathbf{1 8 4}$ & $\mathbf{1 9 1}$ & $\mathbf{2 1 4}$ & $\mathbf{2 1 9}$ & $\mathbf{2 2 5}$ & $\mathbf{2 2 9}$ & $\mathbf{2 2 8}$ & $\mathbf{1 . 4 9 0}$ & $\mathbf{9 8 \%}$ & $\mathbf{1 . 5 1 7}$ \\
\hline Dados Totais & $\mathbf{9 7 \%}$ & $\mathbf{9 6 \%}$ & $\mathbf{9 9 \%}$ & $\mathbf{1 0 0 \%}$ & $\mathbf{9 9 \%}$ & $\mathbf{9 8 \%}$ & $\mathbf{9 8 \%}$ & $\mathbf{9 8 \%}$ & & \\
\hline
\end{tabular}




\begin{tabular}{lcccccccccc}
\hline & \multicolumn{10}{c}{ DIVIDENTOS RECOLHIDOS -FCF } \\
\cline { 2 - 12 } & $\mathbf{2 0 0 8}$ & $\mathbf{2 0 0 9}$ & $\mathbf{2 0 1 0}$ & $\mathbf{2 0 1 1}$ & $\mathbf{2 0 1 2}$ & $\mathbf{2 0 1 3}$ & $\mathbf{2 0 1 4}$ & $\begin{array}{c}\text { Total } \\
\text { FCO }\end{array}$ & $\boldsymbol{\%}$ & $\begin{array}{c}\text { Total } \\
\text { Geral }\end{array}$ \\
\hline Deloitte & 14 & 11 & 14 & 14 & 14 & 15 & 18 & 100 & $46 \%$ & 217 \\
EY & 4 & 9 & 12 & 14 & 13 & 9 & 10 & 71 & $37 \%$ & 194 \\
KPMG & 10 & 9 & 16 & 19 & 10 & 12 & 11 & 87 & $45 \%$ & 194 \\
Price & 1 & 6 & 3 & 3 & 10 & 10 & 9 & 42 & $21 \%$ & 198 \\
Outros & 7 & 6 & 4 & 2 & 5 & 6 & 5 & 35 & $17 \%$ & 202 \\
\hline Total & $\mathbf{3 6}$ & $\mathbf{4 1}$ & $\mathbf{4 9}$ & $\mathbf{5 2}$ & $\mathbf{5 2}$ & $\mathbf{5 2}$ & $\mathbf{5 3}$ & $\mathbf{3 3 5}$ & $\mathbf{3 3 \%}$ & $\mathbf{1 . 0 0 5}$ \\
\hline \% & $\mathbf{3 2 \%}$ & $\mathbf{3 3 \%}$ & $\mathbf{3 7 \%}$ & $\mathbf{3 5 \%}$ & $\mathbf{3 3 \%}$ & $\mathbf{3 1 \%}$ & $\mathbf{3 3 \%}$ & $\mathbf{3 3 \%}$ & & \\
\hline Dados Totais & $\mathbf{1 1 1}$ & $\mathbf{1 2 4}$ & $\mathbf{1 3 4}$ & $\mathbf{1 4 7}$ & $\mathbf{1 5 8}$ & $\mathbf{1 6 9}$ & $\mathbf{1 6 2}$ & $\mathbf{1 . 0 0 5}$ & & \\
\hline
\end{tabular}




\section{APÊNDICE D - Lista de empresas (Modelo A)}

\begin{tabular}{|c|c|c|c|c|}
\hline \multicolumn{5}{|c|}{ Empresas utilizadas no Modelo A } \\
\hline Abril Educa & Contax & Grucai & Metalfrio & Sondotecnica \\
\hline AES Tiete & Copasa & Guararapes & Minerva & Souza Cruz \\
\hline AGconcessoes & Cosan & Habitasul & MMX Miner & Springer \\
\hline Alfa Consorc & Coteminas & Haga S/A & Multiplan & Springs \\
\hline Alfa Holding & CPFL Energia & Harpia Part & Mundial & Sul 116 Part \\
\hline Aliansce & Cve Brasil & Helbor & Natura & Taesa \\
\hline All Amer Lat & Cyrela Realt & Hoteis Othon & Net & Tec Blumenau \\
\hline Allis Part & Daleth Part & Hypermarcas & Nova Oleo & Tecnisa \\
\hline Alupar & Dasa & Ideiasnet & Nutriplant & Tegma \\
\hline Ampla Energ & Desenvix & Iguatemi & OGX Petroleo & Tekno \\
\hline Arezzo Co & Direcional & Ind Cataguas & P.Acucar-Cbd & Telebras \\
\hline Arteris & Ecorodovias & Inds Romi & Panatlantica & Telef Brasil \\
\hline Bahema & Eletrobras & Inepar & Par Al Bahia & Telinvest \\
\hline Bardella & Eletron & Invepar & PDG Realt & Time For Fun \\
\hline Battistella & Eletropar & Iochp-Maxion & Petrobras & Totvs \\
\hline Baumer & Emae & Itausa & Polpar & Tran Paulist \\
\hline Belapart & Embratel Part & Itautec & Positivo Inf & Trisul \\
\hline BHG & Encorpar & Jereissati & Profarma & Triunfo Part \\
\hline Bic Monark & Energias BR & Joao Fortes & Providencia & Ultrapar \\
\hline Biomm & Energisa & Karsten & Prumo & Unipar \\
\hline BR Malls Par & Energisa Mt & Kroton & Qualicorp & Usiminas \\
\hline Brasmotor & Equatorial & La Fonte Tel & RaiaDrogasil & Vale \\
\hline Cabambiental & Eternit & Le Lis Blanc & Randon Part & Valetron \\
\hline Cacique & Even & Lin $x$ & Rede Energia & Valid \\
\hline CCR SA & Evora & Litel & Redentor & Viavarejo \\
\hline Cex Carvao & Excelsior & Lix da Cunha & Renova & Vigor Food \\
\hline Ceb & Fleury & Log-In & Ret Part & Viver \\
\hline Ceee-D & Forja Taurus & Lojas Marisa & Rossi Resid & Vulcabras \\
\hline Ceee-Gt & Fras-Le & Lupatech & Sanepar & Weg \\
\hline Celesc & Futuretel & Magaz Luiza & Sansuy & Wembley \\
\hline Celgpar & Gafisa & Magnesita SA & Santos Brp & Whirlpool \\
\hline Cemar & Generalshopp & Mangels Indl & Sao Martinho & \\
\hline Cia Hering & Gol & Maori & Schulz & \\
\hline Coelce & GPC Part & Marcopolo & Sierrabrasil & \\
\hline Comgas & Grendene & Metal Leve & Smiles & \\
\hline
\end{tabular}




\section{APÊNDICE E - Lista de empresas (Modelo B)}

\begin{tabular}{|c|c|c|c|c|}
\hline \multicolumn{5}{|c|}{ Empresas utilizadas no Modelo B } \\
\hline Abril Educa & Comgas & Gafisa & Maori & Santos Brp \\
\hline Aco Altona & Contax & Generalshopp & Marcopolo & Sao Martinho \\
\hline AES Elpa & Copasa & Ger Paranap & Metal Leve & Saraiva Livr \\
\hline AES Tiete & Copel & Gerdau & Metalfrio & Sauipe \\
\hline Afluente $\mathrm{T}$ & Cosern & Gerdau Met & Millennium & Schlosser \\
\hline AGconcessoes & Coteminas & Gol & Mills & Schulz \\
\hline Agpart & CPFL Energia & Grendene & Minerva & Ser Educa \\
\hline Aliansce & CPFL Renovav & Guararapes & MMX Miner & Sid Nacional \\
\hline All Amer Lat & Csu Cardsyst & Haga S/A & Mrs Logist & Sierrabrasil \\
\hline Allis Part & Cve Brasil & Helbor & MRV & SLC Agricola \\
\hline Alpargatas & Cyre Com-Ccp & Hoteis Othon & Multiplan & Smiles \\
\hline Alupar & Cyrela Realt & Hypermarcas & Mundial & Souza Cruz \\
\hline Ambev S/A & Daleth Part & Ideiasnet & Nadir Figuei & Springs \\
\hline Ampla Energ & Dasa & Iguatemi & Natura & Sultepa \\
\hline Anima & Desenvix & Imc Holdings & Neoenergia & Suzano Hold \\
\hline Arezzo Co & DHB & Ind Cataguas & Net & Suzano Papel \\
\hline Arteris & Direcional & Inds Romi & Nova Oleo & Taesa \\
\hline Bardella & Doc Imbituba & Inepar & Nutriplant & Tec Blumenau \\
\hline Battistella & Dohler & Invepar & Odontoprev & Technos \\
\hline Baumer & Dtcom Direct & Iochp-Maxion & OGX Petroleo & Tecnisa \\
\hline Bematech & Duratex & Itausa & Oi & Tectoy \\
\hline BHG & Ecorodovias & Itautec & OSX Brasil & Tegma \\
\hline Biomm & Elekeiroz & Jereissati & Ourofino SA & Tekno \\
\hline Bonaire Part & Elektro & Joao Fortes & P.Acucar-Cbd & Telef Brasil \\
\hline Braskem & Eletrobras & JSL & Panatlantica & Tex Renaux \\
\hline BRF SA & Eletropaulo & Karsten & PDG Realt & Time For Fun \\
\hline Brookfield & Emae & Kepler Weber & Petrobras & Totvs \\
\hline Cabambiental & Embratel Part & Klabin S/A & Plascar Part & Tractebel \\
\hline Cacique & Encorpar & Kroton & Portobello & Tran Paulist \\
\hline Cambuci & Energias BR & La Fonte Tel & Positivo Inf & Triunfo Part \\
\hline CCR SA & Energisa & Le Lis Blanc & Pq Hopi Hari & Tupy \\
\hline Ccx Carvao & Energisa Mt & Light S/A & Profarma & Ultrapar \\
\hline Cedro & Eneva & Lin $x$ & Providencia & Unipar \\
\hline Ceee-D & Equatorial & Litel & Prumo & Uptick \\
\hline Ceee-Gt & Estacio Part & Lix da Cunha & Qgep Part & Usiminas \\
\hline $\mathrm{Ceg}$ & Eternit & Localiza & Qualicorp & V-Agro \\
\hline Celesc & Even & Locamerica & RaiaDrogasil & Vale \\
\hline Celpa & Evora & Log-In & Randon Part & Valid \\
\hline Celpe & Excelsior & Lojas Hering & Rede Energia & Viavarejo \\
\hline Celul Irani & Eztec & Lojas Marisa & Renova & Viver \\
\hline Cemar & Fer Heringer & Lojas Renner & Riosulense & Vulcabras \\
\hline Cemig & Ferbasa & Lopes Brasil & Rodobensimob & Weg \\
\hline Cesp & Fibam & Lupatech & Rossi Resid & Wembley \\
\hline Cia Hering & Fibria & M.Diasbranco & Sabesp & Wetzel S/A \\
\hline Cielo & Fleury & Magaz Luiza & Sanepar & Whirlpool \\
\hline Coelba & Forja Taurus & Magnesita SA & Sansuy & Zain Part \\
\hline Coelce & Fras-Le & Mangels Indl & Santanense & \\
\hline
\end{tabular}




\section{APÊNDICE F - Empresas com maiores diferenças entre o FCO divulgado e o FCO} encorajado pelo CPC

Considerando uma diferença acima de $\mathrm{R} \$ 500$ milhões de reais

\begin{tabular}{|c|c|c|c|c|c|c|}
\hline \multirow[b]{2}{*}{ Empresa } & \multirow[b]{2}{*}{ Exercício } & \multirow[b]{2}{*}{ Setor } & \multirow[b]{2}{*}{ Auditor } & \multicolumn{2}{|c|}{ FCO } & \multirow[b]{2}{*}{$\begin{array}{c}\text { Diferença } \\
\text { (em R\$ mil) }\end{array}$} \\
\hline & & & & Divulgado & Encorajado & \\
\hline Petrobras & 2014 & Petróleo e Gás & Price & 62.241 .000 & 49.033 .000 & 13.208 .000 \\
\hline Petrobras & 2013 & Petróleo e Gás & Price & 56.209 .345 & 45.592 .345 & 10.617 .000 \\
\hline Petrobras & 2012 & Petróleo e Gás & Price & 54.145 .734 & 45.332 .734 & 8.813 .000 \\
\hline Petrobras & 2011 & Petróleo e Gás & KPMG & 56.322 .101 & 49.369.101 & 6.953 .000 \\
\hline Petrobras & 2010 & Petróleo e Gás & KPMG & 53.435 .437 & 47.372 .437 & 6.063 .000 \\
\hline CPFL Energia & 2014 & Energia Elétrica & Deloitte & 1.592 .573 & 259.003 & 1.333 .570 \\
\hline Alupar & 2011 & Energia Elétrica & EY & 407.040 & -753.172 & 1.160 .212 \\
\hline P.Acucar-Cbd & 2014 & Comércio & Deloitte & 5.016 .000 & 3.947 .000 & 1.069 .000 \\
\hline Energias BR & 2011 & Energia Elétrica & KPMG & 1.490 .742 & 431.286 & 1.059 .456 \\
\hline P.Acucar-Cbd & 2012 & Comércio & Deloitte & 5.299 .255 & 4.386 .157 & 913.098 \\
\hline Embratel Part & 2012 & Telecomunicações & Directa & 5.066 .541 & 4.249 .822 & 816.719 \\
\hline CCR SA & 2014 & Transporte - Serviços & Deloitte & 2.187 .686 & 1.393 .914 & 793.772 \\
\hline CCR SA & 2011 & Transporte - Serviços & KPMG & 1.890 .267 & 1.110 .647 & 779.620 \\
\hline Alupar & 2009 & Energia Elétrica & EY & 461.904 & -306.049 & 767.953 \\
\hline CCR SA & 2012 & Transporte - Serviços & Deloitte & 2.426 .811 & 1.682 .292 & 744.519 \\
\hline P.Acucar-Cbd & 2013 & Comércio & Deloitte & 4.891 .950 & 4.171 .444 & 720.506 \\
\hline Embratel Part & 2011 & Telecomunicações & EY & 2.260 .973 & 1.559 .152 & 701.821 \\
\hline Ultrapar & 2014 & Química & Deloitte & 2.650 .696 & 2.011 .574 & 639.122 \\
\hline CCR SA & 2013 & Transporte - Serviços & Deloitte & 2.464 .567 & 1.843 .503 & 621.064 \\
\hline OGX Petroleo & 2012 & Petróleo e Gás & EY & 811.023 & 245.341 & 565.682 \\
\hline Embratel Part & 2013 & Telecomunicações & Directa & 5.862 .835 & 5.306 .252 & 556.583 \\
\hline Ultrapar & 2013 & Química & Deloitte & 2.120 .686 & 1.572 .189 & 548.497 \\
\hline Invepar & 2014 & Transporte - Serviços & Deloitte & 1.200 .589 & 694.533 & 506.056 \\
\hline
\end{tabular}

Considerando uma diferença dividida pelo ativo total a partir de $6 \%$

\begin{tabular}{ccccccc}
\hline & & & & \multicolumn{2}{c}{ FCO } & \multicolumn{2}{c}{$\begin{array}{c}\text { Diferença } \\
\text { Dividido pelo } \\
\text { Empresa }\end{array}$} & Exercício & Setor & Auditor & Divulgado & Encorajado & Ativo Total \\
\hline Dommo Empr & 2013 & Outros & KPMG & -327 & -385 & $446 \%$ \\
Dommo Empr & 2012 & Outros & KPMG & -4.535 & -4.687 & $249 \%$ \\
Dommo Empr & 2011 & Outros & Deloitte & -4.540 & -4.667 & $88 \%$ \\
Tec Blumenau & 2008 & Têxtil & Auditan & -2.863 & -5.696 & $34 \%$ \\
Alupar & 2009 & Energia Elétrica & EY & 461.904 & -306.049 & $18 \%$ \\
Alupar & 2011 & Energia Elétrica & EY & 407.040 & -753.172 & $18 \%$ \\
Biomm & 2008 & Outros & Price & -5.715 & -7.880 & $18 \%$ \\
Karsten & 2009 & Têxtil & Price & 107.032 & 59.026 & $17 \%$ \\
Unipar & 2010 & Química & Price & 41.781 & -38.693 & $8 \%$ \\
Nova Oleo & 2013 & Petróleo e Gás & Crowe & -391.959 & -781.410 & $8 \%$ \\
Energias BR & 2011 & Energia Elétrica & KPMG & 1.490 .742 & 431.286 & $8 \%$ \\
Battistella & 2008 & Comércio & Deloitte & -8.384 & -44.482 & $8 \%$ \\
& & & & & & $($ Continua)
\end{tabular}


Considerando uma diferença dividida pelo ativo total a partir de 6\% (Continuação)

\begin{tabular}{|c|c|c|c|c|c|c|}
\hline \multirow[b]{2}{*}{ Empresa } & \multirow[b]{2}{*}{ Exercício } & \multirow[b]{2}{*}{ Setor } & \multirow[b]{2}{*}{ Auditor } & \multicolumn{2}{|c|}{ FCO } & \multirow{2}{*}{$\begin{array}{c}\text { Diferença } \\
\text { Dividido pelo } \\
\text { Ativo Total }\end{array}$} \\
\hline & & & & Divulgado & Encorajado & \\
\hline Karsten & 2012 & Têxtil & Price & 37.493 & 6.624 & $7 \%$ \\
\hline Karsten & 2011 & Têxtil & Price & 23.099 & -2.926 & $7 \%$ \\
\hline OGX Petroleo & 2013 & Petróleo e Gás & EY & -495.972 & -870.706 & $7 \%$ \\
\hline BHG & 2014 & Outros & KPMG & 70.542 & -26.760 & $7 \%$ \\
\hline Unipar & 2011 & Química & Price & 145.983 & 85.763 & $7 \%$ \\
\hline Karsten & 2013 & Têxtil & KPMG & 13.049 & -11.371 & $7 \%$ \\
\hline Mangels Indl & 2013 & Siderurgia e Metalurg. & EY & -16.338 & -44.303 & $6 \%$ \\
\hline CCR SA & 2011 & Transporte - Serviços & KPMG & 1.890 .267 & 1.110 .647 & $6 \%$ \\
\hline Excelsior & 2008 & Alimentos e Bebidas & KPMG & -669 & -2.189 & $6 \%$ \\
\hline Forja Taurus & 2014 & Siderurgia e Metalurg. & EY & 51.513 & -6.419 & $6 \%$ \\
\hline OGX Petroleo & 2014 & Petróleo e Gás & Price & -3.815 .679 & -3.822 .770 & $6 \%$ \\
\hline
\end{tabular}




\section{APÊNDICE G - Dados e coeficientes da regressão por efeitos fixos (Modelo A)}

\begin{tabular}{ll}
\multicolumn{2}{l}{ Sumário do modelo A (efeitos fixos) } \\
\hline Dados & Quantidade/Valor \\
\hline Seção cruzada & 171 unidades \\
Série temporal & Mínimo de 1/ Máximo de 7 \\
F & 1,8159 \\
p-valor & $<0,00001$ \\
R-Quadrado & 0,433 \\
R-Quadrado ajustado & 0,194 \\
Erro padrão & 0,0586 \\
\hline
\end{tabular}

Coeficientes do modelo A (efeitos fixos)

\begin{tabular}{lcccc}
\hline \multicolumn{1}{c}{ Variáveis } & Coeficientes & Erro padrão & t & p-valor \\
\hline$\beta_{0}$ & $-0,02975$ & 0,01078 & $-2,758$ & $0,0061^{* * *}$ \\
End & 0,000556 & 0,000165 & 3,365 & $0,0008^{* * *}$ \\
Rent & $1,5136 \times 10^{-5}$ & $8,729 \times 10^{-6}$ & 1,734 & $0,0837 *$ \\
FCO & 0,002491 & 0,008576 & 0,2905 & 0,7716 \\
\hline
\end{tabular}

Nota. $*$ p-valor $<0,10 ; * * * \mathrm{p}$-valor $<0,01$. 


\section{APÊNDICE H - Dados e coeficientes da regressão por efeitos fixos (Modelo B)}

Sumário do modelo B (efeitos fixos)

\begin{tabular}{ll}
\hline Dados & Quantidade/Valor \\
\hline Seção cruzada & 234 unidades \\
Série temporal & Mínimo de 1/ Máximo de 7 \\
F & 17,837 \\
p-valor & $<0,00001$ \\
R-Quadrado & 0,823 \\
R-Quadrado ajustado & 0,777 \\
Erro padrão & 0,2297 \\
\hline
\end{tabular}

Coeficientes do modelo B (efeitos fixos)

\begin{tabular}{lcccc}
\hline \multicolumn{1}{c}{ Variáveis } & Coeficientes & Erro padrão & t & p-valor \\
\hline$\beta 0$ & 0,324827 & 0,025677 & 12,65 & $<0,0001$ *** \\
End & 0,00087 & 0,00038 & 2,293 & $0,0221^{* *}$ \\
Rent & $2,9097 \times 10-6$ & $3,399 \times 10-5$ & 0,08559 & 0,9318 \\
FCO & 0,0144285 & 0,02422 & 0,5956 & 0,5516 \\
\hline
\end{tabular}

Nota. $* *$ p-valor $<0,05 ; * * *$ p-valor $<0,01$ 